JULIANA DA ROCHA DOS SANTOS

Análise da associação dos perfis de expressão gênica e das concentrações de metabólitos com a resposta ao tratamento antitabagismo

Tese apresentada à Faculdade de Medicina da Universidade de São Paulo para a obtenção do título de Doutor em Ciências

Programa de Ciências Médicas

Área de concentração: Distúrbios Genéticos de Desenvolvimento e Metabolismo

Orientador: Prof. Dr. Paulo Caleb Júnior de Lima Santos

São Paulo

2020 


\title{
Análise da associação dos perfis de expressão gênica e das concentrações de metabólitos com a resposta ao tratamento antitabagismo
}

\author{
Tese apresentada à Faculdade de Medicina da \\ Universidade de São Paulo para a obtenção do título \\ de Doutor em Ciências \\ Programa de Ciências Médicas \\ Área de concentração: Distúrbios Genéticos de \\ Desenvolvimento e Metabolismo \\ Orientador: Prof. Dr. Paulo Caleb Júnior de Lima \\ Santos
}

(Versão corrigida. Resolução CoPGr 6018/11, de 13 de outubro de 2011. A versão original está disponível na Biblioteca da FMUSP)

\section{São Paulo}




\section{Dados Internacionais de Catalogação na Publicaçăo (CIP)}

Preparada pela Biblioteca da

Faculdade de Medicina da Universidade de Săo Paulo

Creprodução autorizada pelo autor

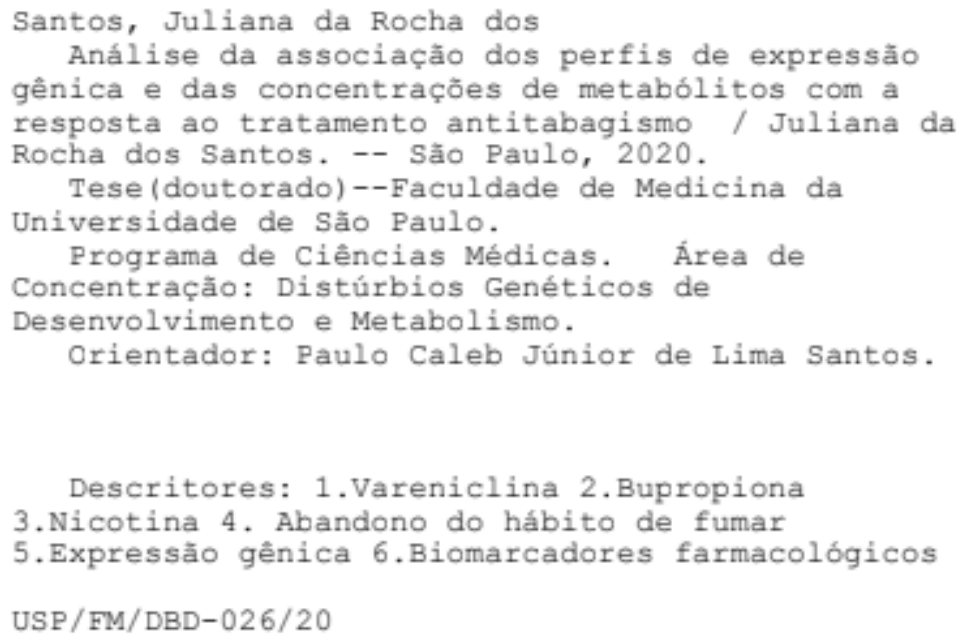

Responsável: Erinalva da Conceição Batista, CRB-8 6755 


\section{Dedicatória}

Dedico esse trabalho primeiramente a Deus, meu Pai querido, que me guia e sempre me concede ao que há de melhor!!!

Aos meus pais Gedeão e Deolinda, ao meu marido Sidnei e aos irmãos e sobrinhos que sempre me incentivaram e me apoiaram em todos os momentos! 


\section{Agradecimentos}

Ao meu orientador, Dr. Paulo Caleb

Obrigada Paulo por ter apostado e confiado em mim, eu não tenho palavras para agradecer diante de tudo que você me ensinou. Hoje me sinto mais confiante e, parte dessa confiança, devo a você! Obrigada por me ajudar a amadurecer e por ter sido tão compreensível em momentos difíceis. Te considero mais que um mentor, você é também um grande amigo.

Ao meu amigo mestrando, Paulo Roberto

Muito obrigada por tudo! Fico feliz que Deus meu deu a graça de ter você como amigo! A sua participação foi essencial neste trabalho! Obrigada por me ouvir e me ajudar, acredito que ainda faremos muitas coisas juntos!!!

Aos Doutores Alexandre Pereira, Jaqueline Issa, Patrícia Gaya, Tânia Ogawa Abe e Regina

Obrigada pelas dicas, instruções, correções e pelo conhecimento proporcionado. Jaque, Paty, Tania e Regina, esse estudo não teria existido sem o excelente trabalho que vocês executam no ambulatório do tabagismo. Vocês foram fundamentais!!!

Aos meus amigos do laboratório de Genética e cardiologia molecular: Leiliane, Emanuelle, Mariana, Fábinho, Fábio, Bruna, Gabriela Venturini, Pamela, Tamiris, Kalliandra, Michelle Sabrina, Lígia, Gabriele Darezzo, Théo, Maurício, Isabela, Almir, 
Fernanda, Karina, Mariliza, Renata Carmona, Ana Piesco, Ednalva e Andréia e Márcio

Agradeço a instrução e auxílio na parte técnica desse trabalho e muito obrigada pela amizade, companhia, conselhos, brincadeiras e almoços juntos.

Aos doutores Eduardo Costa de Figueiredo, Henrique Dipe Faria e Isarita Martins do LATF (Unifal, MG)

Obrigada pela colaboração neste trabalho. Obrigada por esse produto maravilhoso desenvolvido no laboratório de vocês (o novo RAM). Tenho a certeza que será de grande aplicabilidade. Obrigada pela mensuração das amostras. Henrique, muito obrigada pela paciência em explicar o trabalho que vocês realizaram. Muito obrigada pelo tempo disponibilizado e pelos dados fornecidos.

Ao Prof. Dr. José Eduardo Krieger e ao LGCM (FMUSP)

Obrigada por disponibilizar a infraestutura do laboratório, equipamentos, materiais e reagentes para execução deste trabalho.

Aos membros titulares e suplentes da banca examinadora Muito obrigada pelo aceite do convite e por todas as sugestões e contribuições.

À FAPESP, à CAPES e à CNPQ

Agradeço o apoio financeiro para a execução desse trabalho. 


\section{A Deus}

Pai, muito obrigada pelo Senhor ter me dado essa oportunidade maravilhosa! O Senhor sempre me preparou o melhor e creio que continuará preparando! Obrigada por me dar forças em todos os momentos! Te amo!!!!

À minha família

Obrigada por toda compreensão. Obrigada pelo apoio e por terem acreditado na minha capacidade. Vocês são uma bênção e essenciais na minha vida! Amo vocês!!!

Ao meu marido Sidnei

Lindo, te amo muito!!! Obrigada por ter me incentivado. Obrigada pelos chás, chocolates e comindinhas que você sempre ia me trazendo enquanto eu estava escrevendo este trabalho. Obrigada por ter me ajudado nas tarefas domésticas também, para que eu pudesse ter tempo para me dedicar. Obrigada por todo amor, carinho e cumplicidade. Você é um marido excelente!!! 
"Porque os meus pensamentos não são os vossos pensamentos, nem os vossos caminhos, os meus caminhos, diz o Senhor. Porque, assim como os céus são mais altos do que a terra, assim são os meus caminhos mais altos do que os vossos caminhos, e os meus pensamentos, mais altos do que os vossos pensamentos.

Isaías 55:8,9 
Esta tese está de acordo com as seguintes normas, em vigor no momento desta publicação:

Referências: adaptado de International Committee of Medical Journals Editors (Vancouver).

Universidade de São Paulo. Faculdade de Medicina. Divisão de Biblioteca e Documentação. Guia de apresentação de dissertações, teses e monografias. Elaborado por Anneliese Carneiro da Cunha, Maria Julia de A. L. Freddi, Maria F. Crestana, Marinalva de Souza Aragão, Suely Campos Cardoso, Valéria Vilhena. 3a ed. São Paulo: Divisão de Biblioteca e Documentação; 2011. Abreviaturas dos títulos dos periódicos de acordo com List of Journals Indexed in Index Medicus. 


\section{SUMÁRIO}

\section{LISTA DE ABREVIATURAS, SÍMBOLOS E SIGLAS}

\section{LISTA DE EQUAÇÕES}

LISTA DE TABELAS

\section{LISTA DE FIGURAS}

\section{LISTA DE QUADROS}

\section{RESUMO}

\section{ABSTRACT}

1 INTRODUÇÃ

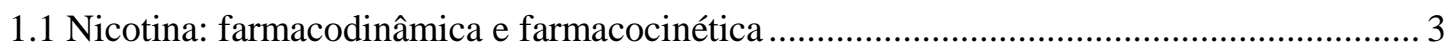

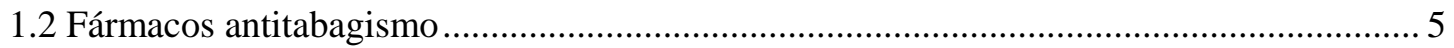

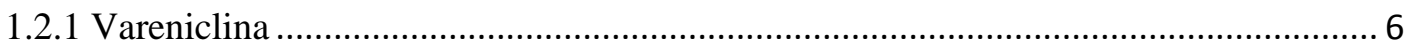

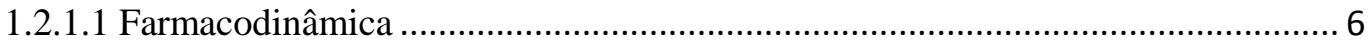

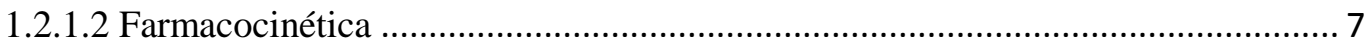

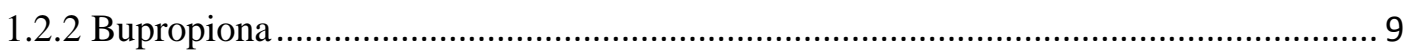

1.2.2.1 Farmacodinâmica ........................................................................................ 9

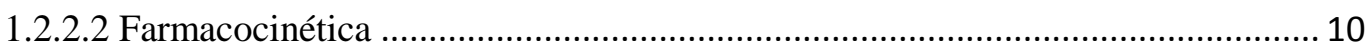

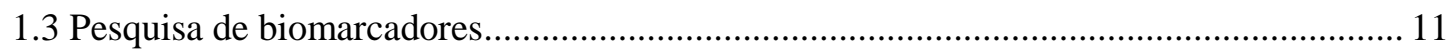

1.3.1 Estudos farmacogenéticos e de expressão gênica para vareniclina e bupropiona ...... 12

1.3.2 Mensuração de nicotina, bupropiona, vareniclina e seus metabólitos em amostras

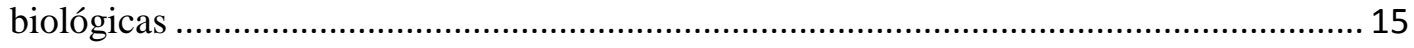

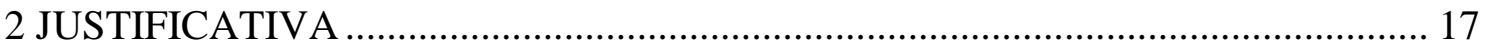

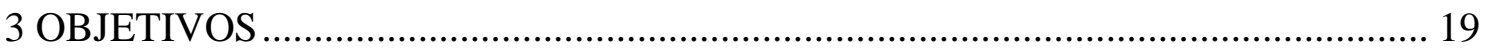

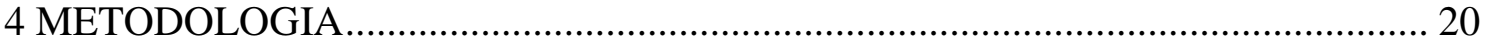

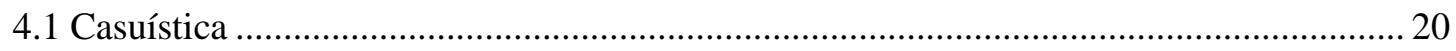

4.2 Fluxo de procedimentos adotados no atendimento aos pacientes .................................. 23 
4.3 Coleta e armazenamento das amostras dos pacientes tratados com vareniclina e

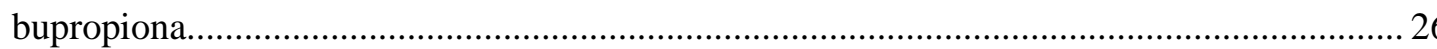

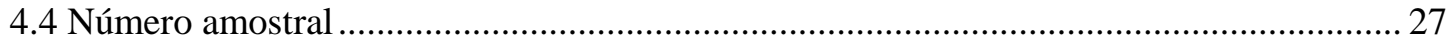

4.5 Análise de expressão gênica para amostras de pacientes tratados com vareniclina .......... 28

4.5.1 Concentração, purificação e extração de RNA............................................................. 28

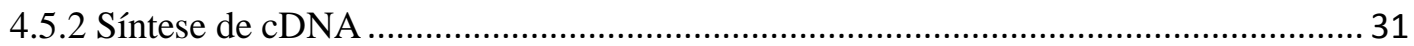

4.5.3 Ensaio de controle de qualidade das amostras para o ensaio de expressão gênica .... 31

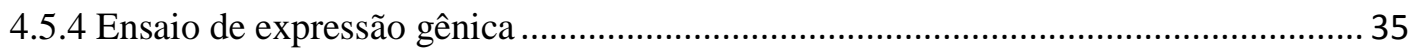

4.5.5 Análise dos dados de expressão gênica ...................................................................... 37

4.6 Mensuração de bupropiona, vareniclina e de seus metabólitos por HPLC-MS/MS .......... 38

4.6.1 Materiais, equipamentos e condições adotadas para a mensuração dos analitos após validação do método........................................................................................................ 38

4.6.2 Visão geral do desenvolvimento da coluna e padronização da análise ....................... 41

4.6.3 Desenvolvimento da coluna RAM para a purificação da amostra .............................. 43

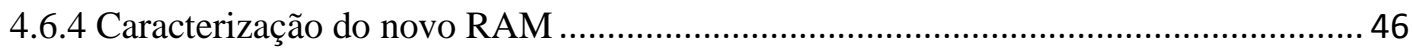

4.6.4.1 Capacidade de exclusão de proteínas com BSA................................................. 46

4.6.4.2 Capacidade de exclusão de proteínas no soro .................................................... 46

4.6.4.3 Capacidade de exclusão de proteínas com BSA em diferentes pHs...................... 47

4.6.5 Parâmetros espectrométricos ................................................................................. 47

4.6.6 Otimização do sistema cromatográfico multidimensional ......................................... 48

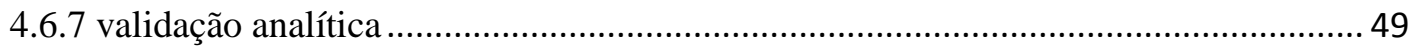

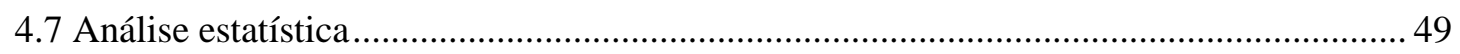

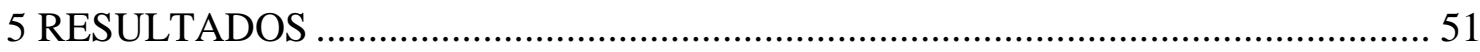

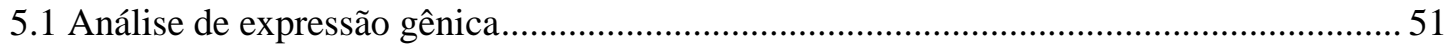

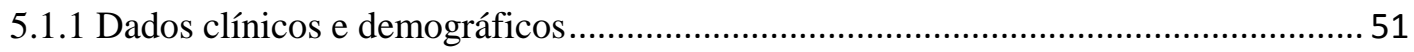

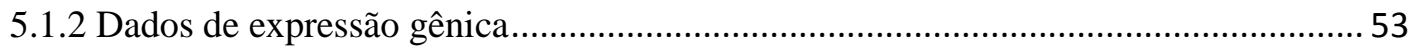

5.1.3 Análise de associação da expressão gênica entre os desfechos e os tempos de

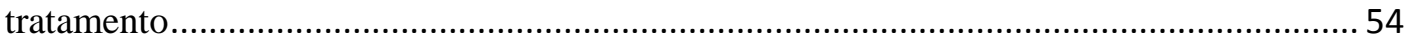


5.2 Mensuração dos analitos

5.2.1 Caracterização da coluna: teste exclusão de proteínas e interferentes da matriz ........58

5.2.2 Otimização dos parâmetros espectrométricos .......................................................... 60

5.2.3 Otimização do sistema cromatrográfico multidimensional ....................................... 61

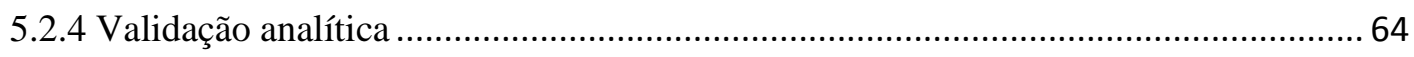

5.2.5 Dados clínicos e demográficos dos pacientes submetidos a mensuração dos analitos

5.2.6 Análise de associação dos analitos com desfecho de tratamento..... .72

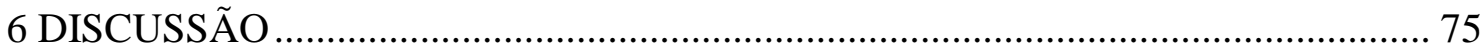

6.1 Para os dados da análise de expressão gênica .................................................................... 75

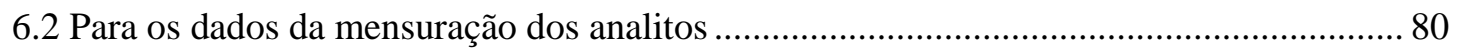

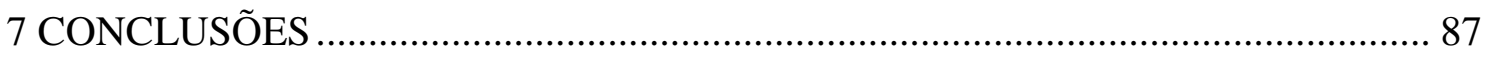

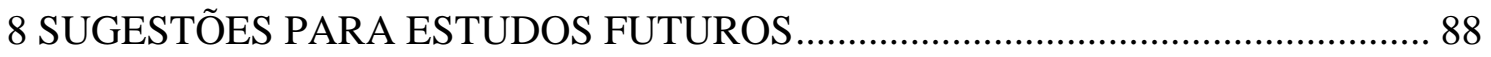

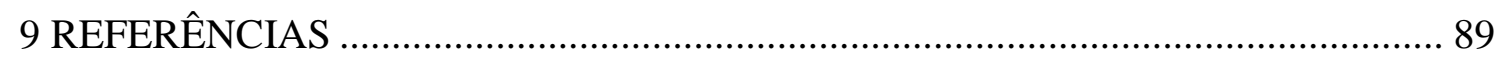

APÊNDICE - TCLE

ANEXO 1 - Aprovação no Comitê de Ética em Pesquisa

ANEXO 2 - Teste de Fagerström para a dependência à nicotina (versão em Português)

ANEXO 3 - Escore de consumo situacional Issa

ANEXO 4 - Desenho de estudo do projeto "Eficácia do uso de marcadores genéticos na escolha do tratamento farmacológico do tabagismo"

ANEXO 5 -Pedido de depósito de patente na Agência de Inovação e Empreendedorismo da Universidade Federal de Alfenas-MG 


\section{LISTA DE ABREVIATURAS, SÍMBOLOS E SIGLAS}

API

$A C T B$

ANKK1

B2M

BC3

BR1

BR2

BR3

BR4

BR5

BRT

BSA

$\left[C^{14}\right]$

cDNA

CHRNA3

CHRNA4

CHRNA5

CHRNA6

CHRNA7

CHRNB2

CHRNB3

CHRNB4
Ionização em pressão atmosférica - Atmospheric pressure ionization

Gene que codifica a proteína $\beta$ actina

Gene codificador da proteína quinase envolvida em vias de transdução de sinal Gene que codifica a microbulina subunidade $\beta 2$

Tampão de reaçao de transcriptase reversa

Tampão de ressuspensão

Tampão de ligação

Tampão de lavagem 1

Tampão de lavagem 2

Tampão de eluição

Tubos PAXgene

Albumina de soro bovino

Carbono 14 (isótopo radioativo do carbono de massa atômica 14)

DNA complementar sintetizado a partir de uma molécula de RNA

Gene codificador do receptor acetilcolínico-nicotínico subunidade $\alpha 3$

Gene codificador da subunidade $\alpha 4$ dos receptores acetilcolínicos nicotínicos Gene codificador da subunidade $\alpha 5$ dos receptores acetilcolínicos nicotínicos Gene codificador da subunidade $\alpha 6$ dos receptores acetilcolínicos nicotínicos Gene codificador da subunidade $\alpha 7$ dos receptores acetilcolínicos nicotínicos Gene codificador da subunidade $\beta 2$ dos receptores acetilcolínicos nicotínicos Gene codificador da subunidade $\beta 3$ dos receptores acetilcolínicos nicotínicos Gene codificador da subunidade $\beta 4$ dos receptores acetilcolínicos nicotínicos 
CHRNG

CNTs

COMT

CS - SPE

CT

CYP2B6

CYP2B6

Disco QC

DN

DNA

DNAse

dNTP

DRD1

DRD2

DRD3

DRD4

E\%

EDTA

Escore Issa

ESI+

FDA

FTND
Gene codificador do receptor acetilcolínico-nicotínico subunidade $\delta$

Nanotubos de carbono - Carbon nanotubes

Gene codificador da enzima catecol-O-metiltransferase (metaboliza dopamina)

Extração em fase sólida no modo column switching

Ciclo de linha de base - threshold cicle (número de ciclo em que a amostra amplificou)

Gene codificador do receptor acetilcolínico-nicotínico subunidade $\gamma$

Gene codificador da isoenzima CYP2B6

Disco para a realização do controle de qualidade de amostras que serão utilizadas para o ensaio de expressão gênica

Dependência à nicotina

Ácido desoxirribonucleico

Enzima que degrada moléculas de DNA

Dinucleotídeos: dATP, dCTP, dGTP e dTTP

Gene codificador do receptor dopaminérgico do tipo 1

Gene codificador do receptor dopaminérgico do tipo 2

Gene codificador do receptor dopaminérgico do tipo 3

Gene codificador do receptor dopaminérgico do tipo 4

Erro relativo

Ácido etilenodiamino tetra-acético

Escore de consumo situacional Issa

Ionização positiva por electrospray - positive Electrospray ionization

Orgão de controle de alimentos e medicamentos americano - Food and drug administration

Teste de Fagerström para dependência à nicotina - Fargeström test for nicotine dependence 
Velocidade de rotação em força $\mathrm{g}$, a qual considera a aceleração da gravidade

GDC

Controle de contaminação de DNA genômico do disco QC

GE

Tampão de degradação de DNA genômico

HGDC Controle de contaminação de DNA genômico do ensaio de expressão gênica

HPLC Cromatografia líquida de alta eficiência - High Performance Liquid Cromatograph

HPLC-MS/MS Cromatografica líquida de alta eficiência seguida por espectrometria de massas em tandem - High Performance Liquid Cromatograph fowed by tandem Mass Spectrometric

HPRT1 Gene que codifica a enzima hipoxantina fosforribosiltransferase 1

HTR3A Gene codificador da subunidade 3A do receptor de serotonina

HTR3B Gene codificador da subunidade 3B do receptor de serotonina

K.V. $\quad$ Energia de colisão em quilovolt

LC-MS Cromatografia líquida seguida de espectrometria de massas - Liquid Cromatograph fowed by Mass Spectrometric

LD Limite de detecção

LLE Extração líquido-líquido (com o uso de solvente)

LQ Limite de quantificação

LogP Coeficiente de partição: relação das concentrações da substância em um solvente orgânico e em água, dado que ambos os solventes são necessariamente imiscíveis

MCT Microtubos de $1,5 \mathrm{~mL}$

MS Espectrometria de massas - Mass Spectrometric

MRM Múltiplas transições de monitoramento de reação - multiple reaction monitoring

MS/MS Espectrometria de massas em tandem

$\mathbf{m} / \mathbf{z} \quad$ Relação massa/carga dos analitos

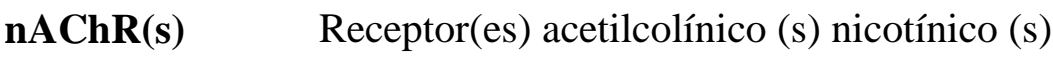

NMR Taxa de metabolização da nicotina - Nicotine metabolite ratio 
NTC

NTR

OCT2

P2

PAF

PBMC

PCR

PIs

PK

pKa

pKb

PP

PPC

PRC

PSC

PT

RAM

Rcf

RDD

RE3

RNA

RNase

RNFD

RNFW

RFLP
Controle negativo

Controle de não transcrição reversa

Transportador catiônico orgânico

Controle externo de RNA

Programa de Assistência ao Fumante

Células mononucleares de sangue periférico - Peripheral blood mononuclear cell

Amplificação em cadeia da polimerase

Padrões internos

Enzima proteinase $\mathrm{K}$

Valor negativo do logaritmo da constante de dissociação de um ácido

Valor negativo do logaritmo da constante de dissociação de uma base

Extração por preciptação de proteínas

Controle positivo de PCR

Coluna de rotação de RNA vermelho

Coluna de rotação do homogeneizador lilás

Tubo de processamento

Material de acesso restrito - restrict access material

Força centrífuga relativa - Relative centrifugal force

Tampão de digestão de DNA

Mix de transcriptase reversa

Ácido ribonucleico

Enzima ribonuclease, a qual degrada as moléculas de RNA

Solução mãe de DNase

Água livre de RNase

Restrição enzimática - Restriction fragment length polymorphism 
RP-HPLC Cromatografia líquida de alta eficiência em fase reversa - Reverse-Phase High Performance Liquid Cromatograph

Rpm Rotação por minuto

RSD\% Desvio padrão relativo

SLC6A3 Gene codificador da proteína transportadora de dopamina

SLC22A2 Gene codificador da proteína OCT2, transportadora de cátions orgânicos (transporta vareniclina)

SNC Sistema nervoso central

SPE $\quad$ Extração em fase sólida

Sty I Enzima de restrição proveniente da Salmonella Typhi

TAE Tampão formado com Tris, Acetato e EDTA

TRN Terapia de reposição nicotínica

UGT2B7 Gene codificador da enzima UGT2B7, a qual metaboliza a vareniclina

UPLC Cromatografica líquida de ultra eficiência - Ultra Performance Liquid Cromatograph

UV Detector ultravioleta

$\alpha 3 \quad$ Subunidade alfa 3 dos receptores acetilcolínicos nicotínicos neuronais

$\boldsymbol{\alpha 4} \quad$ Subunidade alfa 4 dos receptores acetilcolínicos nicotínicos neuronais

a5 Subunidade alfa 5 dos receptores acetilcolínicos nicotínicos neuronais

a6 Subunidade alfa 6 dos receptores acetilcolínicos nicotínicos neuronais

$\alpha 7 \quad$ Subunidade alfa 7 dos receptores acetilcolínicos nicotínicos neuronais

B2 Subunidade beta 2 dos receptores acetilcolínicos nicotínicos neuronais

B4 Subunidade beta 4 dos receptores acetilcolínicos nicotínicos neuronais

T-1 Visita inicial

T0 Visita de início do tratamento (coleta realizada antes de começar o tratamento no mesmo dia) 
T2

T4

T12

TFC
Visita de 2 semanas após tratamento farmacológico

Visita de 4 semanas após tratamento farmacológico

Visita de 12 semanas após tratamento farmacológico

Cromatografia líquida turbulenta - Turbulent flow-liquid chromatography 


\section{LISTA DE EQUAÇÕES}

$\Delta \mathbf{C T}=\left(\mathbf{C} \mathbf{T}_{\text {amostra }}\right.$ - a média de $\left.\mathbf{C T}_{\text {housekeeping genes }}\right)$ : Normalização da expressão gênica dos genes alvo através de valores de expressão de genes fisiológicos.

2- $^{-\Delta \mathbf{C T}}$ : Transformação dos valores de $\Delta \mathbf{C T}$ em escala logarítmica para a realização dos testes de hipótese.

$\Delta \Delta \mathbf{C T}=$ (mediana de $\Delta \mathbf{C T}$ grupo teste - mediana de $\Delta \mathbf{C T}$ grupo referência): Fórmula utilizada para posterior cálculo de fold change. Considera-se os dois grupos envolvidos no teste de hipótese.

2- $\Delta \Delta \mathrm{CT}$ : Transformação dos dados de $\Delta \Delta \mathrm{CT}$ em escala logarítmica. Através dessa fórmula se obtém ofold change (diferença de expressão entre dois grupos).

NMR=(trans-3-hidroxicotinina/cotinina): Taxa de metabolização da nicotina. $\mathrm{NMR}<0,31=$ metabolizador lento, $\mathrm{NMR}>0,31$ metabolizador normal ou rápido. 


\section{LISTA DE TABELAS}

Tabela 1 - Analitos, precursores, fragmentos e energias de colisão otimizados

Tabela 2 - Características clínicas e demográficas dos pacientes tratados com vareniclina selecionados para os ensaios de expressão gênica.

Tabela 3 - Características clínicas e demográficas dos pacientes tratados com vareniclina submetidos aos ensaios de expressão gênica de acordo com o desfecho de tratamento

Tabela 4 - Valores de mediana de $\Delta \mathrm{CT}$ dos genes de acordo com os tempos de tratamento e grupos de desfecho.

Tabela 5 - Fold change e análise de associação entre os tempos de tratamento e grupos de desfecho.

Tabela 6 - Parâmetros de validação obtidos na determinação de fármacos antitabagismo em soro humano.

Tabela 7 - Características clínicas e demográficas dos pacientes tratados com vareniclina submetidos às análises das concentrações dos analitos....

Tabela 8 - Características clínicas e demográficas dos pacientes tratados com vareniclina submetidos às análises das concentrações dos analitos de acordo com o desfecho de tratamento.

Tabela 9 - Características clínicas e demográficas dos pacientes tratados com bupropiona submetidos às análises das concentrações dos analitos....

Tabela 10 - Características clínicas e demográficas dos pacientes tratados com bupropiona submetidos às análises das concentrações dos analitos de acordo com o desfecho de tratamento.

Tabela 11 - Frequência do desfecho de tratamento nos pacientes submetidos às análises das concentrações dos analitos de acordo com os medicamentos antitabagismo.

Tabela 12 - Concentração dos analitos nas amostras de soro dos pacientes tratados com vareniclina.

Tabela 13 - Concentração dos analitos de acordo com o desfecho de tratamento com vareniclina.

Tabela 14 - Concentração dos analitos nas amostras de soro dos pacientes tratados com bupropiona. 
Tabela 15 - Concentração dos analitos de acordo com o desfecho de tratamento com bupropiona.. 


\section{LISTA DE FIGURAS}

Figura 1 - Áreas estimuladas através de vias dopaminérgicas e serotoninérgicas e sistema de recompensa..................................................... 2

Figura 2 - Receptor acetilcolínico-nicotínico.................................................. 4

Figura 3 - Via primária do metabolismo da nicotina........................................ 5

Figura 4 - Mecanismo de ação da vareniclina............................................... 7

Figura 5 - Metabolismo da vareniclina em humanos....................................... 8

Figura 6 - Mecanismo de ação da bupropiona............................................... 9

Figura 7 - Metabolismo da bupropiona em seus principais metabólitos ativo... 11

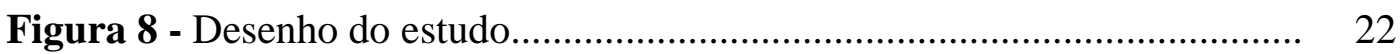

Figura 9 - Representação do Rotor-Disc 100............................................... 33

Figura 10 - Mapa do disco QC (representação planilhada)............................. 33

Figura 11 - Exemplo de ajuste de Threshold ............................................. 34

Figura 12 - Mapa do disco do ensaio $R T^{2}$ profiler PCR array (representação planilhada)

Figura 13 - Representação da composição da coluna extratora (Novo RAM)... 45

Figura 14 - Diferença de expressão do gene CHRNA7 entre os tempos de tratamento e desfecho.

Figura 15 - Diferença de expressão do gene $C H R N G$ entre os tempos de tratamento e desfecho

Figura 16 - Heat map de expressão gênica

Figura 17 - Cromatograma de teste de remoção de proteínas com solução de BSA.

Figura 18 - Cromatograma de teste de remoção de proteínas com amostra de soro diluída.

Figura 19 - Influência do pH na exclusão de proteínas. 
Figura 20 - Ilustração do sistema de columm switching na configuração de backflush

Figura 21 - Cromatograma obtido de amostras de soro branco diluídas em água ultra pura.

Figura 22 - Cromatograma obtido após análise de soro diluído e dopado com os analitos no nível médio de calibração e mais os padrões internos deuterados

Figura 23 - Cromatograma obtido através da análise das amostras de soro dos pacientes tratados com bupropiona.

Figura 24 - Cromatograma obtido através da analise de amostras de soro de pacientes tratados com vareniclina. 


\section{LISTA DE QUADROS}

Quadro 1- Procedimentos do protocolo em relação aos pacientes.......................... 25

Quadro 2 - Parâmetros de qualidade do ensaio QC.............................................. 34

Quadro 3 - Genes escolhidos para o ensaio de expressão.................................... 36

Quadro 4 - Housekeeping genes.................................................................. 36

Quadro 5 - Propriedades físico-químicas dos analitos..................................... 42

Quadro 6 - Comparação dos dados de validação com outros estudos.................... 85 


\section{RESUMO}

Santos JR. Análise da associação dos perfis de expressão gênica e das concentrações de metabólitos com a resposta ao tratamento antitabagismo [tese]. São Paulo: Faculdade de Medicina, Universidade de São Paulo; 2020.

Introdução: O tabagismo é considerado a maior causa de morbidade e mortalidade evitável no mundo. Estudos têm buscado a identificação de preditores de resposta aos tratamentos de cessação tabágica. Os principais objetivos deste estudo foram analisar a possível associação da expressão de genes alvo e das concentrações de analitos (fármacos antitabagismo, nicotina e seus metabólitos) com a resposta ao tratamento. Métodos: Foram incluídos 105 pacientes fumantes que iniciariam o tratamento com vareniclina $(n=74)$ ou bupropiona $(n=31)$. As análises de expressão gênica foram realizadas através do ensaio customizado $R T^{2}$ Profiler PCR Array, com a inclusão de 17 genes para a análise em células mononucleares de sangue periférico (PBMC). A preparação das amostras de soro para a mensuração dos analitos foi realizada através de uma coluna extratora composta por nanotubos híbridos de carbono e sílica, modificados com a adição de grupos hidrofílicos (material de acesso restrito - RAM) desenvolvida no LATF, Unifal, MG. A mensuração dos analitos foi realizada por cromatografia líquida de alta eficiência em modo column switching, seguida de espectrometria de massa em tandem (HPLC-MS/MS). Os tempos para a coleta de amostras foram: para as análises de expressão gênica (sangue total), antes de iniciar o tratamento (T0), duas e quatro semanas após o início do tratamento (T2 e T4, respectivamente) e para a mensuração dos analitos (soro), as amostras foram coletadas na T2. Resultados: Para as análises de expressão gênica, selecionamos 14 pacientes que obtiveram sucesso e 13 pacientes resistentes ao tratamento com vareniclina. Foi considerado sucesso quando o paciente alcançava abstinência ao tabaco até a $4{ }^{\text {a }}$ semana de tratamento e resistente quando o paciente não conseguia parar de fumar até a $4^{a}$ semana de tratamento. Foi observada diferença significativa para a expressão do gene CHRNA7: no grupo resistente, amostras dos tempos T2 e T4 apresentaram menor expressão comparadas ao tempo T0 (fold change: $0,38, \mathrm{P}=0,007$; fold change: $0,67, \mathrm{P}=0,004$; respectivamente). Para a mensuração dos analitos, a coluna RAM desenvolvida mostrou alta capacidade para a remoção de macromoléculas e de análise conjunta dos diferentes analitos, além de poder ser reutilizada diversas vezes (cerca de 400 ciclos). Os pacientes do grupo resistente tratados com ambos os fármacos apresentaram maior concentração de metabólitos da nicotina na T2. No entanto, não houve associação dos fármacos e seus metabólitos com desfecho de tratamento. Conclusões: Para as análises de expressão gênica, este estudo exploratório mostrou um possível preditor de efetividade no tratamento com vareniclina, reafirmando a associação da subunidade $\alpha 7$ para os processos de dependência à nicotina e tratamento antitabagismo. Estes resultados podem contribuir, ao menos em parte, para o desenvolvimento de uma terapia individualizada. Contudo, estudos futuros são necessários para o entendimento do papel da subunidade $\alpha 7$ dos receptores acetilcolínicos-nicotínicos no tratamento com vareniclina. Para a mensuração dos analitos, o novo RAM sintetizado é um produto de extremo valor científico, podendo apresentar diversas aplicações em análise de amostras com matrizes complexas, sem muita preparação prévia. Para a associação das concentrações dos fármacos e seus metabólitos com o desfecho de tratamento, são necessários estudos com um maior número amostral.

Descritores: Vareniclina; Bupropiona; Nicotina; Abandono do hábito de fumar; Expressão gênica; Biomarcadores farmacológicos. 


\begin{abstract}
Santos JR.Association analysis of gene expression profiles and metabolite concentrations with response for smoking cessation treatment [thesis]. São Paulo: "Faculdade de Medicina, Universidade de São Paulo"; 2020.
\end{abstract}

Introduction: Smoking is considered the largest cause of preventable morbidity and mortality in the worldwide. Studies have sought to identify predictors of responses to smoking cessation treatments. The main objectives of this study were to analyze the possible association of the expression of target genes and concentrations of analytes (drugs for smoking cessation, nicotine and their metabolites) with the response to treatment. Methods: We included 105 smoker patients who would start treatment with varenicline $(n=74)$ or bupropion $(n=31)$. Gene expression analysis was performed through custom $\mathrm{RT}^{2}$ Profiler PCR array assay, including 17 genes for analysis in peripheral blood mononuclear cells (PBMC). Serum sample preparation for the measurement of analytes was performed by an extraction column composed of hybrid carbon and silica nanotubes modified with the addition of hydrophilic groups (restricted access material - RAM) developed by LATF, Unifal, MG. The measurement of analytes was performed by high efficient liquid chromatography, in column switching mode, followed by tandem mass spectrometry (HPLC-MS/MS). Times for sample collection were: for gene expression analysis (total blood), before start of therapy (T0), two and four weeks after start of treatment (T2 and T4, respectively) and for measurement of analytes (serum), the samples were collected at T2. Results: For gene expression analysis, we selected 14 patients who had success and 13 patients resistant to the varenicline treatment. Success was considered to be when a patient achieved tobacco abstinence until the 4th week of treatment and resistant was when a patient had not stopped smoking as of the 4th week of treatment. We observed a significant difference for CHRNA7 gene expression: in the resistant group, samples from T2 and T4 had lower expression compared with T0 (fold change: $0.38, \mathrm{P}=0.007$; fold change: $0.67, \mathrm{P}=0.004$; respectively). For measurement of analytes, the developed RAM column showed high capacity to remove macromolecules and joint analyzes of different analytes, besides being able to be reuse manny times (about 400 cycles). Patients from resistant group of the both drugs treatment had a higher concentration of nicotine metabolites in T2. However, there was no association of drugs for smoking cessation and their metabolites with outcome treatment. Conclusions: For gene expression analysis, this exploratory study showed a possible predictor of effectiveness in the treatment with varenicline, reaffirming the association of the $\alpha 7$ subunit for nicotine dependence and smoking therapy processes. These results may contribute, at least in part, to the development of individualized therapy. However, further studies are needed to understand the role of the a7 subunit of acetylcholinic-nicotinic receptors in varenicline treatment. For the measurement of analytes, the new synthesized RAM is a product of extreme scientific value, being able of several applications in the analysis of samples with complex matrices, without much prior preparation. For an association of drugs for smoking cessation and their metabolites with outcome treatment, studies with a larger sample size are needed.

Descriptors: Varenicline; Bupropion; Nicotine; Smoking cessation; Gene expression; Biomarkers pharmacological. 


\section{INTRODUÇÃO}

O tabagismo é considerado a maior causa de morbidade e mortalidade evitável em todo o mundo ${ }^{1}$. Doenças cardíacas, cerebrovasculares, cerca de um quinto de todos os tipos de cânceres, doenças pulmonares como apneia e enfisema, além de distúrbios pré-natais, estão associadas ao consumo do tabaco ${ }^{2-5}$.

Dados recentes da Vigitel mostraram que no conjunto das 27 capitais brasileiras, a frequência de adultos fumantes foi de 9,3\%, com valores duas vezes maior no sexo masculino $(12,1 \%)$ do que no feminino $(6,9 \%)$. As menores frequências foram encontradas na população de jovens adultos (antes dos 25 anos) e em pessoas de mais de 65 anos. As maiores frequências foram encontradas entre homens, em Porto Alegre (17,3\%), Campo Grande e São Paulo $(15,6 \%)^{6}$.

A nicotina é o principal componente do tabaco causador de dependência. Esta age nos receptores acetilcolínicos-nicotínicos (nAChRs) promovendo a liberação de diversos neurotransmissores e neuroreguladores, tais como: dopamina, acetilcolina, epinefrina, norepinefrina, serotonina, beta-endorfina, vasopressina e GABA. O principal neurotransmissor estudado é a dopamina, pois a nicotina promove aumento de seus níveis na região mesocorticolímbica cerebral, principalmente em um circuito conhecido como "sistema de recompensa" (área tegmental ventral, núcleo accumbens e córtex préfrontal), gerando sensações de prazer e bem-estar ${ }^{7-15}$.

O processo de adição à nicotina é complexo e nem todos os mecanismos estão elucidados. Além da ativação do sistema de recompensa, há a formação de memórias associativas do efeito hedônico com os ambientes e situações de disponibilidade e uso do tabaco, resultando em reforço positivo após o fumante entrar em contato com fatores relacionados ao seu consumo. Este tipo de memória aprendida envolve a amigdala, o hipocampo, o córtex pré-frontal e o córtex parietal ${ }^{15-17}$. Evidências também são 
consistentes com a hipótese da ativação do estriado dorsal, o qual está envolvido no processamento de memórias de formação de hábito em processos motores, o que poderia automatizar o ato de fumar ${ }^{15,18}$ (Figura 1).

O uso continuado do tabaco promove a desensibilização e adaptação dos nAChRs, causando tolerância e diminuição dos efeitos de recompensa naturais. Como resultado, o indivíduo experimenta fissura, ansiedade, humor deprimido e irritabilidade na ausência da nicotina. Estes sintomas acabam promovendo um reforço negativo para o fumo e o número de cigarros consumidos aumenta cada vez mais ${ }^{14,15}$.

Todos os fatores acima mencionados contribuem para o mecanismo de dependência à nicotina (DN). Os efeitos hedônicos estão relacionados com o processo de iniciação do tabagismo, enquanto os efeitos negativos da falta da nicotina estão mais associados à manutenção do fumo ${ }^{15}$.

Para os indivíduos que desejam parar de fumar, o tratamento farmacológico antitabagismo é o que apresenta maior eficácia na redução da prevalência de fumantes 19.

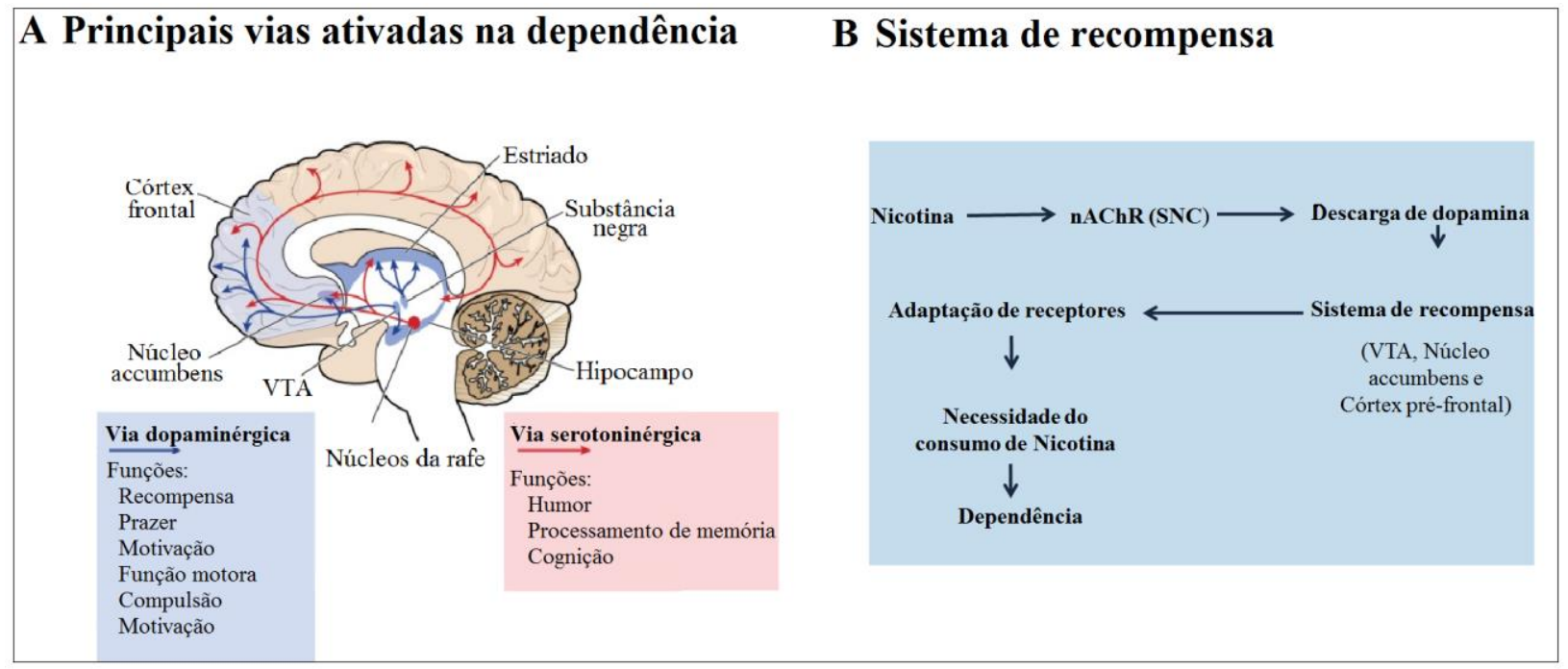

Figura 1 - Áreas estimuladas através de vias dopaminérgicas e serotoninérgicas e sistema de recompensa. A: Principais vias ativadas na dependência, como a área tegmental ventral, núcleos accumbens e da rafe, córtex-frontal, estriado, susbstância negra e hipocampo. As setas em rosa indicam áreas estimuladas pelas vias serotoninérgicas de transmissão e, em azul, pelas vias dopaminérgicas, gerando diversos comportamentos. B: Sistema de recompensa (composto pela VTA, núcleo accumbéns e córtex pré-frontal). A nicotina age nos nAChRs no SNC, gerando uma 
descarga de dopamina no sistema de recompensa. Há uma adaptação desses receptores com o fumo continuado, fazendo com que haja a necessidade de maior consumo de nicotina e o desenvolvimento da dependência. VTA= área tegmental ventral; SNC: sistema nervoso central; $\mathrm{nAChR}=$ receptor acetilcolínico-nicotínico. Fonte: adaptado de Habermann, A. Brain awareness week: addiction and the brain's reward system, Sovereign Health Group, 2016 e de Koob \& Volkow, $20099^{14}$

\subsection{Nicotina: farmacodinâmica e farmacocinética}

O fumo permite uma titulação precisa da dose de nicotina por parte do fumante. Sua absorção é rápida, chegando em cerca de 10 segundos em todo o sistema nervoso central (SNC), onde se liga nos nAChRs $20,2122$.

Os nAChRs são receptores de canais iônicos compostos por cinco subunidades que podem estar combinadas de diferentes formas (Figura 2) ${ }^{20}$. Os subtipos desses receptores mais abundantes no cérebro humano são os $\alpha 4 \beta 2, \alpha 3 \beta 4$ e $\alpha 7$ (homomérico). Os receptores compostos pelas subunidades $\alpha 4 \beta 2 *$ (o asterisco indica que outras subunidades podem estar presentes) possuem um papel fundamental na DN. O nocaute da subunidade $\beta 2$ em ratos resultou na eliminação dos efeitos comportamentais da nicotina ${ }^{23}$. Quanto à subunidade $\alpha 4$, parece estar envolvida na sensibilidade à nicotina, o que pode impactar nos efeitos de recompensa, dessensibilização e tolerância ${ }^{24,25}$. Os receptores compostos pelas subunidades $\alpha 3 \beta 4$ acredita-se mediar os efeitos cardiovasculares ${ }^{26}$. Os nAChRs $\alpha 7$ homomérico, estão envolvidos na velocidade de sinapses, em processos de aprendizagem e controle sensorial ${ }^{27,}{ }^{28}$. Os receptores compostos pelas subunidades $\alpha 4 \beta 2^{*}$ podem conter outras subunidades, como por exemplo, $\alpha 5, \alpha 6$ e/ou $\beta 3$ as quais podem modificar a sensibilidade e função do receptor 21,29 .

Como um agonista desses receptores, a nicotina promove a sua abertura permitindo a entrada de sódio e cálcio, despolarizando assim, a membrana dos neurônios. Além da entrada de cálcio através dos nAChRs, há também a abertura de 
canais de cálcio voltagem dependentes, fazendo com que as vesículas que armazenam os neurotransmissores sejam liberadas ${ }^{20,21}$. O resultado da ativação dos nAChRs em neurônios pós-sinápticos é a liberação de diversos neurotransmissores, ativando várias áreas como já mencionado.

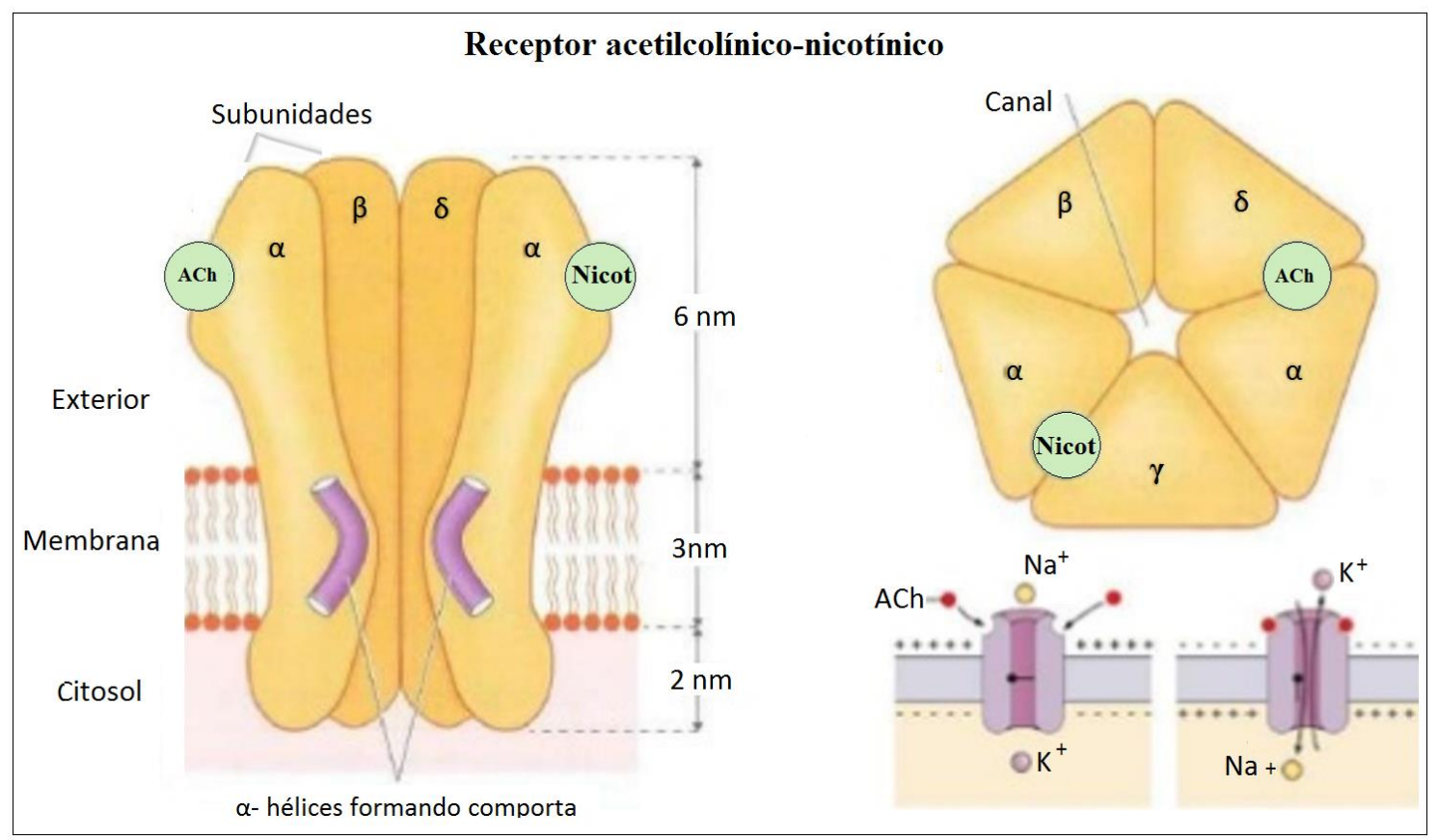

Figura 2 - Receptor acetilcolínico-nicotínico. O receptor acetilcolínico-nicotínico funciona como um canal iônico transmembrânico. Sua composição é pentâmera, ou seja, é formada por 5 subunidades que podem se combinar de diferentes formas. As subunidades são classificadas de acordo com diferenças nos domínios da sua estrutura proteíca. A acetilcolina e a nicotina são agonistas desses receptores, fazendo com que os mesmos sejam abertos. Assim ocorre a entrada de sódio, despolarizando a membrana, gerando o potencial de ação. $\mathrm{ACh}=$ acetilcolina; $\mathrm{Nicot}=\mathrm{Nicotina} ; \mathrm{Na}^{+}=$sódio; $\mathrm{K}^{+}=$potássio; $\alpha=$ subunidade alfa; $\beta=$ subunidade beta; $\delta=$ subunidade delta; $\gamma=$ subunidade gama. Fonte: adaptado de Rang \& Dale. Farmacologia, 5 ed. Elsevier, 2012.

Há oscilação dos picos de nicotina entre um cigarro e outro, mas as quantidades se acumulam entre 6 e 9 horas em um fumo regular, saturando os nAChR, causando desensibilização, adaptação, tolerância, sintomas de abstinência na falta do fumo e DN 30.

A nicotina é rapidamente e extensivamente metabolizada pelo fígado através da isoenzima CYP2A6 (e em menor grau pelas isoenzimas CYP2B6 e CYP2E1) à nicotina -íon íminio e, após pela enzima aldeído oxidase, à cotinina. O tempo de meia vida da nicotina é de aproximadamente 2 horas e da cotinina 16 horas. Posteriormente, a 
cotinina é metabolizada em trans-3-hidroxicotinina quase que exclusivamente pela CYP2A6 (outros isômeros da hidroxicotina representam menos de $2 \%$ da dose) ${ }^{31,32}$ (Figura 3). Esta é a maior via de metabolização da nicotina (70 - $80 \%$ do metabolismo da nicotina em todo o corpo) ${ }^{33}$, no entanto, há vias menores como por exemplo, a glucoronidação, que pode ser a maior determinante no clearence da nicotina em indivíduos com menor atividade da CYP2A6 ${ }^{31}$.

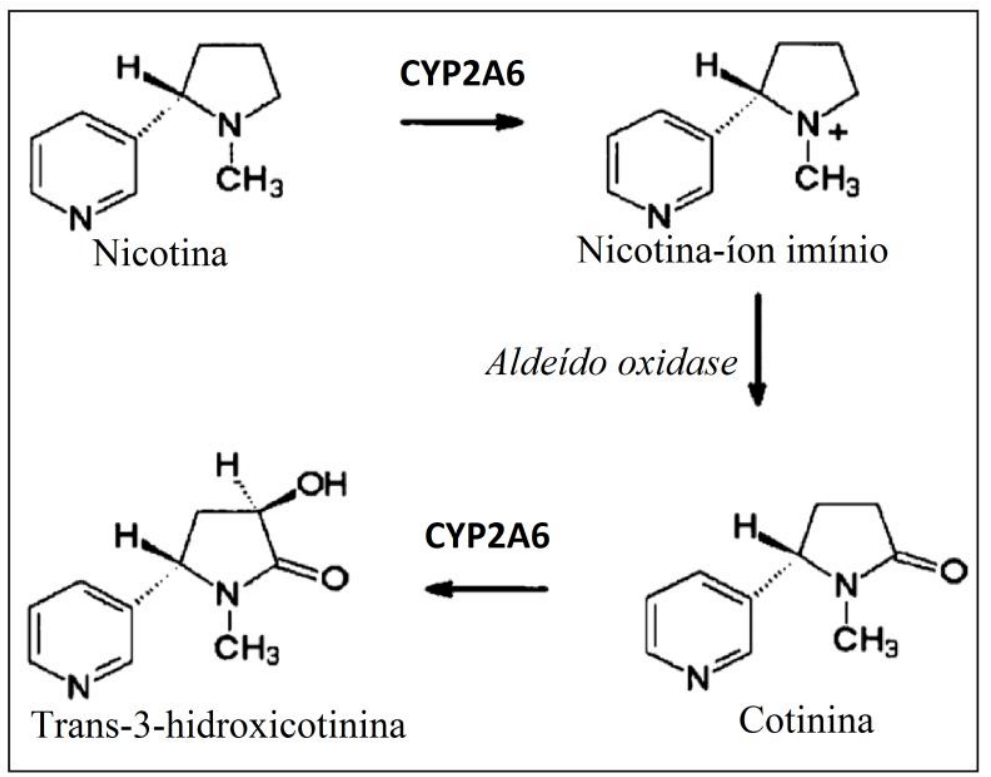

Figura 3 - Via primária do metabolismo da nicotina. A nicotina é metabolizada marjoritaramente pela isoenzima CYP2A6 em nicotinaíon imínio e, através da enzima aldeído oxidase, é convertida em cotinina. A cotinina é posteriomente metabolizada em trans-3hidroxicotinina, novamente pela isoenzima CYP2A6. Fonte: adaptado de Llaquet et al, $2010^{34}$.

\subsection{Fármacos antitabagismo}

Os medicamentos de primeira escolha aprovados pela Agência Nacional de Vigilância Sanitária (ANVISA) incluem tratamentos com base na terapia de reposição nicotínica (TRN) como: adesivo, goma e pastilha e também são utilizados vareniclina e bupropiona. Estes últimos possuem maior eficácia terapêutica na cessação tabágica ${ }^{35,36}$. 


\subsubsection{Vareniclina}

\subsubsection{Farmacodinâmica}

A vareniclina é o fármaco mais recentemente utilizado para a interrupção do tabagismo, este foi desenvolvido especificamente para atuar nos nAChRs. A sua farmacodinâmica está mais associada à atuação como um agonista parcial nos nAChRs compostos pelas subunidades $\alpha 4 \beta 2{ }^{37}$, os quais são importantes alvos de ação da nicotina, pois são necessários e suficientes para a recompensa, tolerância e sensibilização ${ }^{25,38,39}$ (Figura 4).

Estudos mostraram que, em relação à nicotina, a vareniclina possui 15 vezes maior afinidade pelas subunidades $\alpha 4 \beta 2$ e ativa em torno de $50 \%$ a liberação de dopamina no sistema mesocorticolímbico ${ }^{37}$. O fármaco atua também em outros nAChR, como nos nAChRs ( $\alpha 3 \beta 4$ ), age fracamente nos receptores contendo a subunidade $\alpha 6$ e em nAChRs ( $\alpha 3 \beta 2$ ), além de exercer atividade agonista total nos receptores $\alpha 7^{40}$.

Quanto às reações adversas no uso do fármaco, a náusea é a mais comum (cerca de 10 a 45\% dos indivíduos tratados), a qual muitas vezes leva à não aderência ao tratatamento $^{41-43}$. 


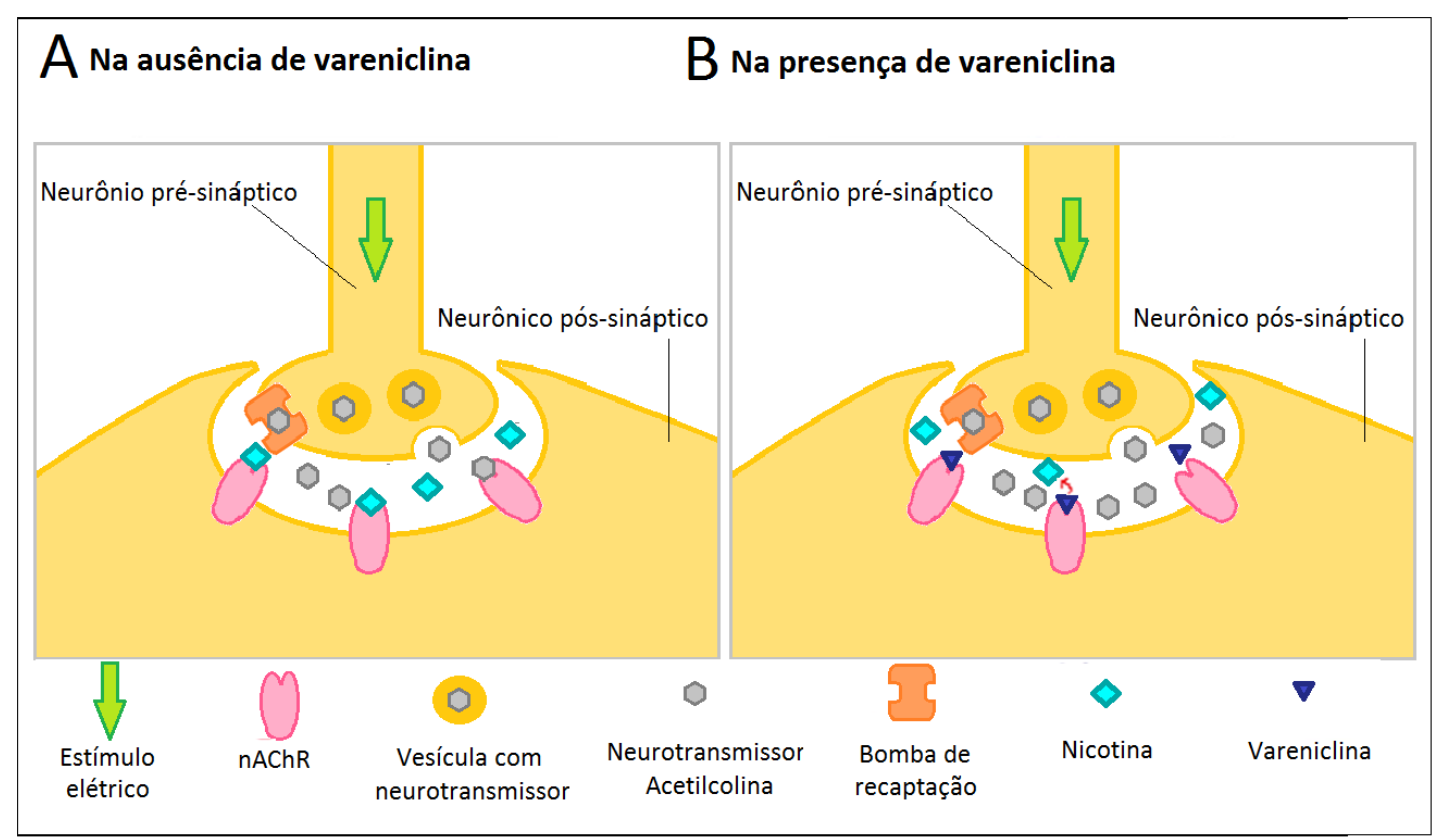

Figura 4 - Mecanismo de ação da vareniclina. A: Na ausência da vareniclina, a nicotina se liga aos nAChRs, aumentando a ativação nesses receptores. Além disso, há o estímulo endógeno (promovido pela acetilcolina). B: A vareniclina é um agonista parcial de nAChR ( $\alpha 4 \beta 2)$, ou seja, também estimula os nAChRs, mas em menor nível do que a nicotina e, ao mesmo tempo, é antagonista na presença de nicotina, fazendo com que ela não consiga se ligar ao receptor. Fonte: do autor, baseado nas informações de Kassem et al, $2012^{37}$.

\subsubsection{Farmacocinética}

A vareniclina é rapidamente absorvida pelo trato intestinal, com absorção >90\% logo após a administração oral. As concentrações plasmáticas máximas são alcançadas no período entre 3 e 4 horas ${ }^{44}$ e o estado de equilíbrio da sua concentração ocorre dentro de 4 dias 37, 44-46. O fármaco possui baixa ligação com proteínas plasmáticas, sendo que, de acordo com ensaios in vitro, a fração de vareniclina (100 ng/mL) livre foi de $79,7 \%{ }^{47}$. A sua biodisponibilidade não é afetada pelo tempo de administração ou ingestão de alimentos $37,45,46$. Além disso, a vareniclina possui ampla distribuição nos tecidos, sendo que o volume médio de distribuição aparente é de 415 litros, apresentando um coeficiente de variação (CV\%) de $50 \%{ }^{48}$.

Na circulação humana, a vareniclina se encontra em quantidade marjoritária, são também encontrados os metabólitos conjugados: vareniclina N-carbomoil glucoronídeo, 
$\mathrm{N}$-formilvareniclina e oxovareniclina. O tempo de meia vida da vareniclina é em torno de 24 horas, independente da dose administrada.

A eliminação do fármaco e metabólitos se dá principalmente pela urina $(99 \%)^{49}$. A eliminação renal exibe cinética linear e a sua excreção ocorre pela filtração glomerular, na qual está associada à secreção tubular realizada pelo transportador catiônico orgânico OCT2. O clearence estimado da vareniclina é de 88 a $155 \mathrm{~mL} / \mathrm{min}$ após administração de dose única e, 92 a $143 \mathrm{~mL} / \mathrm{min}$ após doses repetidas. A depuração de vareniclina é reduzida na presença de doença renal. Na urina, cerca de 90\% do produto eliminado é encontrado como vareniclina em sua forma inalterada, e menos de $10 \%$ é encontrado na forma de 2 metabólitos: a hidroxivareniclina e a vareniclina-N-carbomoil glucoronídeo ${ }^{37,49-51}$.

Nenhum dos metabólitos da vareniclina é acreditado ser farmacologicamente ativo. Além disso, esses metabólitos estão presentes em concentrações muito baixas ${ }^{37,}$ 46-49. A Figura 5 mostra os metabólitos provenientes da vareniclina.

A formação dos metabólitos da vareniclina não é catalisada pelo complexo enzimático CYP450. Ensaios realizados com microssoma hepático humano mostraram que a formação do conjugado vareniclina N-carbomilglucoronídeo, é provavelmente catalisado pela enzima UGT2B7 ${ }^{37,49}$.

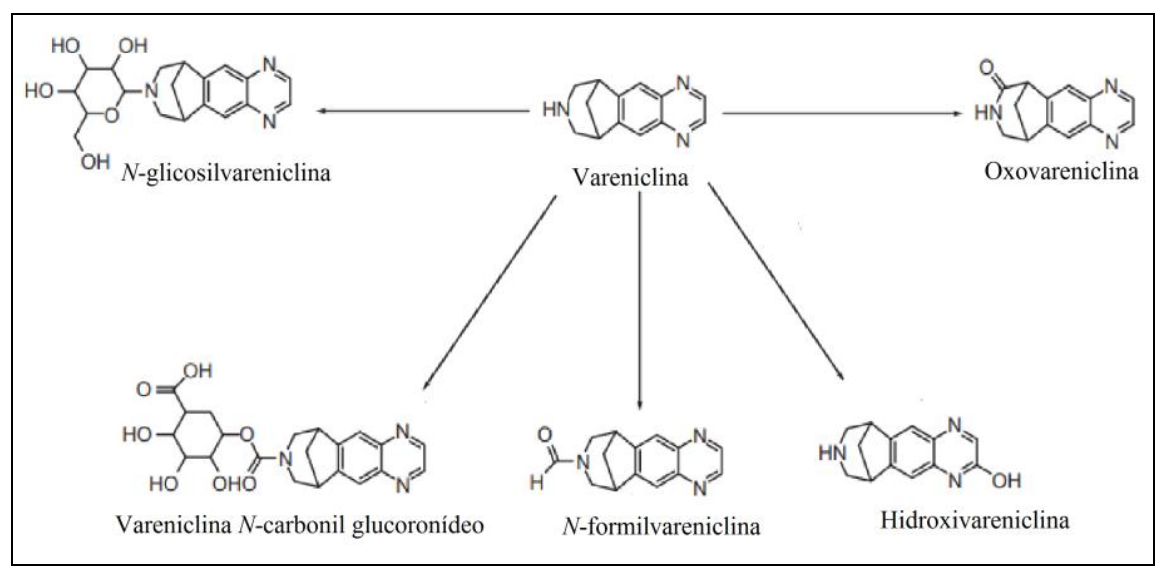

Figura 5 - Metabolismo da vareniclina em humanos. Fonte: adaptado de Obach et al, $2006{ }^{49}$. 


\subsubsection{Bupropiona}

\subsubsection{Farmacodinâmica}

A bupropiona é um antidepressivo, no entanto, tem sido utilizado como fármaco antitabagismo devido o seu potencial em diminuir o desejo de fumar (o qual foi percebido durante o tramento de índivíduos fumantes). Como mecanismo de ação, a bupropiona atua como um inibidor relativamente se

letivo da recaptação de norepinefrina e dopamina, com pequeno efeito na recaptação de serotonina (Figura 6), além de ser um antagonista de nAChR não competitivo. Essas propriedades minimizam os sintomas de retirada da nicotina aumentando a probabilidade do indivíduo se abster do fumo ${ }^{52}$.

Insônia e boca seca são as reações adversas mais comumente relatadas ao uso da bupropiona (30-40\% e $10 \%$ dos pacientes, respectivamente) ${ }^{53}$.

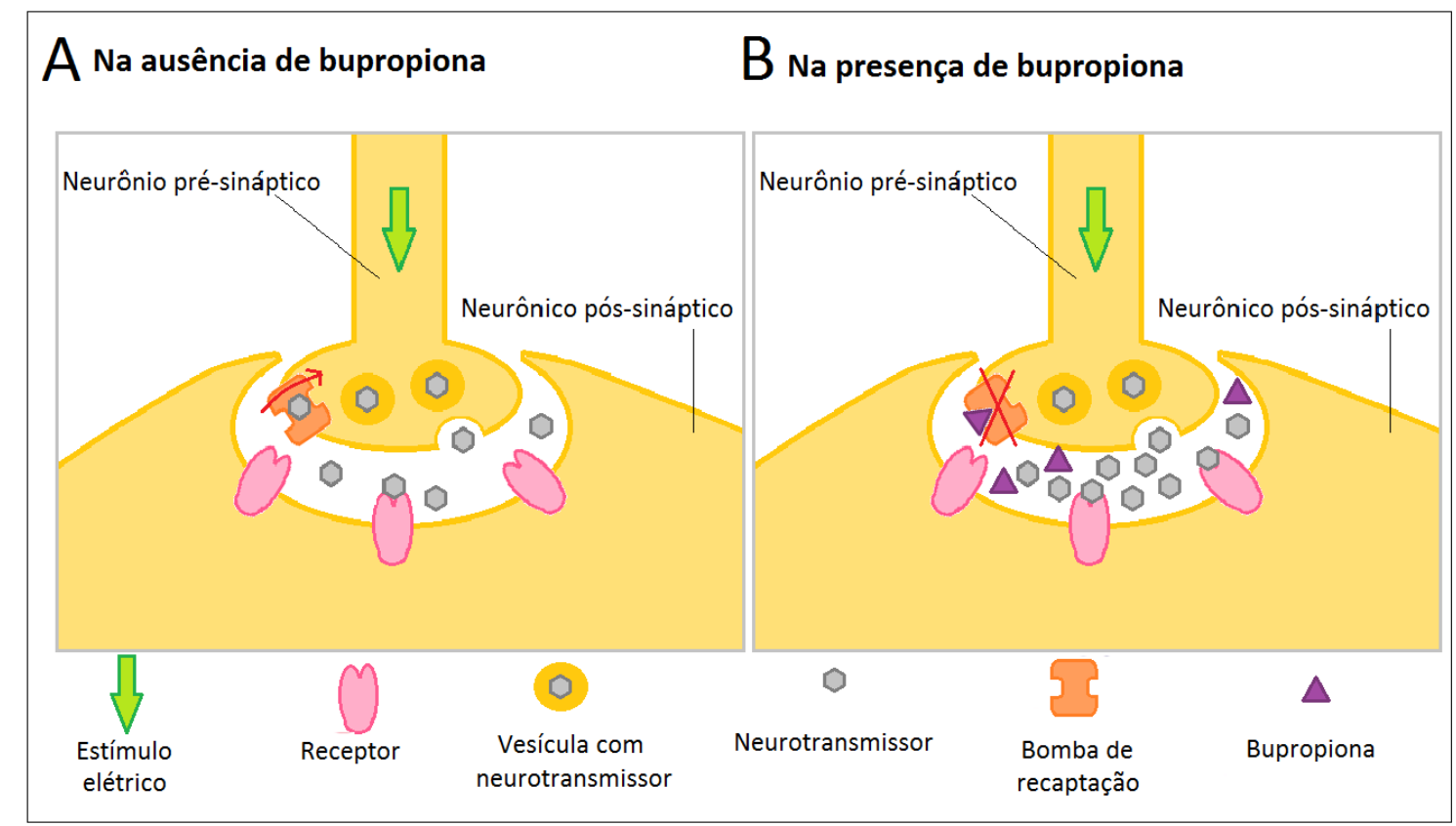

Figura 6 - Mecanismo de ação da bupropiona. A: Na ausência da bupropiona, neurotransmissores como a noradrenalina, serotonina e a dopamina são recaptados endogenamente pela bomba de recaptação. B: Na presença da bupropiona, a qual é inibidora da bomba de recaptação desses neurotransmissores, há a estimulação do sistema de recompensa, mais especificamente através do aumento da concentração de dopamina. Dessa forma, o sistema continua sendo estimulado, mas em menor grau que a nicotina e as chances de abstinência ao tabaco são aumentadas. Fonte: do autor, baseado nas informações de Slemmer et al, $2000{ }^{52}$. 


\subsubsection{Farmacocinética}

Conforme ensaios em voluntários sadios, os picos máximos de concentração plasmática de bupropiona são alcançados aproximadamente 3 horas após a sua administração oral. O volume de distribuição aparente é de aproximadamente 2000L e a ligação com proteínas plasmáticas é de $84 \%$ para a bupropiona e de $77 \%$ para a hidroxibupropiona (o seu principal metabólito ativo) ${ }^{54}$.

A bupropiona é metabolizada primariamente em uma série de metabólitos ativos, como a hidroxibupropiona, a threohidrobupropiona e a eritrohidrobupropiona (Figura 7). A CYP2B6 é a principal enzima que converte a bupropiona em hidroxibupropiona em humanos. No entanto, a formação de threohidrobupropiona e a eritrohidrobupropiona que ocorre através de reação redutiva, não é mediada pela CYP2B6 55, 56. A eritroidrobupropiona não pode ser mensurada no plasma após a administração de uma única dose de bupropiona. Os metabólitos ativos são posteriormente metabolizados em inativos e estes são excretados na urina ${ }^{54}$.

Inibidores da CYP2B6 como, por exemplo, a ticlodipina, um agente antiplaquetário derivado da tienopiridina, interagem com a bupropiona diminuindo a sua hidroxilação ${ }^{57,58}$.

Após a administração crônica de doses de 150 a 300 mg/dia a bupropiona e seus metabólitos assumem cinética linear. A bupropiona possui meia vida de 20 horas aproximadamente, e apresenta clearence médio aparente correspondente a cerca de 200L/h. A eliminação da bupropiona ocorre principalmente através da urina (87\%) e das fezes $(10 \%)$ e, é excretada em apenas $0,5 \%$ de forma inalterada, nos mostrando um extenso metabolismo ${ }^{54}$. 


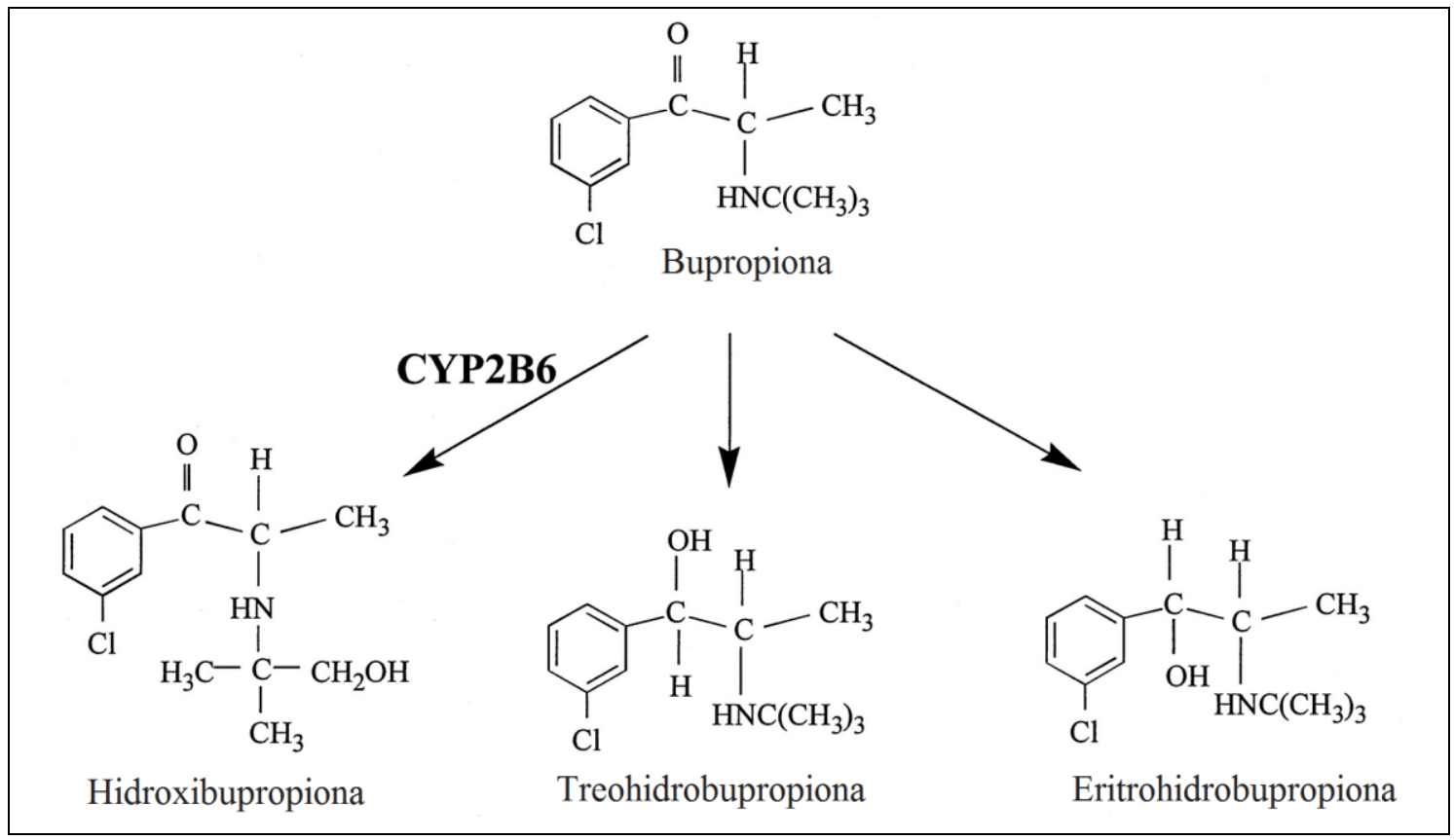

Figura 7 - Metabolismo da bupropiona em seus principais metabólitos ativos. A bupropiona é extensamente metabolizada em hidroxibupropiona pela isoenzima CYP2B6. Os demais metabólitos ativos aão metabolizados por outras enzimas. Fonte: adaptado de Hesse et al, $2000{ }^{55}$.

\subsection{Pesquisa de biomarcadores}

A variabilidade interindividual em resposta a fármacos antitabagismo sugere que os tratamentos podem ser mais efetivos em subgrupos de fumantes ${ }^{59-64}$. No contexto de medicina personalizada, diversos pesquisadores têm buscado a identificação de preditores de resposta aos tratamentos de cessação tabágica, os quais geralmente estão envolvidos em aspectos farmacocinéticos e farmacodinâmicos ou via de atuação do fármaco, como por exemplo, os fatores genéticos, o perfil de expressão gênica, de proteínas e de metabólitos ${ }^{65-68}$.

Além de refletir a efetividade do tratamento, estes biomarcadores também poderiam indicar a toxicidade ou a ocorrência de efeitos adversos. A combinação desses fatores com outras variáveis individuais pode ser utilizada para adequar as estratégias preventivas e terapêuticas ${ }^{65-68}$. 


\subsubsection{Estudos farmacogenéticos e de expressão gênica para vareniclina e bupropiona}

Diversos polimorfismos genéticos têm sido associados com resposta à vareniclina e à bupropiona ${ }^{41,65,67-71}$.

King et $a l{ }^{65}$ mostraram a associação de polimorfismos de nucleotídeos únicos (SNPs - single nucletide polimorfisms) nos genes CHRNA4, CHRNA5, CHRNA7, CHRNB2 (codificadores das subunidades $\alpha 4, \quad \alpha 5, \quad \alpha 7$ e $\quad \beta 2$ dos nAChRs, respectivamente) com abstinência contínua em resposta à vareniclina. O mesmo trabalho também encontrou associação dos polimorfismos nos genes CHRNA3, CHRNA5, CHRNB4, CHRNG (codificam as subunidades $\alpha 3, \alpha 5, \beta 4$ e $\gamma$ dos nAChR, respectivamente). Além disso, os autores demonstraram a associação de polimorfismos nos genes HTR3A e HTR3B (codificadores dos receptores serotoninérgicos) com a frequência de recaída no tratamento antitabagismo.

Swan $e a^{41}$ verificaram a associação de polimorfismos no gene CHRNB2 com náusea severa, em pacientes tratados com vareniclina.

Nosso grupo de pesquisadores encontrou a associação do polimorfismo rs10443196 no gene CHRNA4 e do polimorfismo $785 \mathrm{~A}>\mathrm{G}$ no gene CYP2B6 (codificador da principal isoenzima metabolizadora da bupropiona) com uma maior taxa de sucesso no tratamento com vareniclina e bupropiona, respectivamente ${ }^{67,68}$.

O gene $C Y P 2 B 6$ é um dos alvos mais importantes de estudos farmacogenéticos no tratamento com bupropiona. Diversos polimorfismos neste gene são preditores de metabolização lenta ou rápida, os quais foram associados com as diferenças de concentrações do fármaco e de seu principal metabólito ativo, hidroxibupropiona, em amostras biológicas. Essas concentrações também se associaram à variabilidade na resposta ao tratamento com bupropiona ${ }^{72-74}$. 
Polimorfismos podem implicar em diversos mecanismos moleculares, como por exemplo, alteração, constituição ou conformação de proteínas, mudanças póstraducionais e a regulação da expressão gênica, gerando variabilidade interindividual nos níveis de RNA transcrito, o que poderiam explicar as diferenças de resposta aos fármacos antitabagismo ${ }^{72}$.

O polimorfismo CHRNA4 (rs2236196), assim como diversos polimorfismos presentes no gene $C Y P 2 B 6$, os quais foram associados à resposta ao tratamento com vareniclina e bupropiona, respectivamente, foram também associados a maiores e menores níveis de expressão gênica ${ }^{72-75}$. Também vale salientar que, assim como a expressão gênica pode afetar a resposta ao tratamento, a expressão gênica também pode ser alterada em resposta aos fármacos ${ }^{76}$. Neste sentido, Smith et al ${ }^{76}$ mostraram que a vareniclina pode afetar a expressão gênica da enzima DNA metiltransferase-1 (DNMT) que mostrou estar envolvida em mecanismos epigenéticos em neurônios corticais GABaérgicos, os quais estão relacionados a processos cognitivos em indivíduos esquizofrênicos fumantes.

O tratamento crônico com vareniclina modificou a expressão dos nAChRs em cérebros de camundongos. O upregulation dos nAChRs ( $\alpha 4 \beta 2)$ pelo uso crônico da vareniclina foi similar ao promovido ao uso crônico da nicotina. Similar dowregulation foi visto para os nAChRs ( $\alpha 6 \beta 2$ ). A vareniclina aumentou significantemente ambos nAChRs ( $\alpha 3 \beta 4)$ e $\alpha 7$, enquanto a nicotina teve menor efeito nestes sítios ${ }^{77}$.

Em estudos com pacientes voluntários, a obtenção de amostras do sistema nervoso central é inviável. Como alternativa a esse problema, estudos têm proposto a análise de expressão gênica em sangue periférico ${ }^{78-80}$. Embora não seja o tecido alvo da farmacodinâmica dos medicamentos antitabagismo, o sangue possui muitas similaridades a nível transcricional com múltiplas regiões cerebrais ${ }^{81}$. 
Hennings et $a l^{82}$ mostraram diferenças no perfil de expressão gênica em células mononucleares de sangue periférico (PBMCs) de pacientes respondedores e não respondedores a tratamentos com antidepressivos e muitos dos genes diferentemente expressos são codificadores de receptores também presentes no SNC.

Ota et al ${ }^{83}$ mostraram que os genes GABRR2 (codificador de receptor GABAérgico) e CHRNA3 (codificador da subunidade $\alpha 3$ de nAChR) foram diferentemente expressos em sangue periférico em resposta ao tratamento com risperidona em pacientes com esquizofrenia.

Em outro estudo, Kordi-Tamandani et al ${ }^{84}$ mostraram que os níveis de expressão gênica de $S L C 6 A 3$, em leucócitos, diferiram entre indivíduos dependentes de opióides e voluntários sádios. Este gene é codificador de uma importante proteína recaptadora de dopamina em neurônios, chamada DAT.

Wongsriraksa et al ${ }^{85}$ mostraram a expressão das subunidades $\alpha 4, \alpha 5, \alpha 7, \beta 1$, e $\beta 2$ em um estudo de caracterização de nAChRs em amostras de PBMC de humanos através de nicotina radioligante, sugerindo conter as subunidades $\alpha 4 \beta 2, \alpha 4 \beta 2 \alpha 5$ e/ou $\alpha 7$. Por fim, diversos estudos têm mostrado que os nAChRs são importantes para processos imunológicos ${ }^{86-91}$.

Estudos têm evidenciado a expressão de receptores dopaminérgicos em leucócitos humanos. Embora a dopamina não ultrapasse a barreira hematoencefálica, as diferenças nos níveis de dopamina do sistema nervoso central poderiam alterar a expressão desses receptores em leucócitos ainda durante a sua formação via inervação da coluna espinal; doenças como Parkinson, Alzheimer e adição às substâncias psicoativas poderiam influenciar na expressão desses receptores em sangue periférico ${ }^{92}$. 


\subsubsection{Mensuração de nicotina, bupropiona, vareniclina e seus metabólitos em amostras biológicas}

A nicotina possui um baixo tempo de meia-vida e a isoenzima CYP2A6 é predominante responsável pelo metabolismo da nicotina em cotinina e trans-3hidroxicotinina (seus principais metabólitos) ${ }^{93,94}$. Estes e a nicotina são marcadores de exposição ao tabaco e indicativo de fumo ${ }^{95}$.

A taxa de metabolização da nicotina (NMR), obtida pela relação da concentração de trans-3-hidroxicotinina/cotinina, tem sido associada com DN, com desfecho e com escolha farmacológica de tratamento antitabagismo ${ }^{95,96}$. Os valores contínuos e categóricos de NMR (metabolizadores lentos vs. normais e rápidos) se mostraram estáveis em fumantes independente da carga tabágica 32, 97, 98 .

A bupropiona é um fármaco extensamente metabolizado e a principal isoenzima envolvida em seu metabolismo é a CYP2B6, a qual medeia quase que exclusivamente o processo de hidroxilação desse fármaco, formando o metabólito hidroxibupropiona ${ }^{55}$. Diversos estudos têm associado as concentrações de bupropiona e de hidroxibupropiona em amostras de soro, plasma e urina com a resposta ao fármaco ${ }^{73,74}$.

Zhu et al ${ }^{73}$, em um estudo clínico, duplo-cego e placebo controlado, os indivíduos foram tratados com bupropiona ou placebo por 6 meses. Na terceira semana de tratamento, foram colhidas amostras de plasma para mensuração de bupropiona e seu principal metabólito ativo, a hidroxibupropiona. As concentrações mais elevadas de hidroxibupropiona resultaram em melhores resultados de cessação do tabagismo.

Laib et al ${ }^{74}$ apresentaram que as concentrações de hidroxibupropiona em soro foram correlacionadas com as diferentes respostas à bupropiona em pacientes com depressão analisadas através de uma escala de impressão clinica global. 
Quanto à vareniclina, este é um fármaco pouco metabolizado, sendo que 5 a $10 \%$ da dose pode ser encontrada na forma metabólitos (soro, plasma e urina) ${ }^{49}$. Os metabólitos de vareniclina já identificados em humanos em estudos prévios são hidroxivareniclina, vareniclina N-carbomoilglucoronídeo, oxovareniclina, Nglicosilvareniclina e $\mathrm{N}$-formilvareniclina ${ }^{47,49,99}$. Pouco se conhece sobre as enzimas que metabolizam a vareniclina. Obach et al ${ }^{49}$ mostrou o envolvimento da enzima UG2B7 com o processo de glucoronidação do fármaco. Ainda não há estudos que associam os metabólitos de vareniclina com resultados de desfecho de tratamento. 


\section{JUSTIFICATIVA}

Considerando a elevada prevalência do tabagismo e a dificuldade dos indivíduos fumantes em se abster do tabaco, estudos que apontem uma terapêutica farmacológica mais efetiva podem contribuir enormemente para o processo de cessação tabágica. Neste cenário, a análise da expressão de genes de interesse e a mensuração de analitos podem ser ferramentas úteis na identificação de marcadores e de subgrupos de resposta ao tratamento antitabagismo.

Escolhemos a realização da mensuração de analitos nas amostras de soro dos pacientes tratados com ambos os fármacos antitabagismo (vareniclina e bupropiona) e, especialmente para os pacientes tratados com vareniclina, foram realizadas análises de expressão gênica de células mononucleares provenientes de amostras de sangue periférico (do inglês Peripheral Blood Mononuclear Cell - PBMC). O ensaio customizado para as análises da expressão de 17 genes foi um grande investimento financeiro nesta pesquisa e, portanto, o priorizamos para analisar as amostras dos pacientes tratados com vareniclina, já que é o fármaco mais novo, eficaz e custoso no tratamento antitabagismo.

As análises de expressão gênica em amostras de PBMC são de grande valia, pois seria importante encontrar em amostras de tão fácil obtenção, como amostras de sangue, um marcador de resposta que poderia ter correlação com a expressão gênica do sistema nervoso central.

Identificar um possível marcador preditivo de sucesso na utilização de um determinado fármaco no início da sua administração foi uma das investigações deste protocolo. Os resultados desse estudo exploratório podem ser úteis no entendimento do comportamento de expressão dos genes escolhidos (mais comumente expressos no 
SNC) em amostras de sangue e na elaboração de pesquisas mais amplas para a identificação de biomarcadores de resposta ao tratamento antitabagismo. 


\section{OBJETIVOS}

3.1 Analisar a possível associação da expressão de genes de interesse, em amostras de sangue periférico, com a resposta ao tratamento com vareniclina;

3.2 Analisar a possível associação das concentrações de fármacos antibagismo, nicotina e seus metabólitos com a resposta ao tratamento com vareniclina e bupropiona. 


\section{METODOLOGIA}

\subsection{Casuística}

Foi realizado um estudo de coorte prospectivo no qual foram incluídos 105 pacientes, homens e mulheres, fumantes, provenientes do Programa de Assistência ao Fumante (PAF) do Instituto do Coração do Hospital das Clínicas da Faculdade de Medicina da Universidade de São Paulo (InCor), com idade $\geq 18$ anos, IMC $\geq 18,5$ e $<$ $30 \mathrm{~kg} / \mathrm{m}^{2}$, e que iniciariam o tratamento com vareniclina $(\mathrm{n}=74$, para a mensuração dos analitos; destes, n=27 para as análises de expressão gênica) ou com bupropiona ( $n=31$, para a mensuração dos analitos) (Figura 8).

A inclusão dos pacientes ocorreu através do protocolo de pesquisa: "Eficácia do uso de marcadores genéticos na escolha do tratamento farmacológico do tabagismo", o qual foi aprovado no processo de submissão ao Comitê de Ética Institucional (CAAE: 60133816.0.0000.0068) - SDC: 4341/16/007 (Anexo 4). O presente estudo foi aprovado como subprojeto do anterior através do parecer $n^{\circ} 2.118 .913$ (Anexo 1). Os pacientes foram informados do estudo e consentiram a sua participação ao assinar o termo de consentimento livre e esclarecido (Apêndice).

Foram excluídos do estudo: os pacientes que possuíssem desordens hepática, renal e gastrointestinal que comprometessem o metabolismo e eliminação dos fármacos; os pacientes que faziam uso de medicamentos indutores ou inibidores das enzimas do citocromo P450 nas últimas 6 semanas; os pacientes etilistas e usuários de droga; os pacientes com doenças psiquiátricas instáveis; as mulheres em risco de gravidez e os pacientes com contra-indicação ao tratamento com bupropiona ou vareniclina mencionados acima. 
Os pacientes foram acompanhados pela equipe do PAF e o tratamento farmacológico foi conduzido por 12 semanas. Foram considerados os seguintes desfechos no tratamento: "sucesso" se o paciente parasse de fumar até a $4^{\mathrm{a}}$ semana de tratamento (T4) e "resistente" se o paciente não conseguisse parar de fumar até a $4^{\mathrm{a}}$ semana de tratamento. 

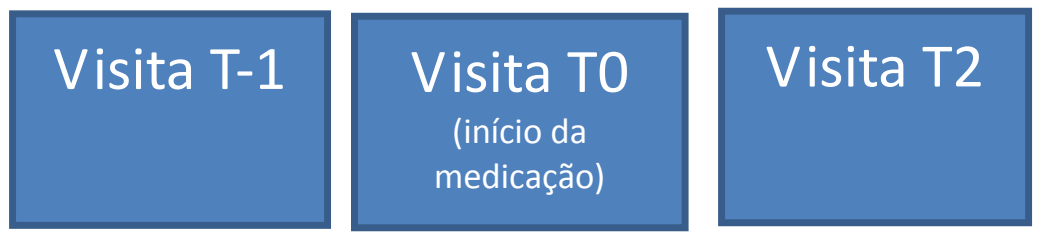

\section{Visita T4 \\ Desfecho}

• • •
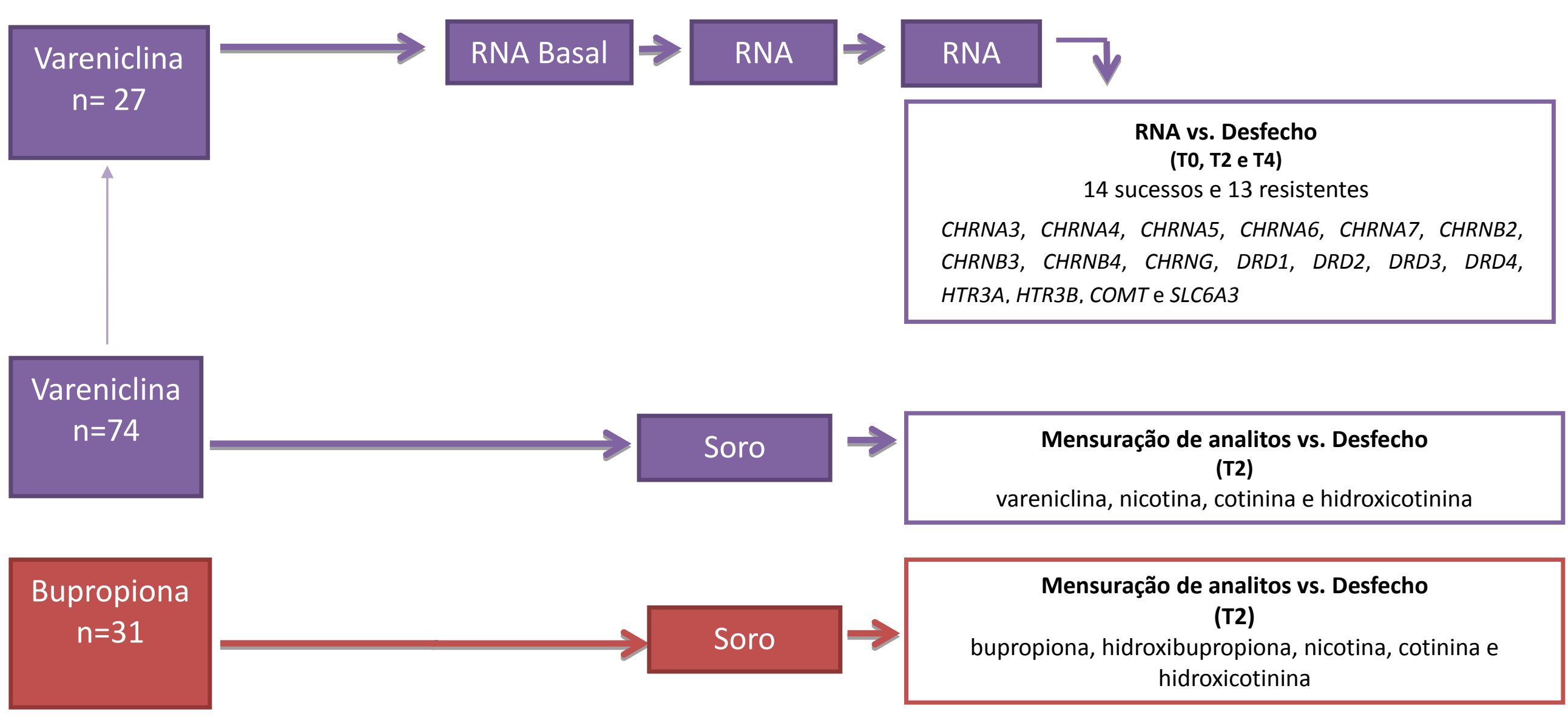

Mensuração de analitos vs. Desfecho
(T2)
bupropiona, hidroxibupropiona, nicotina, cotinina e
hidroxicotinina

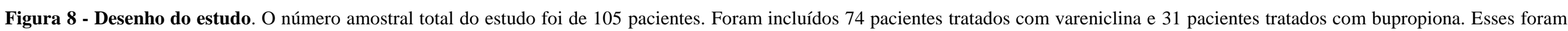

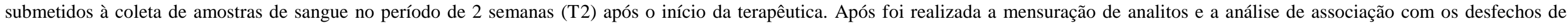

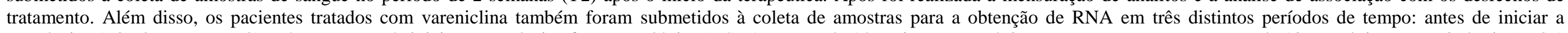

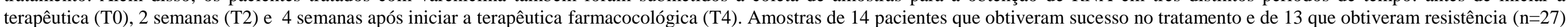

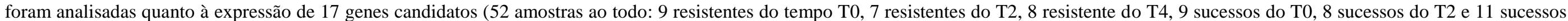

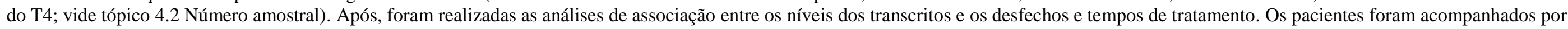

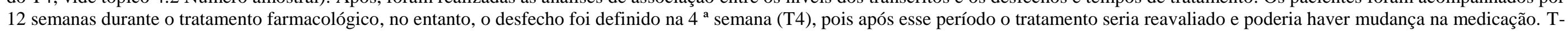

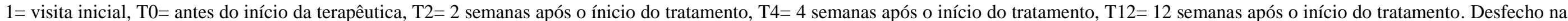

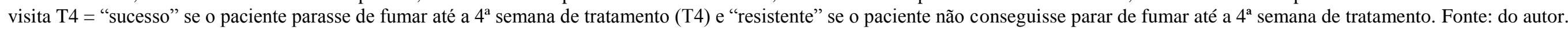




\subsection{Fluxo de procedimentos adotados no atendimento aos pacientes}

O tratamento farmacológico antitabagismo possui a duração de 3 meses (12 semanas). No estudo de "Eficácia do uso de marcadores genéticos", foram coletados dados clínicos em 7 visitas: T-1 (visita inicial), T0 (visita de início do tratamento), T2, T4, T6, T8 e T12 (2, 4, 6, 8 e 12 semanas após o início do tratamento farmacológico).

Neste projeto foram utilizados os tempos de visita dos pacientes nas consultas para a realização da coleta de amostras. Dessa forma, foi facilitado o comparecimento desses pacientes ao procedimento. Os pacientes precisavam estar comprometidos em administrar os medicamentos todos os dias no horário combinado e terem disponibilidade de tempo para as coletas, as quais, não necessariamente coincidiram com o horário das consultas, pois as coletas foram realizadas no mesmo horário de tomada do medicamento para que as análises de todos os pacientes pudessem ser comparáveis.

Na visita T-1 foi aplicado o TCLE do projeto "Eficácia do uso de marcadores genéticos”, bem como o questionário para coletar informações clínicas. Além disso, os pacientes foram avaliados quanto à DN através do teste de Fagerström para DN (FTND) 100 e do escore de consumo situacional Issa (escore Issa) ${ }^{101}$ (Anexos 2 e 3, respectivamente). O escore Issa é utilizado pelo PAF para a reclassificação como moderados ou altamente dependentes, os pacientes que obtém o escore de FTND abaixo de 5, mas que, no entanto, possuem nível de DN considerável em relação aos efeitos psicoativos da nicotina. A reclassificação ocorre quando os pacientes obtêm escore Issa 23. Após, os pacientes foram randomizados em dois braços do estudo: tratamento com vareniclina ou tratamento baseado na farmacogenética. Os pacientes realizaram coleta de sangue, com o objetivo de obtenção do DNA, para o estudo "Eficácia do uso de marcadores genéticos”. 
Após a genotipagem das amostras e escolha da medicação dos pacientes (vareniclina ou conforme genética), foi realizada ligação telefônica para o paciente informando o medicamento que iria tomar. Nesta mesma ligação, o paciente também foi convidado a participar do presente estudo e, todas as informações, quanto à necessidade de tomar o medicamento antitabagismo sempre no mesmo horário, quanto aos dias das coletas, bem como, as informações de preparação para os procedimentos, foram transmitidas aos pacientes.

Para os pacientes que seriam tratados com vareniclina, ainda foi importante levar em consideração o horário que o paciente costumava tomar café da manhã, para então decidir o horário de administração do fármaco, pois o mesmo precisava ser administrado após refeição generosa com o intuito de diminuir o risco de náusea.

As coletas foram padronizadas para serem realizadas às manhãs no mesmo horário que o paciente tomaria a primeira dose do dia do medicamento antitabágico. $\mathrm{O}$ horário de coleta entre os pacientes foi fixado entre 7 e 10 horas da manhã, para evitar variação circadiana interpacientes. No entanto, entre as coletas do mesmo paciente, o horário de coleta e de administração do medicamento foi sempre o mesmo, com variação não superior à 1 hora (esta variação foi registrada).

Os pacientes foram orientados a realizar jejum de 10 horas (sendo liberada a ingestão de água e outros medicamentos até 1 hora antes da coleta) e trazer o medicamento antitabágico para tomar após o procedimento. A dose diurna dos medicamentos antitabagismo não foi administrada antes da coleta para evitar efeitos agudos nas análises. O período de jejum foi realizado para que a amostra tivesse menor quantidade de interferentes possível e, também, para não promover efeitos agudos dos alimentos na expressão gênica. Um dia antes de cada coleta foi realizada ligação telefônica ou envio de mensagem para os pacientes com o objetivo de lembrá-los do 
procedimento, das orientações de preparo e confirmar o uso e o cumprimento do horário de administração do medicamento antitabagismo (essa confirmação da adesão foi realizada para as coletas nas visitas T2 e T4, quando os pacientes já haviam iniciado o tratamento farmacológico).

Na visita T0, para os pacientes que iniciariam o tratamento com vareniclina, foi aplicado o TCLE do presente projeto e colheu-se uma amostra de sangue para a obtenção do RNA ainda antes de iniciarem o tratamento. Foram fornecidas aos pacientes as orientações de como tomar o medicamento e informações para a próxima coleta. Os pacientes foram orientados à tomarem o medicamento neste mesmo dia ou no dia seguinte.

$\mathrm{Na}$ visita $\mathrm{T} 2$, foram coletadas amostras de soro dos pacientes tratados com bupropiona e amostras de soro e RNA dos pacientes tratados com vareniclina.

Na visita T4, foram coletadas amostras de RNA dos pacientes tratados com vareniclina.

No Quadro 1 abaixo estão resumidos os procedimentos, orientações e coletas de amostras.

Quadro 1 - Procedimentos do protocolo em relação aos pacientes

\begin{tabular}{|c|l|}
\hline T-1 & $\begin{array}{l}\text { Aplicação do TCLE do projeto "Eficácia do uso de marcadores } \\
\text { genéticos"; }\end{array}$ \\
& • Aplicação de questionários; \\
& - Coleta de DNA. \\
\hline 1 dia antes de T0 & • Ligação para informar o medicamento que o paciente iria tomar; \\
& - Convite para participar do presente estudo; \\
& - Determinar com o paciente qual era o melhor horário para \\
\hline
\end{tabular}




\begin{tabular}{|c|c|}
\hline & $\begin{array}{l}\text { administração do medicamento antibagismo (neste mesmo horário } \\
\text { que foram realizadas todas as coletas); } \\
\text { - Orientações para a coleta em T0. }\end{array}$ \\
\hline T0 & $\begin{array}{l}\text { - Aplicação do TCLE do presente estudo; } \\
\text { - Coleta de amostra de RNA (para os pacientes que seriam tratados } \\
\text { com vareniclina). } \\
\text { - Orientações para iniciar o tratamento no mesmo dia ou dia } \\
\text { seguinte. }\end{array}$ \\
\hline 1 dia antes de $\mathrm{T} 2$ & $\begin{array}{l}\text { - Orientações para coleta em } \mathrm{T} 2 \text {; } \\
\text { - Confirmação se o paciente estava tomando o medicamento e no } \\
\text { horário combinado. }\end{array}$ \\
\hline $\mathbf{T 2}$ & $\begin{array}{l}\text { - Aplicação do TCLE do presente estudo para os pacientes tratados } \\
\text { com bupropiona; } \\
\text { - Coleta de soro para os pacientes tratados com bupropiona e coleta } \\
\text { de RNA e soro dos pacientes tratados com vareniclina. }\end{array}$ \\
\hline 1 dia antes de T4 & $\begin{array}{l}\text { - Orientações para coleta em } \mathrm{T} 2 \text {; } \\
\text { - Confirmação se o paciente estava tomando o medicamento e no } \\
\text { horário combinado. }\end{array}$ \\
\hline T4 & - Coleta de RNA dos pacientes tratados com vareniclina. \\
\hline
\end{tabular}

4.3 Coleta e armazenamento das amostras dos pacientes tratados com vareniclina e bupropiona

Os pacientes tratados com vareniclina foram submetidos à coleta de sangue para a obtenção de RNA em 3 períodos de tempo: T0 (ainda antes de iniciar o tratamento, T2 
e T4. Para isto, foram utilizados os tubos PAXgene Blood RNA Tubes BRT (Qiagen, USA) para a obtenção de RNA. Após a coleta, os tubos PAXgene foram encubados em bancada por 2 horas à temperatura ambiente, para garantir a lise completa das células sanguíneas e, após, os tubos foram armazenados a $-20^{\circ} \mathrm{C}$ até a extração do RNA das amostras.

No período T2 também foram coletadas amostras para a obtenção do soro dos pacientes tratados com vareniclina e bupropiona. Neste período, as concentrações dos metabólitos dos fármacos já se encontravam em estado de equilíbrio. Para isto, foram utilizados tubos sem aditivo (Vacuette, Greiner Bio-one). Os tubos foram mantidos a temperatura ambiente até a formação de coágulo. Após, os tubos foram centrifugados a $4^{\circ} \mathrm{C}$, a $3000 \mathrm{rpm}$, por $10 \mathrm{~min}$, para se obter amostras de soro. As amostras foram então aliquotadas em 4 criotubos de soro e armazenadas em freezer a $-80^{\circ} \mathrm{C}$ até o momento das análises.

\subsection{Número amostral}

Quanto ao número amostral para o ensaio de expressão gênica, dos 74 pacientes tratados com vareniclina, foram escolhidas amostras de 27 pacientes (14 do grupo

sucesso e 13 do grupo resistente), baseado em estudos anteriores ${ }^{83,102}$, que seguiram corretamente o jejum, que realizaram a tomada do medicamento nos horários combinados e compareceram em todos e tempos de coleta. Sendo ao todo 81 amostras, devido aos de 3 tempos de tratamento (T0, T2 e T4).

No entanto, algumas amostras não apresentaram bons resultados para a análise de expressão gênica e realizamos o ensaio de expressão para 60 amostras de diversos tempos. Oito amostras não apresentaram resultados de amplificação e finalizamos com 52 amostras ao todo (9 resistentes do tempo T0, 7 resistentes do T2, 8 resistentes do T4, 
9 sucessos do T0, 8 sucessos do T2 e 11 sucessos do T4) provenientes de 14 pacientes do grupo sucesso e 13 do grupo resistente. Esse tamanho amostral para cada grupo de análise é comparável à estudos anteriores ${ }^{102}$.

Quanto ao número amostral para a mensuração dos analitos, houve a inclusão de 74 pacientes tratados com vareniclina e 31 tratados com bupropiona. Número amostral semelhante foi utilizado no estudo de Laib et $a l^{74}$. Das 105 amostras, 3 amostras dos pacientes tratados com vareniclina e 1 de paciente tratado com bupropiona apresentaram concentrações abaixo do limite de quantificação (LQ) e estas foram excluídas das análises de concentração dos analitos, ficando com número amostral final de 71 para vareniclina e 30 para bupropiona.

\subsection{Análise de expressão gênica para amostras de pacientes tratados com vareniclina}

\subsubsection{Concentração, purificação e extração de RNA}

O processo de purificação e concentração do RNA foi realizado através do PAXgene Blood RNA Kit (Qiagen, USA). Antes de iniciar o procedimento, a temperatura dos tubos PAXgene Blood tubes (BRT) (Qiagen, USA), os quais estavam armazenados em freezer $-20^{\circ} \mathrm{C}$, foi estabilizada mantendo os tubos em temperatura ambiente em torno de 4 horas ou over night.

Para o processo de purificação do RNA, primeiramente, realizou-se a homogeneização do sangue total contido no tubo PAXgene Blood tubes (BRT) e a centrifugação dos ácidos nucléicos por 10 min em 3000 rcf, havendo a formação de um pellet e o sobrenadante foi desprezado. Após, foi realizada a lavagem do pellet adicionando-se $4 \mathrm{~mL}$ de água livre de RNase (RNFW), mistura foi submetida ao vórtex até a dissolução visível do pellet e o conteúdo foi centrifugado por 10 minutos a 3000 
rcf, sendo descartado o sobrenadante. O pellet foi ressuspendido com $350 \mu \mathrm{L}$ de tampão de ressuspensão (BR1) através de vórtex até a sua dissolução e, transferido para o tubo de microcentrifugação (1,5 mL, MCT). Foram adicionados no tubo MCT $300 \mu \mathrm{L}$ de tampão de ligação (BR2) e $40 \mu \mathrm{L}$ de proteinase $\mathrm{K}(\mathrm{PK})$; a mistura foi submetida ao vórtex durante 5 segundos e incubada durante 10 minutos a $55^{\circ} \mathrm{C}$ com agitação de 1400 rpm, provocando dessa forma, a digestão de proteínas.

Após o processo de incubação, foram realizados diversos processos de remoção de impurezas em colunas de rotação. O lisado foi transferido para a coluna de rotação do homogeneizador PAXgene (PSC, lilás), a qual foi colocada em um tubo de processamento (PT) de $2 \mathrm{~mL}$ e centrifugado durante 3 minutos à velocidade de 16100 rcf, dessa forma, foi realizada a homogeneização do lisado de células e remoção dos detritos celulares residuais. Em seguida, o sobrenadante da fração residual foi transferido para o tubo de microcentrifugação $(1,5 \mathrm{~mL}, \mathrm{MCT})$ novo (sem interferir no pellet) e foram adicionados $350 \mu \mathrm{L}$ de etanol (96-100\%, grau de pureza P.A.), a mistura foi submetida ao vórtex e centrifugada por breves instantes (1-2 segundos 500-1000 x g) para remover as gotas presentes no interior da tampa do tubo.

Foram transferidos $700 \mu \mathrm{L}$ de amostra para a coluna de rotação de RNA PAXgene (PRC, vermelho), esta foi colocada e um tubo de processamento (PT) de 2 mL, no qual foi centrifugado durante 1 minuto a 12000 rcf. Após, a coluna de rotação foi colocada em um tubo PT novo (o tubo PT utilizado anteriormente foi descartado). O restante da amostra foi colocado na mesma coluna de rotação PRC e o processo de centrifugação foi repetido por mais 2 vezes, sempre transferindo a coluna para um tubo de processamento novo. Antes da última centrifugação foram adicionados $350 \mu \mathrm{L}$ de tampão de lavagem 1 (BR3) na coluna PRC. 
Em seguida foram adicionados $10 \mu \mathrm{L}$ de solução-mãe de DNase I (RNFD) a 70 $\mu \mathrm{L}$ de tampão de digestão de DNA (RDD) em um tubo de microcentrifugação de 1,5 mL (MCT). O conteúdo foi misturado suavemente e centrifugado durante breves instantes, para colher o líquido residual dos lados do tubo. Após, $80 \mu \mathrm{L}$ dessa mistura foram transferidos diretamente para a membrana da coluna PRC e esta foi incubada à temperatura ambiente $\left(20-30^{\circ} \mathrm{C}\right)$ durante 15 minutos.

Após o período de incubação, foram adicionados $350 \mu \mathrm{L}$ de tampão de lavagem 1 (BR3) para a membrana da coluna e esta foi centrifugada durante 1 min a $12000 \mathrm{rcf}$. Após, a coluna PRC foi colocada em um tubo (PT) novo e foram adicionados $500 \mu \mathrm{L}$ de tampão de lavagem 2 (BR4) na membrana da coluna. A centrifugação foi repetida, o tubo PT foi descartado e a coluna PRC foi colocada em um novo tubo PT. A lavagem com 500 uL de BR4 e a centrifugação foi repetida novamente (porém o tempo de centrifugação foi de 3 minutos). Após, foi realizada uma centrifugação adicional em um tubo PT novo durante 1 minuto a 12000 rcf (sem adição de tampão).

A coluna de rotação (PRC) foi colocada em tubo de 1,5 mL (MCT). Foram adicionados diretamente na membrana da coluna $80 \mu \mathrm{L}$ de tampão de eluição (BR5), a qual foi encubada à temperatura ambiente por 5 minutos e centrifugada por 1 minuto a 12000 ref para eluir o RNA.

As amostras foram quantificadas através de leitura em espectrofotômetro no comprimento de onda $260 \mathrm{~nm}$ (utilizando como branco o tampão BR5) e foram armazenadas a $-20^{\circ} \mathrm{C}$ até o momento das análises. Para avaliar a qualidade do RNA gerado, foi realizada uma eletroforese em gel de agarose para a verificação da integridade do RNA ribossomal. 


\subsubsection{Síntese de cDNA}

O processo de síntese de cDNA foi realizado através do $R T^{2}$ First Strand Kit (Qiagen, USA). Os reagentes do kit foram descongelados e centrifugados brevemente (10-15 segundos).

Primeiramente foi preparada uma mix para a degradação do DNA genômico composta por $2 \mu \mathrm{L}$ de tampão GE, 800 ng de RNA e quantidade variável de água livre de RNase até o volume final de $10 \mu \mathrm{L}$ ou $8 \mu \mathrm{L}$ de RNA (para amostras com concentrações abaixo de $100 \mathrm{ng} / \mu \mathrm{L}$ ) sem a água livre de RNase. A mistura foi incubada a $42^{\circ} \mathrm{C}$ por 5 minutos. Após a incubação, a mistura foi colocada imediatamente em gelo durante pelo menos 1 min.

Após, foi preparada uma mix para a realização da transcrição reversa, esta foi composta por $4 \mu \mathrm{L}$ tampão 5x (BC3), $1 \mu \mathrm{L}$ de controle P2 (controle externo de RNA), 2 $\mu \mathrm{L}$ de mix de transcriptase reversa (RE3) e $3 \mu \mathrm{L}$ de água livre de Rnase. Foram adicionados $10 \mu \mathrm{L}$ da mix preparada em cada tubo contendo a mix de eliminação de DNA genômico. A mistura foi homogeneizada delicadamente com a pipeta e incubada a $42{ }^{\circ} \mathrm{C}$ durante exatamente 15 min, em seguida, a reação foi interrompida por incubação a $95{ }^{\circ} \mathrm{C}$ durante 5 min. Após o período de incubação, foram adicionados a cada reação $91 \mu \mathrm{L}$ de água livre de RNase e a mistura foi homogeneizada através de pipeta diversas vezes. O produto final foi armazenado a $-20^{\circ} \mathrm{C}$ até a realização da reação em cadeia da polimerase (PCR) em tempo real.

\subsubsection{Ensaio de controle de qualidade das amostras para o ensaio de expressão gênica}

Todas as amostras de cDNA foram analisadas quanto sua qualidade pelo ensaio de controle de qualidade (disco QC, Qiagen) em disco de 100 poços (representação do 
disco nas Figuras 9 e 10), através do PCR em tempo real com equipamento Rotor Gene 6000 (Corbett). Cada disco QC tem a capacidade de analisar 12 amostras, sendo necessários 5 discos para analisar 60 amostras.

O disco QC é composto por primers específicos para a amplificação de 2 Housekeeping genes - ACTB e HPRT1 (genes constitutivos que são necessários para a manutenção básica da função celular e são expressos em todas as células de um organismo, em condições normais e fisiopatológicas) e 6 controles: 1 controle de transcrição reversa (RTC), 1 controle positivo de PCR (PPC), 1 controle de contaminação com DNA genômico (GDC), 1 controle de não transcrição reversa (NTR), 1 PPC (sem amostra) e 1 controle negativo NTC (mapa na Figura 10).

Foram preparadas 12 mixes para cada uma das amostras de cDNA. Sendo 9,2 $\mu \mathrm{L}$ de água livre de RNase e $0,8 \mu \mathrm{L}$ de cDNA, essas quantidades foram multiplicadas por 6 para se ter sobra e distribuir em 5 poços cada mix de amostra (poços que continham pares de primers para 2 housekeeping genes e 3 controles). Foram distribuídos $10 \mu \mathrm{L}$ de mix e $10 \mu \mathrm{L}$ de $R T^{2}$ FAST SYBR Green/ROX pPCR Master Mix (Qiagen, USA) em cada poço (linhas A a E). Essa master mix contém corante fluorescente intercalante de DNA.

Após foram preparadas 12 mixes, uma para cada amostra mãe de RNA (diluído 1:100). Foram utilizados $9,63 \mu \mathrm{L}$ de água livre de RNase e $0,72 \mu \mathrm{L}$ de RNA (1:100), essas quantidades foram multiplicadas por 3 para se ter sobra. Foram pipetados 10,37 $\mu \mathrm{L}$ de mix de RNA e 9,63 $\mu \mathrm{L}$ de $R T^{2}$ FAST SYBR Green/ROX pPCR Master Mix em cada poço da linha F para a análise do controle de transcrição reversa NTR.

Após, foram preparadas mixes sem as amostras para os 2 últimos controles PPC e NTC, compostas por $10 \mu \mathrm{L}$ de água e $10 \mu \mathrm{L}$ de $R T^{2}$ FAST SYBR Green/ROX pPCR Master Mix (multiplicados por 24) para as linhas G e H. 
$\mathrm{O}$ disco foi submetido à seguinte programação: 1 ciclo de 10 minutos a $95^{\circ} \mathrm{C}$ (temperatura de ativação da Taq polimerase) e 40 ciclos de 15 segundos a $95^{\circ} \mathrm{C}$ e 30 segundos a $60^{\circ} \mathrm{C}$ (para a amplificação e realização da captura dos dados de fluorescência). Através do software real-time cycler (Qiagen, USA) foi ajustada a linha de base (Threshold) do gráfico de amplificação logarítimica do cDNA, para dessa forma, remover ruídos na análise e verificar em qual ciclo de PCR que cada amostra amplificou (cicle threshold - CT) (Figura 11). Os valores de CT foram planilhados e analisados conforme os parâmetros de qualidade (Quadro 2).

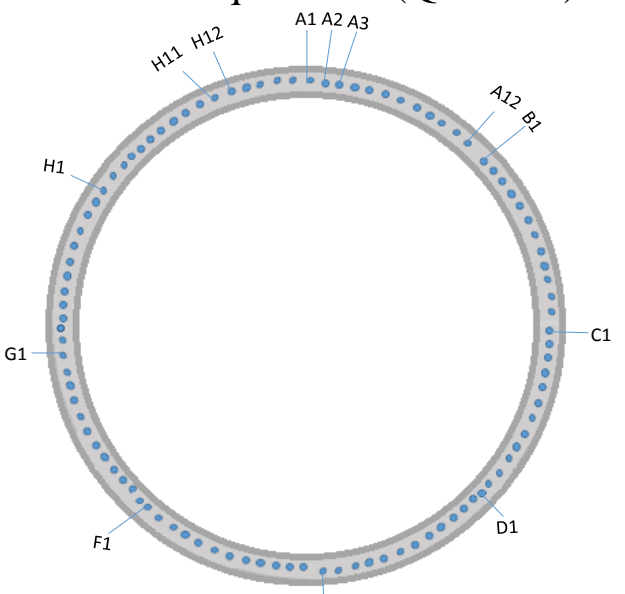

Figura 9 - Representação do Rotor-Disc 100. Refere-se a um disco de material plástico contendo 100 poços. Este veio de fábrica personalizado com primers para os ensaios QC ou $R T^{2}$ profiler PCR array. As amostras e mixes são pipetadas em cada poço. O disco é posteriormente colocado em um anel metálico próprio para o encaixe no equipamento Rotor-Gene. Cada poço é nomeado com uma letra e um número, iniciando no A1 até o H12. Os quatro últimos poços não são nomeados e não contém ensaio (no entanto, preenchemos com mix para equilibrar o peso do disco). Fonte: do autor.

\begin{tabular}{|c|c|c|c|c|c|c|c|c|c|c|c|c|}
\hline & $\mathbf{1}$ & $\mathbf{2}$ & $\mathbf{3}$ & $\mathbf{4}$ & $\mathbf{5}$ & $\mathbf{6}$ & $\mathbf{7}$ & $\mathbf{8}$ & $\mathbf{9}$ & $\mathbf{1 0}$ & $\mathbf{1 1}$ & $\mathbf{1 2}$ \\
\hline $\mathbf{A}$ & $A C T B$ & $A C T B$ & $A C T B$ & $A C T B$ & $A C T B$ & $A C T B$ & $A C T B$ & $A C T B$ & $A C T B$ & $A C T B$ & $A C T B$ & $A C T B$ \\
\hline $\mathbf{B}$ & $H P R T 1$ & $H P R T 1$ & $H P R T 1$ & $H P R T 1$ & $H P R T 1$ & $H P R T 1$ & $H P R T 1$ & $H P R T 1$ & $H P R T 1$ & $H P R T 1$ & $H P R T 1$ & $H P R T 1$ \\
\hline $\mathbf{C}$ & $R T C$ & $R T C$ & $R T C$ & $R T C$ & $R T C$ & $R T C$ & $R T C$ & $R T C$ & $R T C$ & $R T C$ & $R T C$ & $R T C$ \\
\hline $\mathbf{D}$ & $P P C$ & $P P C$ & $P P C$ & $P P C$ & $P P C$ & $P P C$ & $P P C$ & $P P C$ & $P P C$ & $P P C$ & $P P C$ & $P P C$ \\
\hline $\mathbf{E}$ & $G D C$ & $G D C$ & $G D C$ & $G D C$ & $G D C$ & $G D C$ & $G D C$ & $G D C$ & $G D C$ & $G D C$ & $G D C$ & $G D C$ \\
\hline $\mathbf{F}$ & $N T R$ & $N T R$ & $N T R$ & $N T R$ & $N T R$ & $N T R$ & $N T R$ & $N T R$ & $N T R$ & $N T R$ & $N T R$ & $N T R$ \\
\hline $\mathbf{G}$ & $P P C$ & $P P C$ & $P P C$ & $P P C$ & $P P C$ & $P P C$ & $P P C$ & $P P C$ & $P P C$ & $P P C$ & $P P C$ & $P P C$ \\
\hline $\mathbf{H}$ & $N T C$ & $N T C$ & $N T C$ & $N T C$ & $N T C$ & $N T C$ & $N T C$ & $N T C$ & $N T C$ & $N T C$ & $N T C$ & $N T C$ \\
\hline
\end{tabular}

Figura 10 - Mapa do disco QC (representação planilhada). Do A1 ao B12 housekeeping genes para 12 amostras. C1 ao H12 controles. Cada grupo de cor representa a colocação de uma mix. Do A1 ao E1 mix de 
cDNA da amostra 1, do A2 ao E2 mix de cDNA da amostra 2 (assim por diante até A12 e E12). Linha F controle com RNA diluído (1:100). Linhas G e H controles com água livre de RNase. Fonte: do autor.

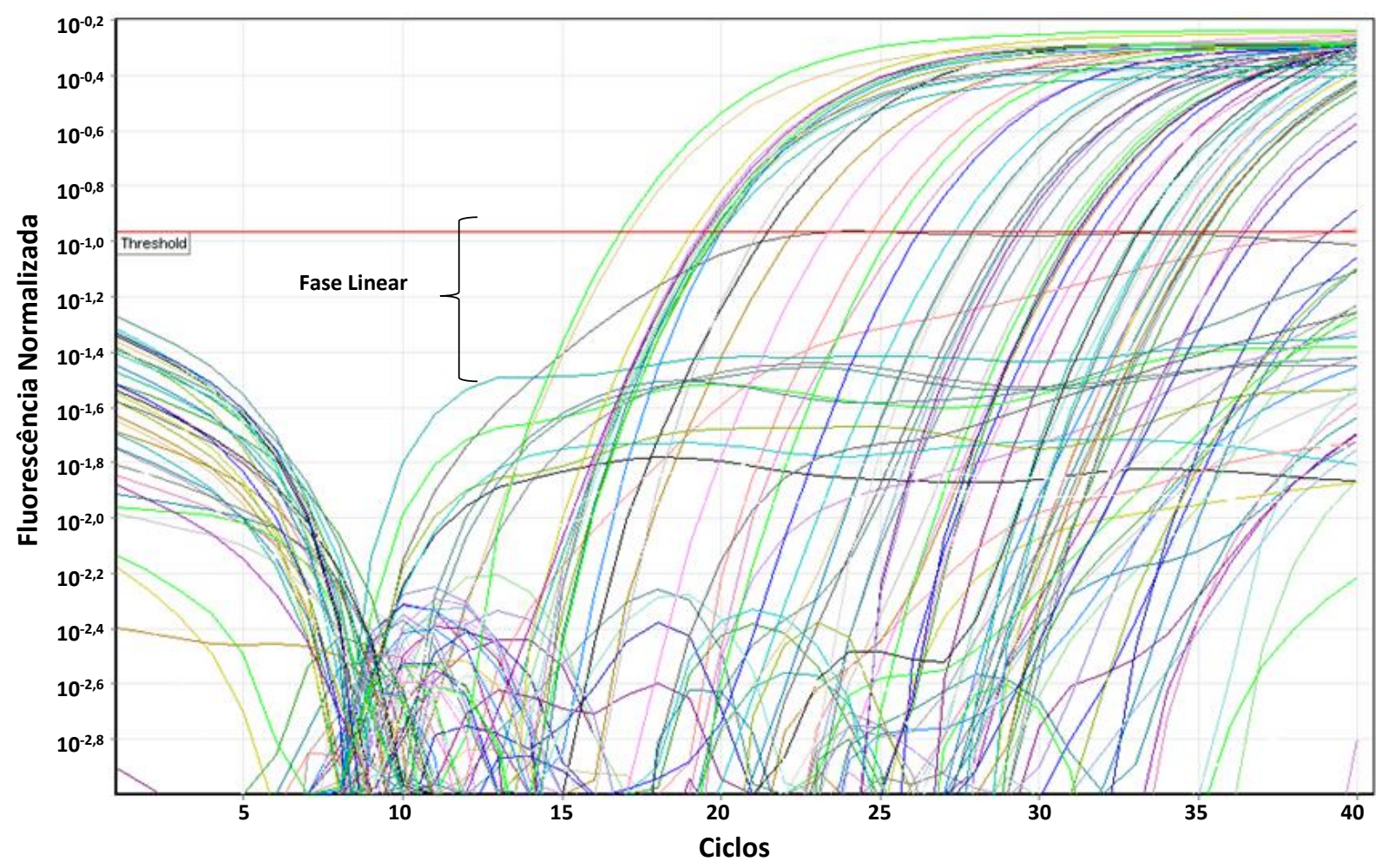

Figura 11 - Exemplo de ajuste de Threshold. A linha de base (Threshold) é ajustada na fase linear do ciclo de amplificação. Dessa forma, é possível remover os ruídos e se obter o ciclo em que cada amostra foi amplificada na PCR (CT). Fonte: do autor, imagem do equipamento Rotor Gene ${ }^{\circledR}$.

Quadro 2 - Parâmetros de qualidade do ensaio QC

\begin{tabular}{|c|c|c|c|}
\hline Controles & Teste & Passa no teste & Falha no teste \\
\hline Controle de transcrição reversa & $\mathrm{CT}^{\mathrm{RTC} \text { (linha B) }}-\mathrm{CT}^{\mathrm{PPC} \text { (linha G) }}$ & $<5$ & $>5$ \\
\hline \multirow[t]{2}{*}{ Controle positivo de PCR } & CT PPC (linha G) & $14 \pm 2$ & $>16$ \\
\hline & $\mathrm{CT}^{\text {PPC (linha D) }}$ - CT PPC (linha G) & $<3$ & $>3$ \\
\hline Controle de contaminação de DNA genômico & CT GDC (linha E) & $>33$ & $<33$ \\
\hline Controle de não transcrição reversa & CT NTR (linha F) & $\geq 33$ ou N/A & $<33$ \\
\hline Controle negativo & CT NTC (linha H) & $\geq 33$ ou N/A & $<33$ \\
\hline
\end{tabular}


De 60 amostras analisadas, 52 passaram no teste quanto aos critérios de qualidade e prosseguiram para a análise de expressão gênica do painel de genes escolhidos.

\subsubsection{Ensaio de expressão gênica}

O protocolo de expressão foi realizado por PCR em tempo real através do equipamento Rotor Gene 6000 (Corbett), com ensaio customizado RT2 Profiler PCR Array em disco com capacidade de 100 poços (Rotor-Disc 100, Qiagen, USA). Nos 100 poços de cada disco estavam distribuídos primers específicos para o ensaio de expressão de 17 genes (Figuras 9 e 12 e Quadro 3) (17 pares de primers para cada gene repetidos 4 vezes na placa, pois foi possível a análise de 4 amostras de cDNA por disco), 4 pares de primers para os Housekeeping genes B2M, GAPDH, HPRT1 e ACTB (Quadro 4) e 3 controles: 1 controle de contaminação com DNA genômico (HGDC), 1 controle de transcrição reversa (RTC) e 1 controle positivo de PCR (PPC). Os 4 Housekeeping genes e os 3 controles também são repetidos 4 vezes no disco (Figura 5). Para as reações foi utilizada a $R T^{2}$ FAST SYBR Green/ROX pPCR Master Mix (Qiagen, USA).

Primeiramente foi preparada 4 mixes (uma para cada amostra de cDNA) para um disco de 100 poços, composta por $275 \mu \mathrm{L}$ de $2 \mathrm{X}$ RT2 SYBR Green ROX FAST Mastermix, 226,2 $\mu \mathrm{L}$ de água livre de RNase e 48,8 $\mu \mathrm{L}$ de amostra de cDNA cada. Em cada um dos poços do disco foram adicionados $20 \mu \mathrm{L}$ da mix preparada (utilizando mixes de diferentes amostras a cada 24 poços). Após deste processo, o disco foi selado com o Rotor-Disc Heat Sealer (Qiagen, USA) e colocado no equipamento Rotor-Gene 6000 (Corbett). O real-time foi programado para ciclagem de PCR nas seguintes condições: 1 ciclo a $95^{\circ} \mathrm{C}$ com duração de 10 minutos; 40 ciclos a $95^{\circ} \mathrm{C}$ por 15 segundos e $60^{\circ} \mathrm{C}$ por 30 segundos. 


\section{Quadro 3 - Genes escolhidos para o ensaio de expressão}

\begin{tabular}{|c|c|}
\hline CHRNA3 & Codifica o receptor acetilcolínico-nicotínico subunidade $\alpha 3$ \\
\hline CHRNA4 & Codifica o receptor acetilcolínico-nicotínico subunidade $\alpha 4$ \\
\hline CHRNA5 & Codifica o receptor acetilcolínico-nicotínico subunidade $\alpha 5$ \\
\hline CHRNA6 & Codifica o receptor acetilcolínico-nicotínico subunidade $\alpha 6$ \\
\hline CHRNA7 & Codifica o receptor acetilcolínico-nicotínico subunidade $\alpha 7$ \\
\hline CHRNB2 & Codifica o receptor acetilcolínico-nicotínico subunidade $\beta 2$ \\
\hline CHRNB3 & Codifica o receptor acetilcolínico-nicotínico subunidade $\beta 3$ \\
\hline CHRNB4 & Codifica o receptor acetilcolínico-nicotínico subunidade $\beta 4$ \\
\hline CHRNG & Codifica o receptor acetilcolínico-nicotínico subunidade $\gamma$ \\
\hline$D R D 1$ & Codifica o receptor de dopamina tipo 1 \\
\hline DRD2 & Codifica o receptor de dopamina tipo 2 \\
\hline DRD3 & Codifica o receptor de dopamina tipo 3 \\
\hline DRD4 & Codifica o receptor de dopamina tipo 4 \\
\hline$H T R 3 A$ & Codifica o receptor $3 \mathrm{~A}$ de serotonina \\
\hline$H T R 3 B$ & Codifica o receptor $3 \mathrm{~B}$ de serotonina \\
\hline COMT & Codifica a enzima catecol-O-metiltransferase (metaboliza dopamina) \\
\hline SLC6A3 & Codifica a proteína DAT, que promove a recaptação de dopamina DAT \\
\hline
\end{tabular}

\section{Quadro 4 - Housekeeping genes}

\begin{tabular}{|ll}
\hline$B 2 M$ & Codifica a microbulina subunidade $\beta 2$ \\
GAPDH & Codifica a enzima gliceraldeído -3 fosfato desidrogenase \\
HPRT1 & Codifica a enzima hipoxantina fosforribosiltransferase 1 \\
ACTB & Codifica a $\beta$ actina
\end{tabular}




\begin{tabular}{|c|c|c|c|c|c|c|c|c|c|c|c|c|}
\hline & 1 & 2 & 3 & 4 & 5 & 6 & 7 & 8 & 9 & 10 & 11 & 12 \\
\hline $\mathbf{A}$ & CHRNA3 & CHRNA4 & CHRNA5 & CHRNA6 & CHRNA7 & CHRNB2 & CHRNB3 & CHRNB4 & CHRNG & DRDI & DRD2 & DRD3 \\
\hline B & DRD4 & HTR3A & HTR3B & COMT & SLC6A3 & $B 2 M$ & GAPDH & HPRT1 & $A C T B$ & $R T C$ & $P P C$ & $H G D C$ \\
\hline $\mathbf{C}$ & $\overline{C H R N A 3}$ & CHRNA4 & CHRNA5 & CHRNA6 & CHRNA7 & CHRNB2 & $\overline{C H R N B 3}$ & CHRNB4 & CHRNG & DRD1 & DRD2 & $\overline{D R D 3}$ \\
\hline $\mathbf{D}$ & DRD4 & HTR3A & HTR3B & COMT & SLC6A3 & $B 2 M$ & GAPDH & HPRTI & $A C T B$ & $R T C$ & $P P C$ & $H G D C$ \\
\hline$\overline{\mathbf{E}}$ & CHRNA3 & CHRNA4 & CHRNA5 & CHRNA6 & CHRNA7 & CHRNB2 & CHRNB3 & CHRNB4 & CHRNG & DRDI & DRD2 & DRD3 \\
\hline$\overline{\mathbf{F}}$ & DRD4 & HTR3A & HTR3B & COMT & SLC6A3 & $B 2 M$ & GAPDH & HPRT1 & $A C T B$ & $R T C$ & $P P C$ & $H G D C$ \\
\hline$\overline{\mathbf{G}}$ & CHRNA3 & CHRNA4 & CHRNA5 & CHRNA6 & CHRNA7 & CHRNB2 & CHRNB3 & CHRNB4 & CHRNG & DRDI & DRD2 & DRD3 \\
\hline $\mathbf{H}$ & DRD4 & HTR3A & HTR3B & COMT & SLC6A3 & $B 2 M$ & GAPDH & HPRT1 & $A C T B$ & $R T C$ & $P P C$ & $H G D C$ \\
\hline
\end{tabular}

Figura 12 - Mapa do disco do ensaio RT2 profiler PCR array (representação planilhada). O disco contém 100 poços, no entanto, apenas 96 poços contêm ensaios, sendo que 4 poços ficam vazios. A1 ao B5 = genes escolhidos para análise de expressão. Do B6 ao B9= Housekeeping genes. Do B10 ao B12= controles. C1 ao D12, E1 ao F12 e G1 ao H12= repetição dos ensaios, permitindo a análise completa de 4 amostra. Cada cor diferente (a cada 2 linhas) representam a análise de uma amostra. Fonte: do autor.

\subsubsection{Análise dos dados de expressão gênica}

Para a análise de expressão gênica foi utilizado o método de $2^{-\Delta \Delta \mathrm{CT}} 103$. Após o término da corrida do ensaio de expressão gênica, através do software real-time cycler (Qiagen, USA), foi ajustada a linha de base (threshold) no gráfico de amplificação em escala logarítmica (Figura 11). Todos os discos (total de 13) foram analisados com o mesmo valor de threshold $(0,10869)$, para que os valores de CT de todas as amostras fossem comparáveis.

Os dados de CT também foram inseridos no programa SPSS para as análises estatísticas. Os valores de CT foram normalizados através da expressão dos housekeeping genes, utilizando a seguinte fórmula: $\Delta \mathrm{CT}=\left(\mathrm{CT}_{\text {amostra }}-\right.$ a média de $\mathrm{CT}_{\text {housekeeping genes }}$ ). Os valores de mediana de $2^{-\Delta \mathrm{CT}}$ (em escala logarítmica) de cada grupo foram utilizados para os testes de hipótese. Após, foram obtidos os valores de $\Delta \Delta \mathrm{CT}$ (mediana de $\Delta \mathrm{CT}_{\text {grupo teste }}$ - mediana de $\Delta \mathrm{CT}$ grupo referência) e o fold change (aumento ou diminuição da expressão dos genes em relação ao grupo referência) foi calculado através da fórmula $2^{-\Delta \Delta \mathrm{CT}}$. 
4.6 Mensuração de bupropiona, vareniclina e de seus metabólitos por HPLCMS/MS

4.6.1 Materiais, equipamentos e condições adotadas para a mensuração dos analitos após validação do método

- Padrões analíticos e padrões internos (PIs) deuterados: bupropiona, hidroxibupropiona, vareniclina $\left(\operatorname{Santa}_{\mathrm{Cruz}}{ }^{\circledR}\right)$; vareniclina d4 $\left(\mathrm{TRC}^{\circledR}\right)$; nicotina $\left(\right.$ ChemCruz $\left.^{\circledR}\right) ; \quad$ cotinina $\quad\left(\right.$ Sigma-Aldrich $\left.^{\circledR}\right) ; \quad$ hidroxicotinina $\quad\left(\right.$ Toronto $\left.^{\circledR}\right) \quad$ e hidroxibupropiona $\mathrm{d} 6$, nicotina $\mathrm{d} 4$, cotinina $\mathrm{d} 3$, hidroxicotinina $\mathrm{d} 3\left(\right.$ Cerilliant $\left.^{\circledR}\right)$;

- Solventes orgânicos: Metanol, acetonitrila (J.T. Baker) e sais acetato de amônio, fosfato de sódio $\left(\operatorname{Vetec}^{\circledR}\right.$ ), fosfato de sódio monobásico (Proquimios ${ }^{\circledR}$ ), fosfato de amônio (Reagen ${ }^{\circledR}$ ), formiato de amônio (Sigma-Aldrich ${ }^{\circledR}$ );

- Equipamentos e acessórios:

○ HPLC Shimadzu ${ }^{\circledR}$ (Kyoto, Japão) equipado com uma válvula comutadora de 6 vias automática;

○ Auto-amostrador Shimadzu ${ }^{\circledR}$ (Kyoto, Japão);

○ Válvula comutadora de 6 vias 11R-0016H (Valco ${ }^{\circledR}$, Houston, TX, USA);

○ Espectrômetro de massas LCMS-8030 Shimadzu ${ }^{\circledR}$ (Kyoto, Japão);

○ Analisador de massa triplo quadrupolo (Shimadzu ${ }^{\circledR,}$ Kyoto, Japão);

○ Coluna analítica: $\mathrm{ACE}^{\circledR} \mathrm{C} 18(100 \mathrm{~mm}$ x $2,1 \mathrm{~mm}$ x $3 \mu \mathrm{m}$, comprimento, diâmetro interno e tamanho de partícula);

○ Pré-coluna: $\mathrm{ACE}^{\circledR} \mathrm{C} 18(2,1 \mathrm{~mm}$ x $3 \mu \mathrm{m}$ diâmetro, tamanho de partícula); 
○ Coluna de extração: coluna contendo aproximadamente $70 \mathrm{mg}$ do novo RAM.

- Software:

○ LabSolutions ${ }^{\circledR:}$ para análise dos dados e programação do método no HPLC-MS/MS;

- Condições espectrometricas e cromatográficas:

- Temperatura da forno da coluna: $40^{\circ} \mathrm{C}$

○ Temperatura da linha de dessolvatação: $250^{\circ} \mathrm{C}$

○ Temperatura do bloco de aquecimento: $400^{\circ} \mathrm{C}$

○ Fluxo do gás de nebulização: $2,0 \mathrm{ml} \mathrm{\textrm {min } ^ { - 1 }}$

○ Fluxo de gás para secagem: $15,0 \mathrm{ml} \mathrm{\textrm {min } ^ { - 1 }}$

○ Energias de colisão, precursores e fragmentos dos analitos (Tabela 1)

○ Fase móvel de carregamento (liberada pela bomba A): Água ultra pura, em um fluxo de $0,4 \mathrm{~mL} \mathrm{m^{-1 }}$.

○ Fase móvel de eluição/separação/ionização (liberada pela bomba C): metanol : tampão formiato de amônio $0,01 \mathrm{~mol} \mathrm{~L}^{-1}, \mathrm{pH}=4,2$ (90:10, v:v) em um fluxo de $0,4 \mathrm{~mL} \mathrm{~min}^{-1}$;

○ Fase móvel de limpeza (liberada pela bomba B): acetonitrila: água ultra pura: isopropanol:, (75:15:10, v:v:v), em um fluxo de 1,0 $\mathrm{mL} \mathrm{min}^{-1}$;

- Sistema de análise: ULPC-MS/MS, no modo columns switching em configuração backflush, modo de ionização positiva por electrospray $(\mathrm{ESI}+)$ 
- Tempos:

- Fase de carregamento e condionamento do sistema (válvula na posição 1): 0 - 3,0 $\mathrm{min}$;

○ Fase de eluição (válvula na posição 2): 0,3 min;

○ Fase de limpeza, separação e análise por MS (válvula na posição 1): 6,7 min;

○ Recondiocionamento do sistema (válvula na posição 1): 5,0 min;

- Tempo total incluindo todos os processos: $15 \mathrm{~min}$.

$\bigcirc$

Tabela 1 - Analitos, precursores, fragmentos e energias de colisão otimizados

\begin{tabular}{|c|c|c|c|}
\hline Analitos & Precursor $(\mathbf{m} / \mathbf{z})$ & Fragmentos $(\mathbf{m} / \mathbf{z})$ & $\begin{array}{c}\text { Energia de colisão } \\
(\mathrm{K} . \mathrm{V})\end{array}$ \\
\hline \multirow[t]{3}{*}{ Vareniclina } & 212 & $169^{*}$ & -23 \\
\hline & & 183 & -24 \\
\hline & & 141 & -43 \\
\hline \multirow[t]{3}{*}{ Bupropiona } & 240 & $131^{*}$ & -28 \\
\hline & & 139 & -26 \\
\hline & & 103 & -39 \\
\hline \multirow[t]{3}{*}{ Hidroxibupropiona } & 256 & $139^{*}$ & -29 \\
\hline & & 131 & -29 \\
\hline & & 167 & -29 \\
\hline \multirow[t]{3}{*}{ Nicotina } & 163 & $117^{*}$ & -28 \\
\hline & & 130 & -22 \\
\hline & & 77 & -44 \\
\hline \multirow[t]{3}{*}{ Cotinina } & 177 & $80^{*}$ & -24 \\
\hline & & 98 & -21 \\
\hline & & 70 & -34 \\
\hline \multirow[t]{3}{*}{ Hidroxicotinina } & 193 & $80^{*}$ & -30 \\
\hline & & 134 & -19 \\
\hline & & 118 & -21 \\
\hline
\end{tabular}

*Fragmentos quantificados. 


\subsubsection{Visão geral do desenvolvimento da coluna e padronização da análise}

Todos os padrões para as análises dos analitos foram adquiridos e armazenados conforme recomendação do fabricante, até o momento da padronização das análises. As análises foram realizadas através da colaboração com o Prof. Dr. Eduardo Costa de Figueiredo, Dr. Henrique Dipe Faria e Prof. Dra. Isarita Martins do Laboratório de Análises de Toxicantes e Fármacos - LATF da Faculdade de Ciências Farmacêuticas da Universidade Federal de Alfenas (Unifal, MG). A escolha de cada analito foi determinada através de sua importância clínica e também devido à disponibilidade dos padrões dos analitos no mercado. Os analitos mensurados para as amostras provenientes dos pacientes tratados com os fármacos antitabagismo foram: bupropiona, hidroxibupropiona, vareniclina, nicotina, cotinina e hidroxicotinina (os três últimos são proveninentes do fumo). Foi realizado um levantamento das propriedades físicoquímicas dos metabólitos, conforme Quadro 5.

Para a remoção das macromoléculas (como proteínas) presentes na matriz de soro, foi desenvolvida uma coluna extratora de acesso restrito a partir de nanotubos híbridos de carbono e sílica, modificados com ligações hidrofílicas (novo RAM). O material foi desenvolvido e caracterizado antes mesmo da padronização das condições de análise nos equipamentos.

Foram obtidas as condições espectométricas (modo de ionização e as condições de sua fonte, temperatura do bloco de calor, fluxo de gás nebulizador e fluxo do gás secante) e cromatográficas (tempo de retenção e separação e áreas obtidas dos picos de cada analito). Após, as condições foram otimizadas em sistema de cromatografia líquida de alta eficiência multidimensional, seguida por espectrometria de massa (HPLCMS/MS). O sistema multimensional, constituído por válvulas comutadoras permite a análise online e automatizada com configuração via software. As válvulas permitem 
diferentes posições promovendo a ocorrência de eventos distintos no sistema, como a concentração dos analitos e remoção de macromoléculas através da coluna extratora (posição 1), a eluição dos analitos da coluna extratora para a coluna analítica (posição 2) e novamente na posição 1 , ocorre a eluição dos analitos da coluna analítica para o espectrômetro de massas, a limpeza da coluna extratora e o recondionamento do sistema.

\section{Quadro 5 - Propriedades físico-químicas dos analitos}

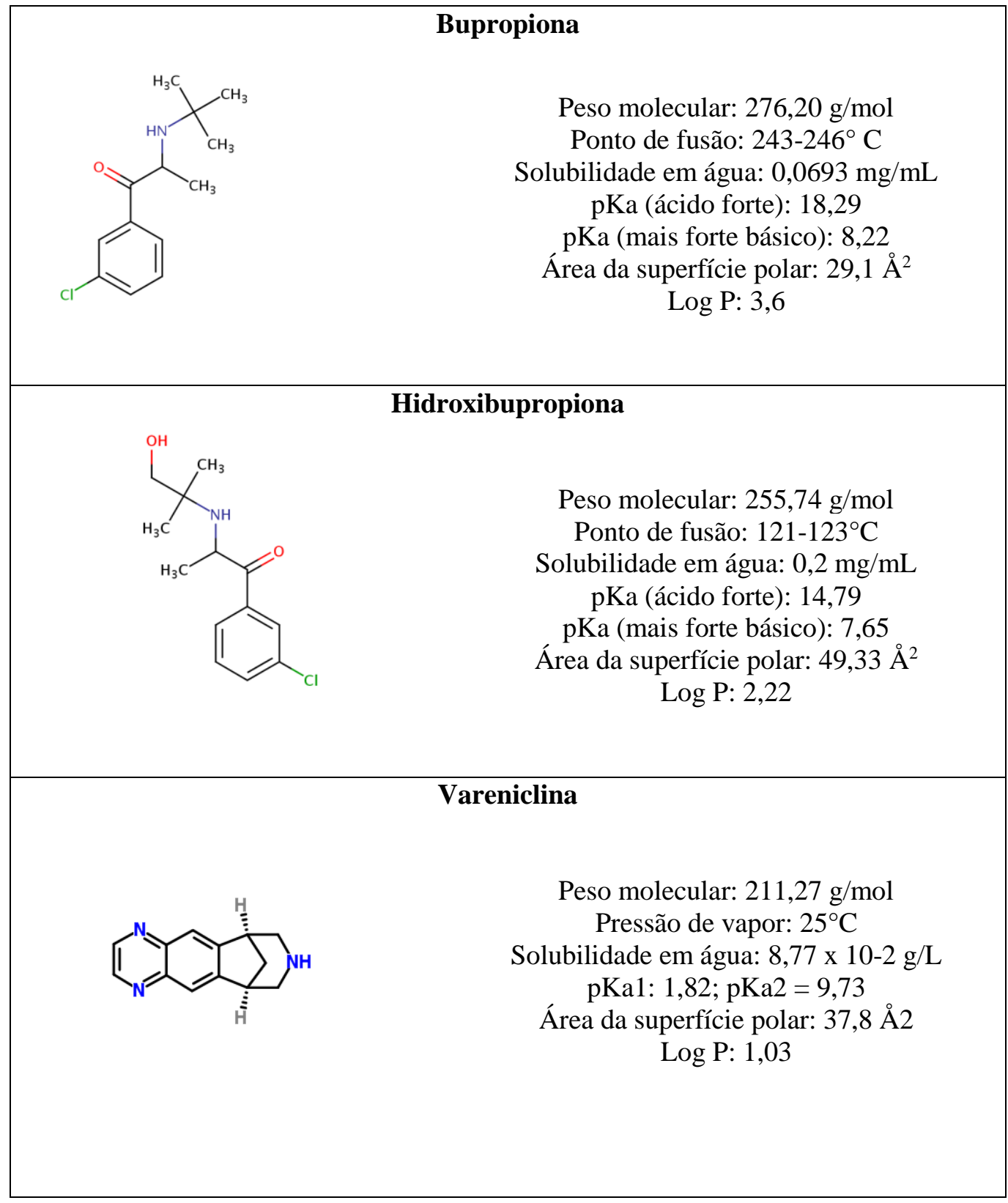




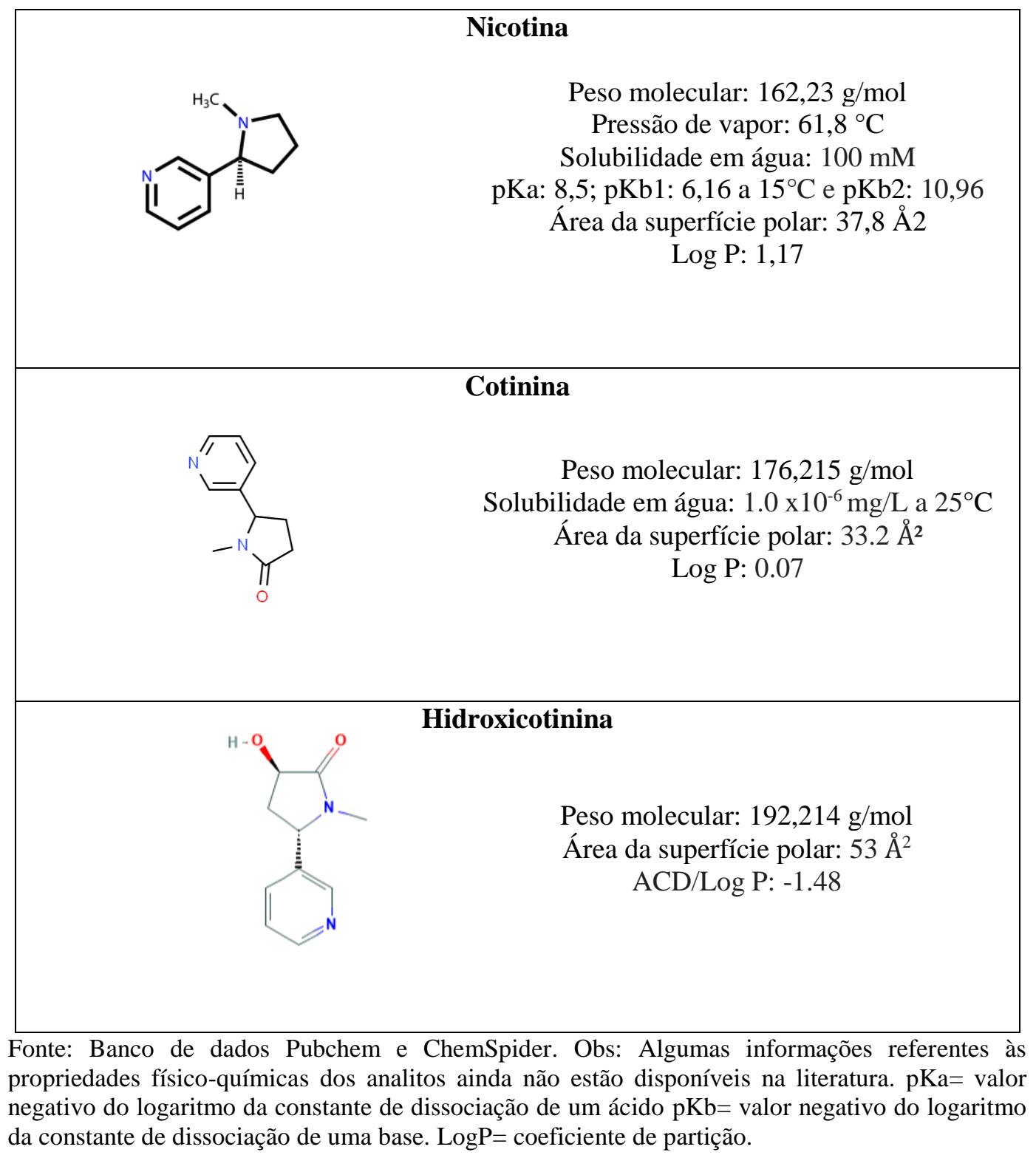

\subsubsection{Desenvolvimento da coluna RAM para a purificação da amostra}

As amostras de soro e plasma são matrizes ricas em moléculas que interferem na mensuração dos analitos, como lipídios e principalmente proteínas. Estas podem obstruir colunas analíticas e diminuir a concentração dos analitos, já que muitos destes estão ligados a essas proteínas. Devido a esse fato, geralmente é realizada uma preparação das amostras antes de sua mensuração. Essa preparação envolve processos como a extração com o uso de solventes, precipitação, entre outros, os quais geram custo de materiais, aumento do tempo de trabalho e de erros ${ }^{104,105}$ 51, 106 . Dessa forma, 
diversos estudos vêm tentando desenvolver métodos que não exijam tanta manipulação das amostras. Os materiais de acesso restrito (RAMs) estão sendo utilizados para a menor preparação da amostra e sua injeção direta. Dentre os RAMs estão os nanotubos de carbono (CNTs) modificados ${ }^{107-109}$. Nesta colaboração foi desenvolvida a coluna extratora composta por nanotubos híbridos de carbono e sílica modificados com a adição de grupos hidrofílicos. Esse material entrou com pedido de patente na Agência de Inovação e Empreendedorismo da Universidade Federal de Alfenas-MG, através do Processo: 23087.000128/2019-84 e, portanto, a sua composição e os resultados de alguns testes da sua caracterização serão mantidos em sigilo (vide declaração, Anexo $5)$.

Diferentes RAMs foram sintetizados a partir de CNTs para que fosse obtido o melhor desempenho na remoção de macromoléculas e retenção dos analitos da amostra. Os CNTs utilizados foram compostos por paredes múltiplas, pois apresentam uma elevada área superficial e consequentemente, uma maior capacidade de adsorção. Os CNTs foram adquiridos comercialmente e inicialmente foram funcionalizados, a partir de reação de oxidação ácida com ácido nítrico, como desenvolvido por Barbosa et al ${ }^{109}$.

Os CNTs oxidados foram utilizados em etapas de síntese posteriores, adicionando grupos químicos hidrofílicos que fossem capazes de realizar a exclusão de proteínas e permitir a adsorção dos analitos. As reações de síntese posteriores foram semelhantes as promovidas para a realização de revestimento externo de polímeros polímeros biomiméticos nanomagnéticos com e sem acesso restrito ${ }^{107,}{ }^{110-112}$, porém foram utilizadas estratégias e proporções de reagentes distintas, na tentativa de obter o RAM mais eficiente. Além disso, também foi priorizada a síntese mais simples e reprodutível, bem como o material que apresentar maior vida útil. Os diferentes materiais sintetizados foram testados em relação à exclusão de proteínas e adsorção dos 
analitos e também, foram realizados testes de caracterização para determinar suas propriedades físico-químicas e confirmar a estrutura originada.

A análise termogravimétrica foi realizada com a finalidade de determinar a variação de massa (ganho ou perda) do RAM em função de emprego de temperatura programada, proporcionando informações importantes a respeito da estabilidade do material e de sua composição. Outras técnicas também foram utilizadas com o objetivo de obter dados relacionados à estrutura e composição do novo RAM, como o infravermelho e análise elementar. Análises de microscopias eletrônicas de varredura e de transmissão também foram realizadas para a determinação da composição da superfície externa e arranjo estrutural do material com as modificações realizadas.

Após o término do preparo do novo RAM, eles foram colocados dentro de uma coluna (aproximadamente $70 \mathrm{mg}$ ), conforme (Figura 13). A coluna foi posteriormente, empregada no preparo de amostras online no sistema cromatográfico.

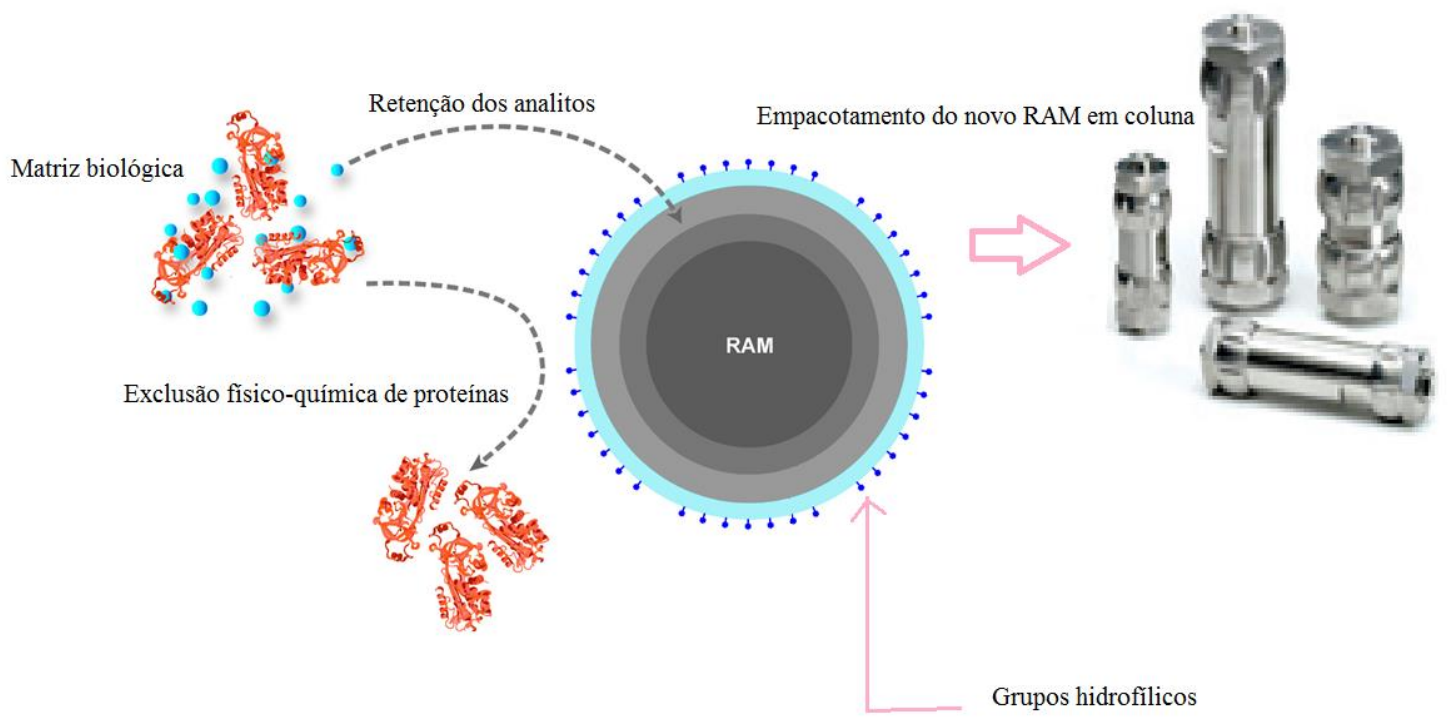

Figura 13 - Representação da composição da coluna extratora (Novo RAM). O novo RAM formado a partir de nanotubos hídridos de carbono e sílica dotado de múltiplas camadas e modificados com grupos hidrofílicos promovem a retenção de analitos e exclusão de macromoléculas como proteínas. O RAM foi posteriormente empacotado em coluna para a utilização em sistema cromatográfico. Fonte: adaptado do colaborador Dr. Henrique Dipe de Faria, Unifal-MG. 


\subsubsection{Caracterização do novo RAM}

\subsubsection{Capacidade de exclusão de proteínas com BSA}

$\mathrm{Na}$ ausência da coluna extratora, foi preparada primeiramente uma solução aquosa de albumina de soro bovino (BSA) em uma concentração de $44 \mathrm{mg} \cdot \mathrm{mL}^{-1}$ (semelhante à concentração de proteínas presentes no plasma humano). Foram injetados $10 \mu 1$ desta solução em triplicata diretamente em sistema cromatográfico com detector U.V. ajustado a $255 \mathrm{~nm}$, utilizando como fase móvel o tampão formiato de amônio 10 $\mathrm{mM}, \mathrm{pH}=4,2$ em um fluxo de $0,4 \mathrm{~mL} \mathrm{~min}^{-1}$. O sinal detectado foi de $100 \%$ BSA. Posteriormente, a coluna preenchida com $70 \mathrm{mg}$ do novo RAM foi inserida no sistema cromatográfico entre o injetor e o detector. A solução de BSA foi analisada em triplicata novamente, no entanto, com a presença da coluna extratora desenvolvida (novo RAM). A área do sinal obtido nesta segunda análise dividida pela área do sinal de $100 \%$ BSA, obtida na primeira análise, foi correspondente à porcentagem de BSA excluída pela coluna.

\subsubsection{Capacidade de exclusão de proteínas no soro}

Para analisar a exclusão total de macromoléculas (como lipídios, proteínas e sacarídeos) agora nas amostras de soro, foi utilizado procedimento semelhante. Na ausência da coluna extratora, injetou-se no sistema cromatográfico em triplicata $100 \mu \mathrm{L}$ de amostra de soro humano branco, foram testados pools de soro puros e diluídos 1:4. A água ultra pura foi utilizada como fase móvel em um fluxo de $0,4 \mathrm{~mL} \mathrm{~min}^{-1}$ e o sinal obtido foi relacionado a $100 \%$ dos interferentes. Após, a coluna extratora (o novo RAM) foi adionado ao sistema e a amostra foi inserida novamente. A divisão entre a área do pico na primeira análise pelo pico da segunda análise refere-se à porcentagem de exclusão de interferentes. As condições cromatográficas foram as mesmas do teste com BSA. 


\subsubsection{Capacidade de exclusão de proteínas com BSA em diferentes pHs}

O teste de exclusão de proteínas também foi realizado nas mesmas condições cromatográficas que a análise anterior utilizando solução de BSA em triplicata, no entanto, diferentes soluções como fase móvel (variação de $\mathrm{pH}$ de 2,2 a 7,0) foram testadas, pois o $\mathrm{pH}$ pode influenciar na ionização dos analitos, dos grupos funcionais presentes na superfície do novo RAM e na interação entre eles, o que pode resultar em diferentes taxas de exclusão de proteínas. Estas soluções foram os tampões: fosfato de sódio $10 \mathrm{mM}$ (pHs 2,2 e 2,6), formiato de amônio $10 \mathrm{mM}$ (pHs 3,0 a 4,6), acetato de amônio $5 \mathrm{mM}$ (pHs 5,2 a 6,6) e fosfato de sódio $5 \mathrm{mM}(\mathrm{pH} 7,0)$.

\subsubsection{Parâmetros espectrométricos}

Com a finalidade de se obter um método de análise capaz de detectar e quantificar menores níveis possíveis de concentração dos analitos, foram otimizados os parâmetros espectrométricos: fluxos dos gases secantes e nebulizador, modo de ionização, temperaturas da linha de dessolvatação e de bloco de aquecimento e as energias de colisões utilizadas para fragmentar os íons precursores para originar os fragmentos iônicos de cada analito. Foram realizadas soluções padrões de cada analito e dos padrões internos (PIs) deuterados (vareniclina d-4, hidroxibupropiona d6, nicotina d4, cotinina d3 e hidroxicotinina d3) na concentração de $1 \mathrm{mg} \mathrm{L}^{-1}$ em metanol. Cada uma destas soluções foram injetadas separadamente no sistema em um volume de $5 \mu \mathrm{L}$. A fase móvel utilizada foi constituída por metanol : tampão formiato de amônio 0,01

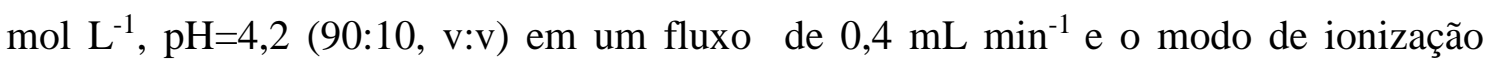
positiva (ESI+) foi utilizado, pois demonstrou ser mais eficiente para ionizar as moléculas analisadas. Essa otimização foi obtida utilizando o software Labsolutions ${ }^{\circledR}$. 


\subsubsection{Otimização do sistema cromatográfico multidimensional}

Para esta otimização foi utilizado um HPLC de dotado de válvula comutadora automática de 6 vias e um injetor automático de amostras, o que permitiu a automatização do processo. Ainda, o sistema cromatográfico foi acoplado a um espectrômetro de massas em tandem (HPLC-MS/MS), dotado de um analisador de massa triplo quadrupolo, o qual possui alta sensibilidade e seletividade. Incorporou-se neste sistema uma coluna extratora preenchida com o RAM desenvolvido.

O forno foi mantido a $40^{\circ} \mathrm{C}$ e o detector UV operando em um comprimento de onda de $255 \mathrm{~nm}$. A fim de padronizar a análise, foram testadas colunas análiticas de diversos tamanhos e composições e variadas proporções de fases de móveis.

Através da análise do cromatograma, foram avaliados o tempo de retenção e separação e as áreas obtidas dos picos de cada analito. O sistema foi utilizado no modo columns switching, na configuração backflush e as condições da análise foram otimizadas como: os tempos de exclusão de proteínas, de adsorção e eluição dos analitos, de separação cromatográfica, de limpeza da coluna extratora e de recondicionamento do sistema, bem como, a composição das fases móveis de carregamento, de eluição/separação e de limpeza.

Para a otimização dos parâmetros de análise, foi utilizado um pool de amostras de soro humano branco em sexplicata. Este soro foi dopado com os analitos vareniclina, bupropiona, hidroxibupropiona, nicotina, cotinina e hidroxicotinina em 3 concentrações: 0,1, 100, e $1000 \mu \mathrm{g} \mathrm{L}^{-1}$ e, com os PIs deuterados na concentração de $500 \mu \mathrm{g} \mathrm{L}^{-1}$. Como o soro é uma matriz com alta concentração de interferentes, foram testados pools de soro branco dopados e injetados sem diluição diretamente no sistema e diluídos em água ultra pura (1:1) e os perfis analíticos foram então avaliados. 


\subsection{7 validação analítica}

Testes para a validação da análise otimizada foram realizadas conforme diretrizes do U.S. Department of Health and Human Services e do Food and Drug Administration (FDA), $2013^{113}$. Os parâmetros avaliados foram a seletividade, limite de detecção (LD), limite de quantificação (LQ), linearidade, estabilidade dos analitos, efeito residual e de matriz e recuperação da extração.

Os ensaios foram realizados em seis repetições $(n=6)$, exceto o ensaio de recuperação $(n=3)$ e foi utilizado um pool de amostras de soro branco dopadas com cada um dos analitos nas concentrações de 5, 10, 20, 50, 75, $100 \mu \mathrm{g} \mathrm{L}^{-1}$ para vareniclina; 1, 5, 50, 250, 500, $1000 \mu \mathrm{g} \mathrm{L^{-1 }}$ para bupropiona; 1, 10, 100, 500, 1000, 2000 para hidroxibupropiona, 5, 10, 50, 250, 500, $1000 \mu \mathrm{g} \mathrm{L}^{-1}$ para nicotina, cotinina e hidroxicotinina. Os PIs deuterados foram utilizados na concentração de $200 \mu \mathrm{g} \mathrm{L}{ }^{-1}$.

\subsection{Análise estatística}

Em relação às características demográficas, as variáveis contínuas foram apresentadas como média e desvio padrão e as categóricas como frequências. Os testes Shapiro-Wilk e Kolmogorov-Smirnov foram realizados para verificar a normalidade da distribuição das variáveis quantitativas e assim escolher testes paramétricos ou não paramétricos. Foram realizados os testes Qui-quadrado, Exato de Fisher, t de Student ou Mann-Whitney para as análises comparativas de características gerais entre os grupos de desfecho dos pacientes, tanto no ensaio de expressão, como de mensuração dos analitos. Para as análises de expressão gênica o método $2^{-\Delta \Delta \mathrm{CT}}$ foi utilizado ${ }^{103}$. Como os dados de expressão não apresentaram distribuição normal, foi realizado o teste não paramétrico de Mann-Whitney para testar a hipótese de diferença (valores de $2^{-\Delta \mathrm{CT}}$ ) intra e entre os grupos de desfechos (sucesso e resistente e tempos de tratamento 
farmacológico T0, T2 e T4). Os valores de $\Delta \Delta \mathrm{CT}$ (mediana de $\Delta \mathrm{CT}_{\text {grupo teste }}-$ mediana de $\left.\Delta \mathrm{CT}_{\text {grupo referência }}\right)$ foram obtidos para o cálculo do fold change. O fold-change $\left(2^{-\Delta \Delta \mathrm{CT}}\right)$ foi calculado para verificar o aumento ou diminuição de expressão gênica entre os grupos analisados. O gráfico heat map foi construído através do software Gene-globe (Qiagen, USA) para verificar as diferenças no perfil de expressão dos genes estudados de acordo com os tempos (T0, T2 e T4) e de acordo com a efetividade de tratamento com vareniclina (sucesso e resistente). O teste de Manny-Whitney foi utilizado para analisar os níveis de concentrações de vareniclina, de bupropiona, de nicotina e de seus metabólitos de acordo com os desfechos de tratamento (sucesso e resistente), pois não apresentaram distribuição normal. A taxa de metabolização de nicotina (NRM) foi calculada pela seguinte fórmula: $\mathrm{NMR}=$ trans-3-hidroxicotinina/cotinina. A hidroxicotinina mensurada no soro foi considerada como sendo trans-3- hidroxicotinina para o cálculo do NMR, já que a quantidade de outros isômeros da hidroxicotinina são irrelevantes 31,32 . Os pacientes foram classificados em metabolizadores lentos se $\mathrm{NMR}<0,31$ e normais ou rápidos se $\mathrm{NMR}>0,31$. Todas as análises estatísticas foram realizadas utilizando o software SPSS (versão 20, IBM, New York, NY), considerando o nível de significância de $\mathrm{P}<0,05$. 


\section{RESULTADOS}

Este projeto incluiu 105 pacientes, sendo 74 tratados com vareniclina e 31 com bupropiona. Dos 74 pacientes tratados com vareniclina, amostras de 27 pacientes foram analisadas quanto à expressão gênica (14 pacientes do grupo de desfecho sucesso e 13 do grupo resistente). Sendo provenientes destes pacientes 52 amostras ao todo (de diversos tempos): 9 resistentes do tempo T0, 7 resistentes do T2, 8 resistente do T4, 9 sucessos do T0, 8 sucessos do T2 e 11 sucessos do T4 (vide tópico 4.2 Número amostral).

Quanto a mensuração dos analitos, foi desenvolvida uma coluna extratora para a purificação da amostra à base de nanotubos hídridos de carbono e sílica modificados com a adição de grupos hidrofílicos (novo RAM), o método HPLC-MS/MS multidimensional, no modo column switching e na configuração backflush, foi otimizado e validado. Setenta e quatro pacientes tratados com vareniclina e 31 tratados com bupropiona foram submetidos à análise. Apenas 4 amostras das 105 apresentaram valores abaixo do LQ (3 de pacientes tratados com vareniclina e 1 de paciente tratado com bupropiona) e estas foram excluídas das análises dos analitos (vide tópico 4.2 Número amostral).

\subsection{Análise de expressão gênica}

\subsubsection{Dados clínicos e demográficos}

As Tabelas 2 e 3 mostram as características clínicas e demográficas dos pacientes selecionados para o ensaio de expressão gênica do grupo total e por grupo de desfecho, respectivamente. A variável idade apresentou diferença significativa entre os grupos resistente e sucesso. 
Tabela 2 - Características clínicas e demográficas dos pacientes tratados com vareniclina selecionados para os ensaios de expressão gênica $(n=27)$

\begin{tabular}{|c|c|}
\hline Idade (anos) & $50 \pm 13$ \\
\hline Gênero, mulheres (\%) & 46,4 \\
\hline Etnia autodeclarada, brancos $(\%)$ & 74,0 \\
\hline Índice de massa corporal $\left(\mathrm{Kg} / \mathrm{m}^{2}\right)$ & $27,1 \pm 5,0$ \\
\hline Cigarros/dia & $17 \pm 7$ \\
\hline FTND & $6,2 \pm 2,0$ \\
\hline FTND, $\geq 6(\%)$ & 60,7 \\
\hline Escore Issa, $\geq 3(\%)$ & 85,7 \\
\hline Hipertensão (\%) & 17,9 \\
\hline Dislipidemia (\%) & 25,0 \\
\hline Diabetes melito tipo $2(\%)$ & 10,7 \\
\hline Depressão (\%) & 7,1 \\
\hline Ansiedade (\%) & 28,6 \\
\hline $\begin{array}{l}\text { FTND }=\text { teste de Fagerström para } \\
\text { Fagerström test for nicotine depen } \\
\text { pontos). Escore Issa = escore de const } \\
\text { de } 0 \text { a } 4 \text { pontos). }\end{array}$ & $\begin{array}{l}\text { ncia à nicotina } \\
\text { escala de } 0 \text { a } 10 \\
\text { acional Issa (escala }\end{array}$ \\
\hline
\end{tabular}

Tabela 3 - Características clínicas e demográficas dos pacientes tratados com vareniclina submetidos aos ensaios de expressão gênica de acordo com o desfecho de tratamento

\begin{tabular}{|c|c|c|c|}
\hline & Resistente $(n=13)$ & Sucesso $(n=14)$ & Valor de $\mathbf{P}$ \\
\hline Idade (anos) & $55 \pm 11$ & $45 \pm 12$ & $\mathbf{0 , 0 4 5}$ \\
\hline Gênero, mulheres (\%) & 53,8 & 35,7 & 0,45 \\
\hline Etnia autodeclarada, brancos (\%) & 76,9 & 78,6 & 1,00 \\
\hline Índice de massa corporal $\left(\mathrm{Kg} / \mathrm{m}^{2}\right)$ & $27,1 \pm 4,6$ & $27,3 \pm 5,4$ & 0,92 \\
\hline Cigarros/dia & $20 \pm 6$ & $15 \pm 6$ & 0,06 \\
\hline FTND & $6,3 \pm 2,2$ & $5,9 \pm 1,9$ & 0,58 \\
\hline FTND, $\geq 6(\%)$ & 53,8 & 64,3 & 0,70 \\
\hline Escore Issa, $\geq 3(\%)$ & 84,6 & 85,7 & 1,00 \\
\hline Hipertensão (\%) & 23,1 & 7,1 & 0,33 \\
\hline Dislipidemia (\%) & 23,1 & 28,6 & 1,00 \\
\hline Diabetes melito tipo $2(\%)$ & 23,1 & 0,0 & 0,10 \\
\hline Depressão (\%) & 7,7 & 7,1 & 1,00 \\
\hline
\end{tabular}


FTND $=$ teste de Fagerström para dependência à nicotina - Fagerström test for nicotine dependence (escala de 0 a 10 pontos). Escore Issa $=$ escore de consumo situacional Issa (escala de 0 a 4 pontos).

\subsubsection{Dados de expressão gênica}

Dos 17 genes escolhidos para testar com a resposta ao tratamento, apenas 4 apresentaram valores de amplificação aceitáveis para uma interpretação de qualidade, mais especificamente valores de $\mathrm{CT}<33$. Os valores das expressões dos genes $(\mathrm{CTs})$ foram normalizados através das médias de CT dos housekeeping genes para cada amostra, obtendo-se os valores de $\Delta \mathrm{CT}=\left(\mathrm{CT}_{\text {gene alvo }}-\right.$ média $\mathrm{CT}$ housekeepings genes $) . \mathrm{A}$ Tabela 4 mostra os valores de mediana de $\Delta \mathrm{CT}$ dos genes analisáveis de acordo com os tempos de tratamento e grupos de desfecho.

Tabela 4 - Valores de mediana de $\Delta C T$ dos genes de acordo com os tempos de tratamento e grupos de desfecho

\begin{tabular}{|c|c|c|c|c|c|c|}
\hline & \multicolumn{2}{|c|}{ Resistente T0 } & \multicolumn{2}{|c|}{ Resistente T2 } & \multicolumn{2}{|c|}{ Resistente T4 } \\
\hline & $\Delta \mathbf{C T}$ & IC 95\% & $\Delta \mathbf{C T}$ & IC 95\% & $\Delta \mathbf{C T}$ & IC 95\% \\
\hline CHRNA5 & 8,18 & $(7,32-8,70)$ & 8,45 & $(7,48-8,87)$ & 7,67 & $(7,27-9,05)$ \\
\hline CHRNA7 & 6,62 & $(6,17-6,97)$ & 8,02 & $(7,07-8,48)$ & 7,19 & $(6,96-7,86)$ \\
\hline CHRNG & 6,20 & $(5,79-6,95)$ & 6,47 & $(6,01-6,68)$ & 6,63 & $(6,02-7,02)$ \\
\hline \multirow[t]{3}{*}{ COMT } & 4,67 & $(4,40-5,01)$ & 4,80 & $(4,43-5,03)$ & 4,87 & $(4,52-5,24)$ \\
\hline & \multicolumn{2}{|c|}{ Sucesso T0 } & \multicolumn{2}{|c|}{ Sucesso T2 } & \multicolumn{2}{|c|}{ Sucesso T4 } \\
\hline & $\Delta \mathbf{C T}$ & IC $95 \%$ & $\Delta \mathbf{C T}$ & IC $95 \%$ & $\Delta \mathbf{C T}$ & IC $95 \%$ \\
\hline CHRNA5 & 8,32 & $(7,38-9,17)$ & 7,07 & $(6,53-8,96)$ & 8,37 & $(7,54-8,82)$ \\
\hline CHRNA7 & 7,26 & $(6,11-8,42)$ & 7,04 & $(6,40-7,79)$ & 7,38 & $(6,76-8,20)$ \\
\hline CHRNG & 6,82 & $(6,19-7,74)$ & 6,83 & $(6,56-7,33)$ & 6,59 & $(6,25-7,03)$ \\
\hline COMT & 4,88 & $(4,30-5,11)$ & 4,58 & $(4,33-5,15)$ & 4,81 & $(4,48-5,16)$ \\
\hline
\end{tabular}

$\Delta \mathrm{CT}=\left(\mathrm{CT}_{\text {gene alvo }}-\right.$ média $\left.\mathrm{CT}_{\text {housekeepings genes }}\right) . \mathrm{T} 0=\mathrm{Tempo}$ inicial, antes do tratamento farmacológico, T2= Duas semanas após o ínicio do tratamento farmacológico, T4= Quatro semanas após o início do tratamento farmacológico. IC 95\% = Intervalo de confiança de 95\%. 


\subsubsection{Análise de associação da expressão gênica entre os desfechos e os tempos de}

\section{tratamento}

A Tabela 5 mostra o fold change e análise de associação entre os grupos de tempos de tratamento e grupos de desfecho. Foi observada diferença significativa para a expressão do gene CHRNA7: no grupo resistente, amostras dos tempos T2 e T4 apresentaram menor expressão comparadas com amostras do T0 (fold change: 0,38, $\mathrm{P}=0,007$; fold change: $0,67, \mathrm{P}=0,004$; respectivamente). Para a expressão do gene CHRNG, amostras do grupo sucesso mostraram menor expressão comparadas com amostras do grupo resistente no tempo $\mathrm{T} 2$ (fold change $=0,77, \mathrm{P}=0,006$ ).

Tabela 5 - Fold change e análise de associação entre os tempos de tratamento e grupos de desfecho

\begin{tabular}{|c|c|c|c|c|c|c|}
\hline \multirow[b]{2}{*}{ Genes } & \multicolumn{2}{|c|}{ Resistente T2 vs. T0 } & \multicolumn{2}{|c|}{ Resistente T4 vs. T0 } & \multicolumn{2}{|c|}{ Resistente T4 vs. T2 } \\
\hline & $2^{-\Delta \Delta \mathrm{CT}}(\mathrm{IC} 95 \%)$ & $\mathbf{P}$ & $2^{-\Delta \Delta \mathrm{CT}}($ IC $95 \%)$ & $\mathbf{P}$ & $2^{-\triangle \Delta C T}($ IC $95 \%)$ & $\mathbf{P}$ \\
\hline CHRNA5 & $0,83(0,34-2,33)$ & 0,57 & $1,42(0,30-2,69)$ & 0,95 & $1,72(0,34-3,03)$ & 0,89 \\
\hline CHRNA7 & $0,38(0,20-0,93)$ & $\mathbf{0 , 0 0 7}$ & $0,67(0,31-1,01)$ & 0,004 & $1,78(0,58-2,87)$ & 0,37 \\
\hline CHRNG & $0,83(0,54-1,92)$ & 0,37 & $0,74(0,43-1,90)$ & 0,44 & $0,90(0,50-1,58)$ & 0,36 \\
\hline \multirow[t]{2}{*}{ COMT } & $0,91(0,65-1,49)$ & 0,92 & $0,87(0,56-1,40)$ & 0,63 & $0,95(0,57-1,42)$ & 0,73 \\
\hline & \multicolumn{2}{|c|}{ Sucesso T2 vs. T0 } & \multicolumn{2}{|c|}{ Sucesso T4 vs. T0 } & \multicolumn{2}{|c|}{ Sucesso T4 vs. T2 } \\
\hline Genes & $2^{-\Delta \Delta \mathrm{CT}}(\mathrm{IC} 95 \%)$ & $\mathbf{P}$ & $2^{-\Delta \Delta \mathrm{CT}}($ IC $95 \%)$ & $\mathbf{P}$ & $2^{-\Delta \Delta C T}($ IC $95 \%)$ & $\mathbf{P}$ \\
\hline CHRNA5 & $2,38(0,33-6,23)$ & 0,37 & $0,97(0,37-3,10)$ & 0,61 & $0,41(0,20-2,68)$ & 0,69 \\
\hline CHRNA7 & $1,16(0,31-4,06)$ & 0,64 & $0,92(0,23-3,16)$ & 0,91 & $0,79(0,29-2,04)$ & 0,55 \\
\hline CHRNG & $0,99(0,45-2,27)$ & 0,49 & $1,17(0,56-2,81)$ & 0,62 & $1,18(0,72-2,11)$ & 0,33 \\
\hline \multirow[t]{2}{*}{ COMT } & $1,23(0,55-1,72)$ & 0,92 & $1,05(0,55-1,55)$ & 0,68 & $0,85(0,56-1,59)$ & 0,41 \\
\hline & \multicolumn{2}{|c|}{ Sucesso vs. resistente T0 } & \multicolumn{2}{|c|}{ Sucesso vs. resistente $\mathrm{T} 2$} & \multicolumn{2}{|c|}{ Sucesso vs. resistente T4 } \\
\hline Genes & $2^{-\Delta \Delta \mathrm{CT}}(\mathrm{IC} 95 \%)$ & $\mathbf{P}$ & $2^{-\Delta \Delta \mathrm{CT}}($ IC $95 \%)$ & $\mathbf{P}$ & $2^{-\Delta \Delta C T}($ IC $95 \%)$ & $\mathbf{P}$ \\
\hline CHRNA5 & $0,91(0,28-2,50)$ & 0,75 & $2,60(0,36-5,06)$ & 0,47 & $0,62(0,34-2,85)$ & 0,85 \\
\hline CHRNA7 & $0,64(0,21-1,82)$ & 0,13 & $1,97(0,61-4,23)$ & 0,09 & $0,88(0,42-2,14)$ & 0,74 \\
\hline CHRNG & $0,65(0,26-1,69)$ & 0,12 & $0,77(0,40-1,09)$ & 0,006 & $1,03(0,50-1,71)$ & 0,79 \\
\hline
\end{tabular}


T0= Tempo inicial, antes do tratamento farmacológico, T2= Duas semanas após o ínicio do tratamento farmacológico, T4= Quatro semanas após o início do tratamento farmacológico. $2^{-\Delta \Delta \mathrm{CT}}=$ Fold change (diferença de expressão). $\mathrm{P}$ valor (análise de associação entre as medianas de $2^{-\Delta \mathrm{CT}}$ dos grupos). IC $95 \%=$ Intervalo de confiança de $95 \%$.

As Figura 14 e 15 mostram gráficos de barras das diferenças de expressão dos genes CHRNA7 e CHRNG entre os tempos de tratamento e desfecho, respectivamente. O heat map (Figura 16) mostra que não houve diferenciação nos perfis de expressão gênica em uma análise conjunta dos genes de acordo com os desfechos e tempos de tratamento.

Devido à diferença significativa nas médias de idade entre os grupos sucesso e resistente, foi realizada regressão linear multipla na análise de expressão dos quatro genes analisáveis. A regressão foi ajustada por idade e, também, gênero e cigarros por dia. No entanto, os resultados de expressão dos genes não foram impactados por estas covariáveis. 


\section{CHRNA7}

\section{A Análise intragrupo resistente}

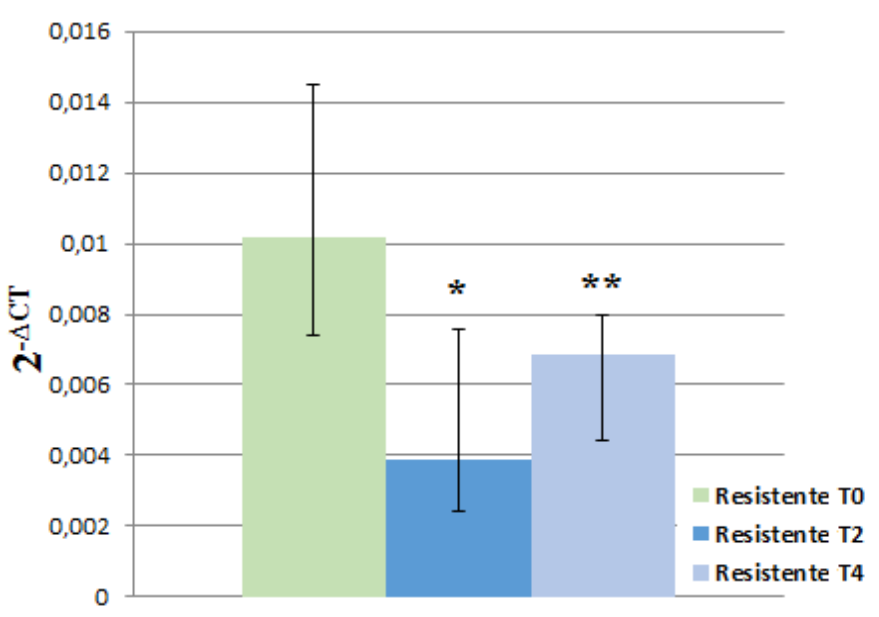

B Análise intragrupo sucesso

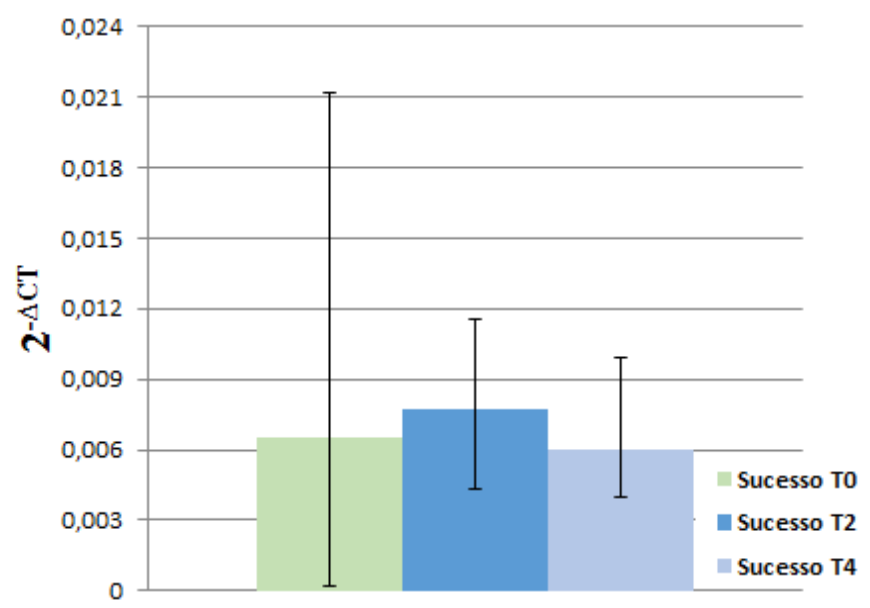

C Análise dos grupos sucesso vs. resistente

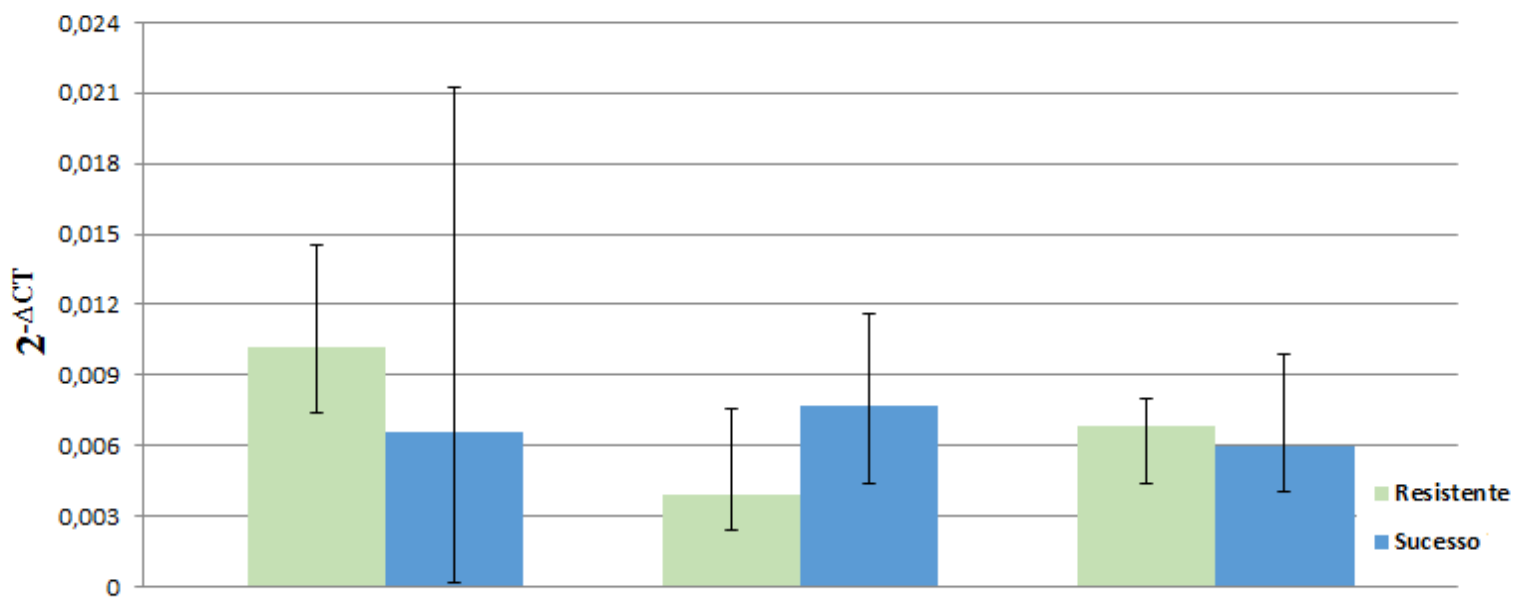

Figura 14 - Diferença de expressão do gene CHRNA7 entre os tempos de tratamento e desfecho. A: Análise intragrupo do desfecho resistente. B: Análise intragrupo do desfecho sucesso. $\mathrm{T} 0=$ tempo inicial, antes do tratamento farmacológico, $\mathrm{T} 2=\mathrm{duas}$ semanas após o início do tratamento farmacológico, T4= quatro semanas após o início do tratamento farmacológico. *: P= 0,007 (resistente T2 vs. T0, fold change de 0,38). **: $\mathrm{P}=0,004$ (resistente T4 vs. T0, fold change de 0,67). Valor de $\mathrm{P}$ (análíse de associação entre as medianas de $2^{-\Delta \mathrm{CT}}$ dos grupos em uma comparação dois a dois). Fonte: do autor. 


\section{CHRNG}

\section{A Análise intragrupo resistente}

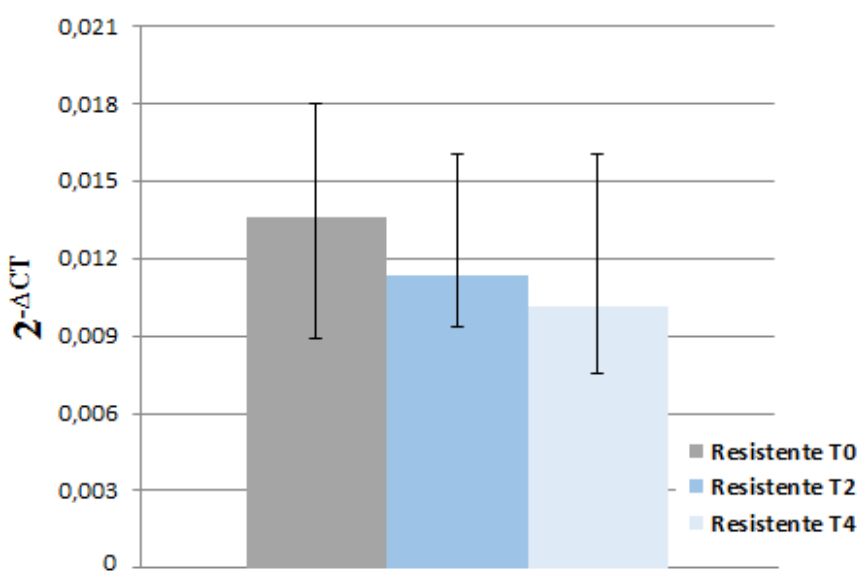

B Análise intragrupo sucesso

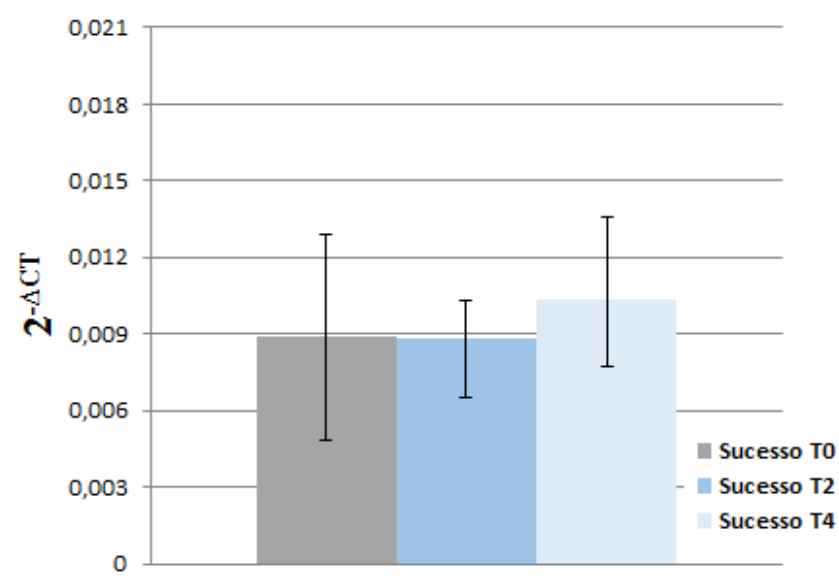

C Análise dos grupos sucesso vs. resistente

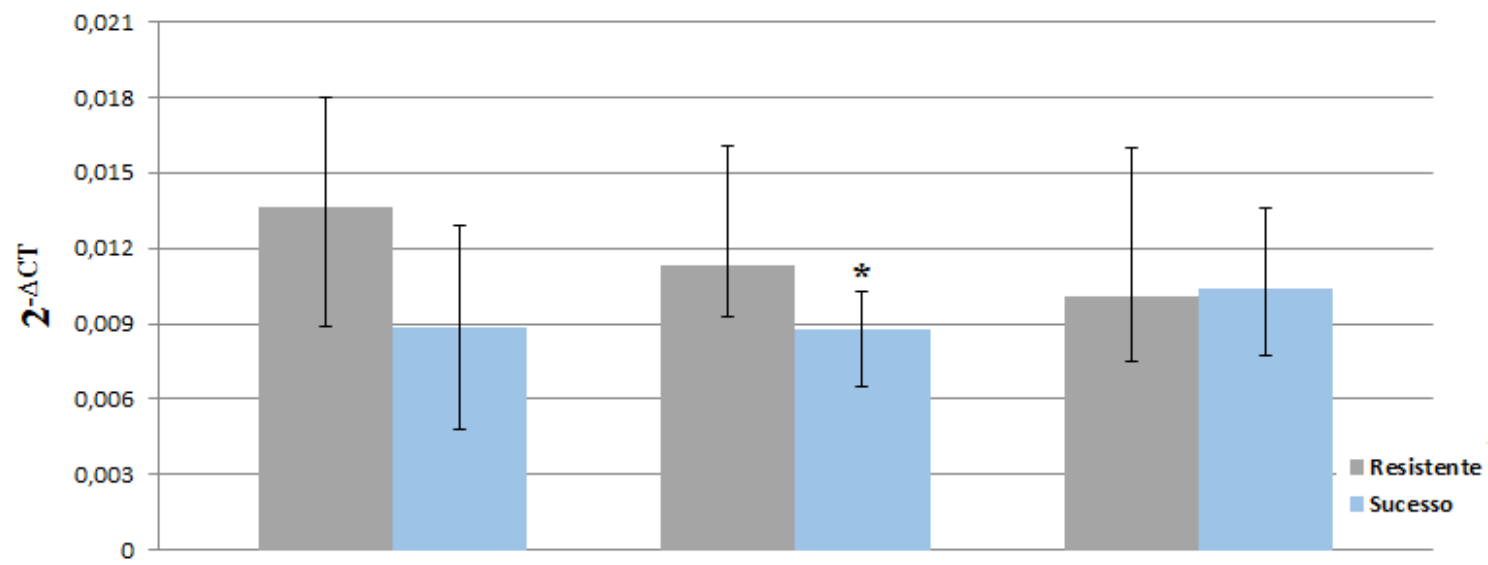

Figura 15 - Diferença de expressão do gene $C H R N G$ entre os tempos de tratamento e desfecho. A: Análise intragrupo do desfecho resistente. B: Análise intragrupo do desfecho sucesso. T0= tempo inicial, antes do tratamento farmacológico, T2= duas semanas após o início do tratamento farmacológico, T4= quatro semanas após o início do tratamento farmacológico. *: P= 0,006 (sucesso vs. resistente T2, fold change de 0,77). Valor de $\mathrm{P}$ (análíse de associação entre as medianas de $2^{-\Delta \mathrm{CT}}$ dos grupos em uma comparação dois a dois). Fonte: do autor. 


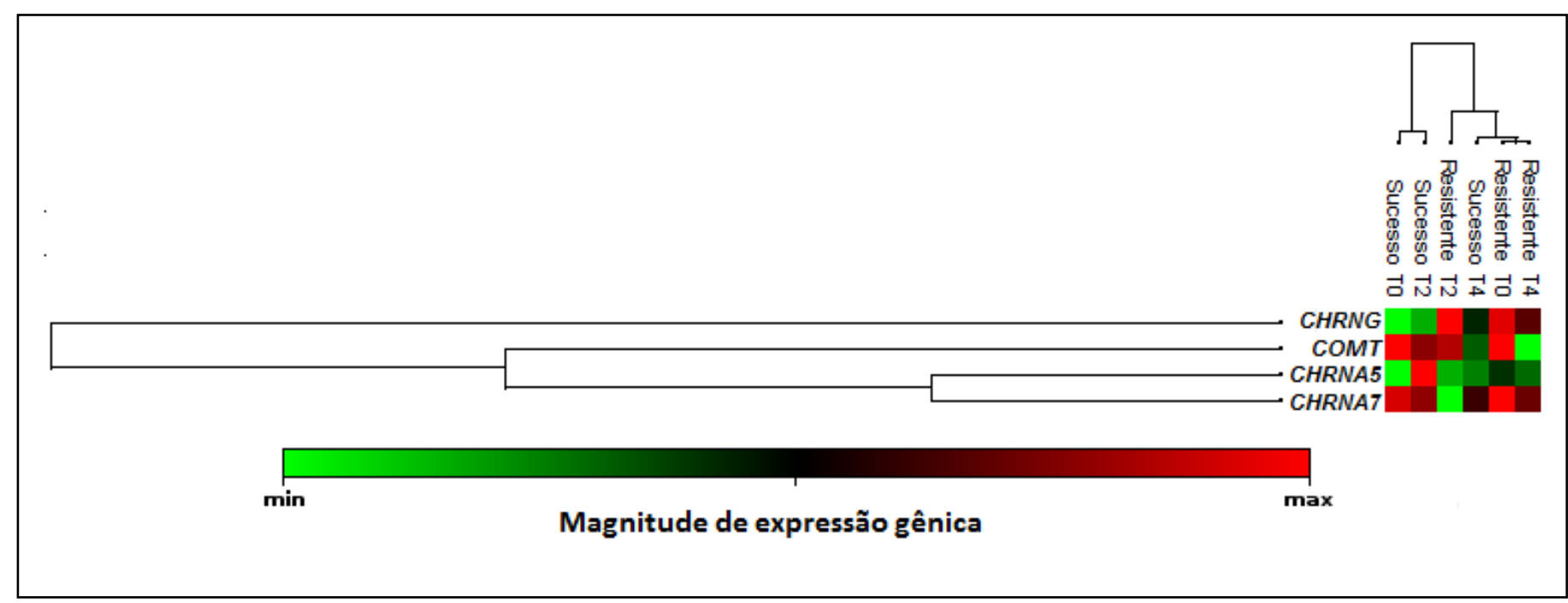

Figura 16 - Heat map de expressão gênica. A figura mostra a magnitude de expressão gênica entre os grupos. A cor mais clara (verde) nos indica menor expressão e a cor mais escura (vermelho) indica maior expressão.T0= tempo inicial, antes do tratamento farmacológico, T2= duas semanas após o início do tratamento farmacológico, T4= quatro semanas após o início do tratamento farmacológico. Fonte: do autor, gerada pelo software Gene Globe, QIAGEN@.

\subsection{Mensuração dos analitos}

\subsubsection{Caracterização da coluna: teste exclusão de proteínas e interferentes da} matriz

Em relação ao teste de capacidade de exclusão de proteínas, o pico de BSA sem e com a nova coluna extratora apresentou tempo de retenção semelhante, no entando, a área da curva do BSA na presença do novo RAM foi bem menor do que na sua ausência, conforme a Figura 17. A redução de proteínas (da solução de BSA) pela coluna foi de aproximadamente $98 \%$ e nas amostras de pools soro diluídas (1:4), a remoção foi de 99\% (Figura 18).

A Figura 19 mostra a influência do pH (escala de de 2,2 a 7,0) na exclusão de proteínas, fato que está diretamente relacionado com a estrutura físico-química do RAM. Diferentes pHs influenciaram na taxa de exclusão de proteínas, esse comportamento pode ser explicado devido à interações eletrostáticas do novo RAM com as proteínas. Valores de $\mathrm{pH}$ menores que o do ponto isoelétrico das proteínas 
podem promover a prevalência de proteínas carregadas positivamente, enquanto que valores de $\mathrm{pH}$ superiores, podem promover proteínas carregadas negativamente ${ }^{114}$. Dessa forma, acredita-se que o comportamento de exclusão de proteínas do novo material é semelhante ao descrito em outros estudos $108,109,115,116$.

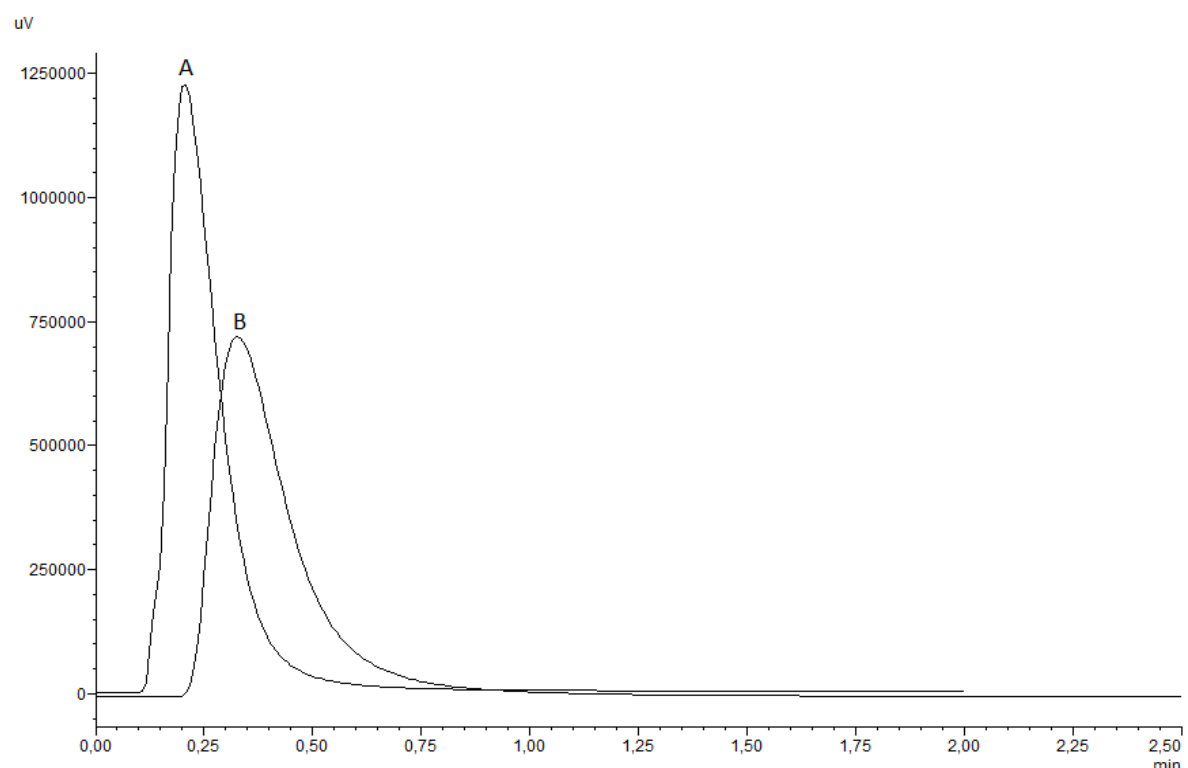

Figura 17 - Cromatograma de teste de remoção de proteínas com solução de BSA. Gráficos obtidos após injeção de $10 \mu \mathrm{L}$ de uma solução aquosa de BSA (44 mg mL ${ }^{-1}$ ), no sistema sem coluna (A) e com coluna extratora (B). A - área do pico: 10.142.590; B - área do pico: 9.713.614. Fonte: do autor e do colaborador Dr. Henrique Dipe de Faria, LATF, Unifal-MG.

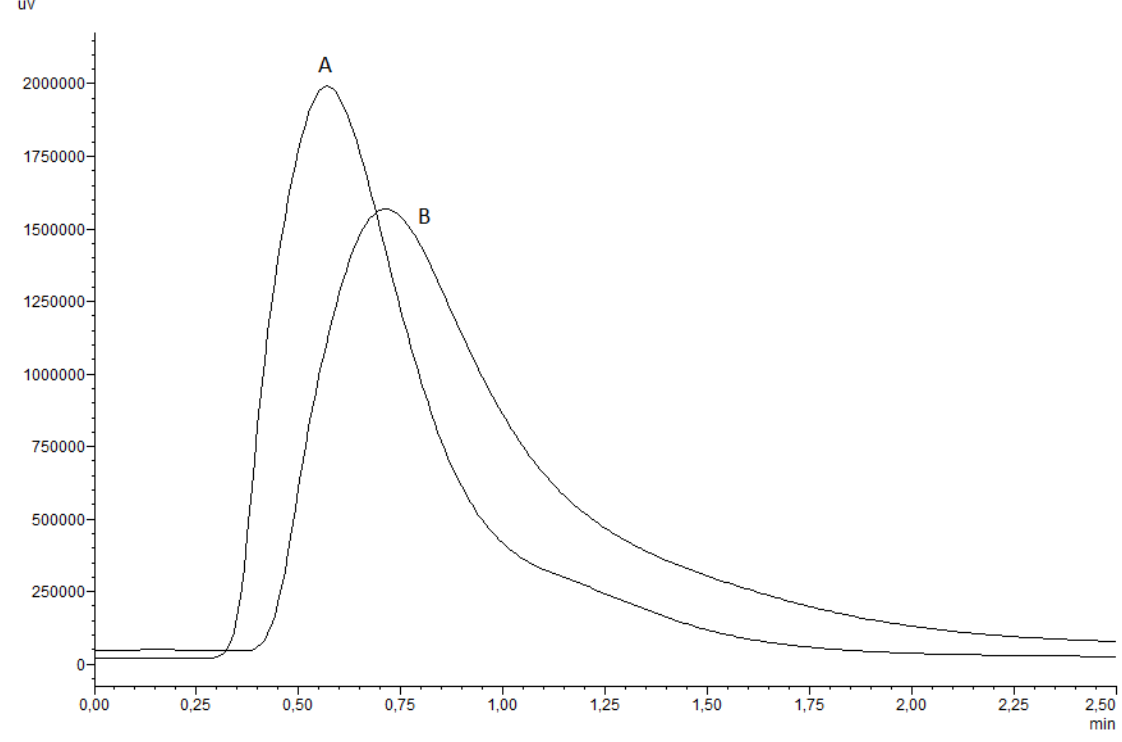

Figura 18 - Cromatograma de teste de remoção de proteínas com amostra de soro diluída. Gráficos obtidos após injeção de $100 \mu \mathrm{L}$ de soro diluído em água ultra pura (1:4, v:v), no sistema sem coluna (A) e com coluna extratora (B). A área do pico: 53.981.550 B - área do pico: 53.552.824. Fonte: do autor e do colaborador Dr.Henrique Dipe de Faria, LATF Unifal-MG. 


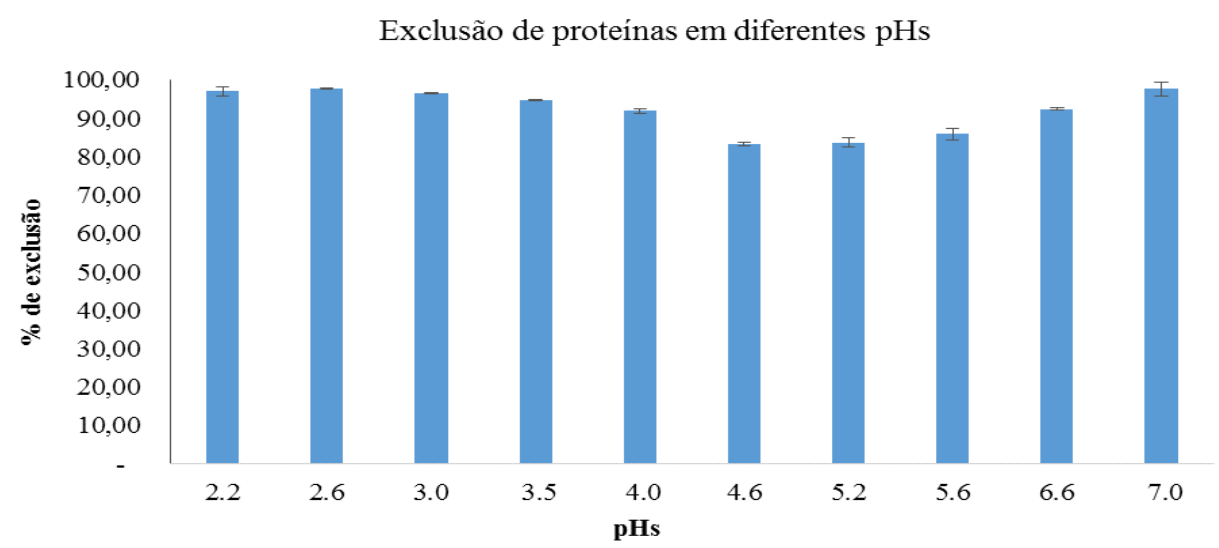

Figura 19 - Influência do pH na exclusão de proteínas. Fonte: do autor e do colaborador Dr. Henrique Dipe de Faria, LATF, Unifal-MG.

\subsubsection{Otimização dos parâmetros espectrométricos}

No processo de otimização das condições espectrométricas foi adotado o modo de ionização positivo (ESI+), isto é, a ionização promove a protonação (adição de $\mathrm{H}^{+}$) dos analitos e de seus fragmentos. As energias de colisão ideais e as múltiplas transições de monitoramento de reação (MRM) foram otimizadas para cada analito separadamente, vide valores de energia de colisão e fragmentos obtidos já mostrados na Tabela 1 (no tópico 4.6.1). A presença de 3 fragmentos de cada analito foi necessária para a identicação qualitativa e a quantificação foi dependente da concentração do fragmento mais abundante.

As seguintes temperaturas foram utilizadas: $40^{\circ} \mathrm{C}$ para o forno da coluna, $250^{\circ} \mathrm{C}$ para a linha de dessolvatação e $400^{\circ} \mathrm{C}$ para o bloco de aquecimento. Foram utilizadas as taxas de 2,0 ml min ${ }^{-1}$ de fluxo de gás de nebulização e 15,0 $\mathrm{ml} \mathrm{min}^{-1}$ de fluxo de gás para a secagem. 


\subsubsection{Otimização do sistema cromatrográfico multidimensional}

Quanto a composição e proporção da fase móvel responsável pela eluição, separação e ionização dos analitos (fase móvel de eluição), testes foram realizados com os solventes orgânicos acetonitrila ou metanol combinados com o tampão formiato de amônio $10 \mathrm{mM}$ em diferentes pHs, com proporções que variaram de 97:3, v:v a 75:25, v:v (fase orgânica: fase aquosa). Os solventes orgânicos utilizados são menos viscosos em relação à água, por isso fluem mais facilmente no sistema e, por serem voláteis, favorecem também a ionização dos analitos e evaporação do solvente. A fase móvel que apresentou melhores resultados foi a composição de metanol : formiato de amônio, 0,01 mol L-1, pH 4,2 (90:10, v:v).

Variados tipos de colunas analíticas foram testadas, sendo elas: A NST ${ }^{\circledR}$ (150 $\mathrm{mm}, 4,6 \mathrm{~mm}$ e $5 \mu \mathrm{m})$, a $\mathrm{ACE}^{\circledR}(150 \mathrm{~mm}$ x 4,6 mm x $5 \mu \mathrm{m})$, a Phenomenex ${ }^{\circledR}(250$ x 4,6 mm x $5 \mu \mathrm{m})$ e a Atlantis T3 e da Waters ${ }^{\circledR}(100 \mathrm{~mm}$ x $2,1 \mathrm{~mm}$ x $3 \mu \mathrm{m})$ (comprimento $\mathrm{x}$ diâmetro interno x tamanho de partícula), no entanto, essas colunas aumentaram o tempo de retenção dos analitos, pioraram o perfil cromatográfico gerando picos largos e fragmentados. Portanto os testes foram realizados com uma nova coluna analítica, a $\mathrm{ACE}^{\circledR} \mathrm{C} 18$ (100 mm x 2,1 mm x 3 นm, comprimento, diâmetro interno e tamanho de partícula) com pré-coluna $\mathrm{ACE}^{\circledR} \mathrm{C} 18(2,1 \mathrm{~mm}$ x $3 \mu \mathrm{m}$ diâmetro, tamanho de partícula), obtendo-se um menor tempo de análise (maior frequência analítica) e melhor perfil cromatográfico (picos simétricos) para os analitos.

Três volumes de injeção de amostra foram testados $(5,10$ e $100 \mu \mathrm{L})$, devido a baixa concentração dos analitos, foi adotada a maior quantidade $(100 \mu \mathrm{L})$, pois forneceu melhores sinais analíticos. Também foi avaliado o uso do pool de soro sem diluição e diluído (1:1, v:v), os perfis cromatográficos de ambos foram ótimos, no entanto, 
escolheu-se trabalhar com a amostra diluída para diminuir a presença de interferentes e consequentemente diminuir efeito matriz e aumentar o tempo de durabilidade da coluna analítica.

Já obtidas as melhores condições espectrométricas e cromatográficas, foi otimizado o sistema columm switching na configuração de backflush, o qual apresenta três eventos, como mostrado na Figura 20.
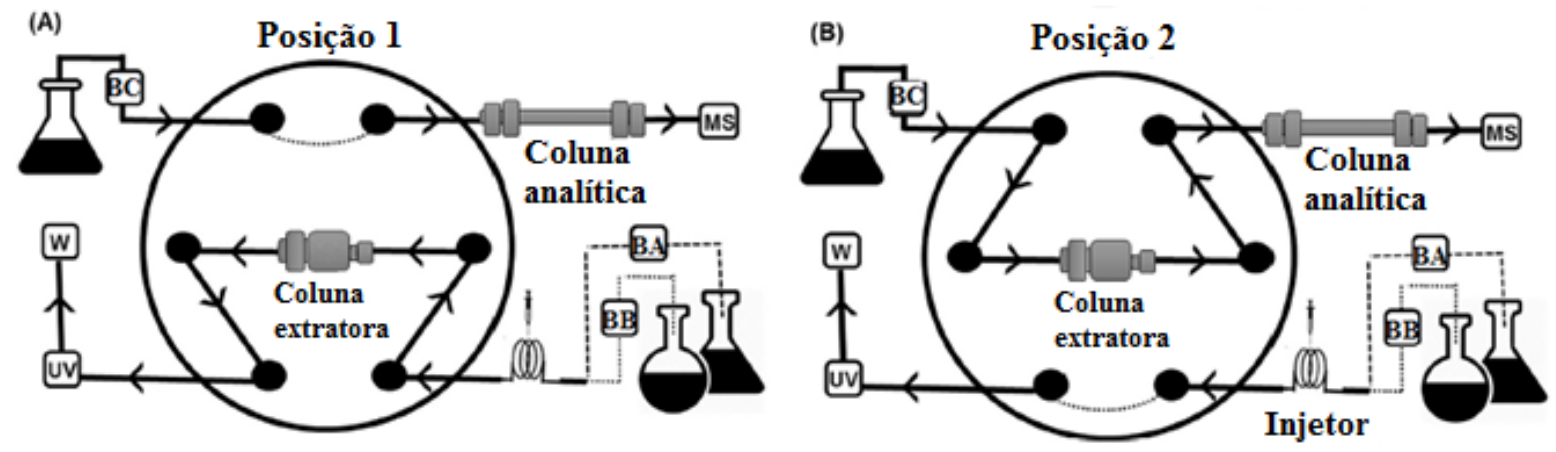

Figura 20 - Ilustração do sistema de columm switching na configuração de backflush. Na posição 1, correspondente ao evento 1, ocorre exclusão dos interferentes e adsorção dos analitos a coluna extratora. $\mathrm{Na}$ posição 2, durante o evento 2 , ocorre a eluição dos analitos adsorvidos. No retorno para a posição 1 , correspondente ao evento 3, ocorre limpeza da coluna extratora, separação e detecção dos analitos e por fim, o recondicionamento do sistema. $\mathrm{BA}=$ bomba $\mathrm{A}, \mathrm{BB}=$ bomba $\mathrm{B}, \mathrm{BC}=$ bomba $\mathrm{C}, \mathrm{MS}=$ espectrômetro de massas, $\mathrm{UV}=$ detector $\mathrm{UV}$ e $\mathrm{W}=$ descarte. Fonte: Traduzido de (De Faria et al., 2017).

Com as válvulas do sistema na posição 1 (evento 1), a bomba A promoveu a liberação da fase móvel de carregamento (água ultra pura) em um fluxo de 0,4 $\mathrm{mL} \mathrm{min}^{-1}$. O tempo de 3 minutos foi o necessário para a adsorção dos analitos e sua pré-concentração, além da eliminação de macromoléculas. A água mostrou ser um solvente ótimo como fase móvel de carregamento, além de ser um recurso barato e não causar danos ao meio ambiente. De forma simultânea, a fase móvel de eluição, fornecida pela bomba C, passa para a coluna analítica de forma a condioná-la, ainda na ausência dos analitos. Ambas as bombas operaram com uma taxa de fluxo inicial de $0,4 \mathrm{~mL} \mathrm{~min}^{-1}$. 
Na posição 2 da válvula (evento 2), a bomba C liberou a fase móvel de eluição (metanol : formiato de amônio, $0,01 \mathrm{~mol} \mathrm{~L}^{-1}, \mathrm{pH}$ 4,2 (90:10, v:v) em direção à coluna analítica em fluxo contrário ao que a fase móvel de carregamento percorreu (backflush). A velocidade do fluxo da bomba $\mathrm{C}$ foi aumentada para $0,8 \mathrm{~mL} \mathrm{~min}^{-1} \mathrm{e}$ o tempo determinado para esta etapa foi de 0,3 minutos, o qual promoveu um ótimo perfil cromatográfico dos analitos.

No evento 3, as válvulas foram colocadas na posição 1 novamente. A fase móvel de eluição (vinda da bomba C), novamente com um fluxo de $0,4 \mathrm{~mL} \mathrm{~min}^{-1}$, passou pela coluna analítica promovendo a separação dos analitos e sua chegada no detector de massas. De forma simultânea, a bomba B, em um fluxo de $1,0 \mathrm{~mL} \mathrm{~min}^{-1}$, liberou a fase móvel de limpeza (acetonitrila: água ultra pura: isopropanol:, 75:15:10, v:v:v), a qual passou pela coluna extratora (RAM) promovendo a remoção de resíduos proveniente da análise anterior, tornando-a pronta para a reutilização em uma nova análise. A fase de limpeza ocorreu no tempo de 3,3 a 10 min. O recondionamento do sistema às condições iniciais de análise ocorreu nos últimos $5 \mathrm{~min}$, em que a fase móvel de limpeza foi substituída pela fase móvel de carregamento. O tempo total para cada análise foi de 15 minutos.

Para a avaliação da capacidade da fase móvel de limpeza (acetonitrila : água ultra pura : isopropanol, 75:15:10, v:v:v), pools de soro branco dopado na maior concentração foram injetados no sistema (com a posição 1 das válvulas mantida) e, após a realização da fase de limpeza, foram injetados pools de soro branco diluídos (1:1, v:v). O experimento foi realizado em triplicata. O cromatograma do soro branco não apresentou sinal analítico no mesmo tempo de retenção dos analitos, o que mostra que a fase móvel de limpeza foi eficiente em seu propósito, evitando o chamado efeito residual (carry-over) De Faria et al ${ }^{110}$. 


\subsubsection{Validação analítica}

Para os testes de validação foram utilizados pools de amostras de soro branco dopadas com cada um dos analitos nas concentrações conforme o tópico 4.6.7, concentrações menores foram utilizadas, no entanto, essas não apresentaram bons sinais analíticos, precisão e exatidão. Os resultados dos testes de validação estão demonstrados na Tabela 6.

O teste de linearidade foi expresso como coeficiente de determinação $\left(r^{2}\right)$, calculado a partir das curvas de calibração intra-ensaio. Para esse teste, foram utilizados os analitos em diferentes concentrações em soro branco, conforme já citado, as repetições geraram 6 curvas de calibração para cada analito. Os intervalos lineares foram baseados nos intervalos terapêuticos 51,117118 .

As mesmas concentrações dos analitos em soro no ensaio de linearidade foram utilizadas no ensaio dos LD e LQ. Estes foram calculados através das 6 curvas de calibração e foram definidos como 3 e 10 vezes a relação sinal/ruído respectivamente para o LD e LQ.

Para avaliar a precisão e a exatidão intra e inter-ensaios, foram realizados 6 repetições de concentrações de calibração dos analitos. Os testes intra-ensaio foram realizados no mesmo dia e os testes inter-ensaios foram realizados em dias diferentes. A exatidão foi calculada através do erro relatico $(\mathrm{E} \%)$ e a precisão através do desvio padrão relativo $(\mathrm{RSD} \%)$.

No teste de seletividade foi avaliado se houve a presença picos de interferentes nos mesmos tempos de retenção dos analitos e dos PIs deuterados. As Figuras 21 e 22 mostram os cromatogramas obtidos após a injeção de soro branco e de soro dopado com os analitos, respectivamente, mostrando que não houve a presença de interferentes nos tempos de retenção dos analitos e PIs deuterados. 


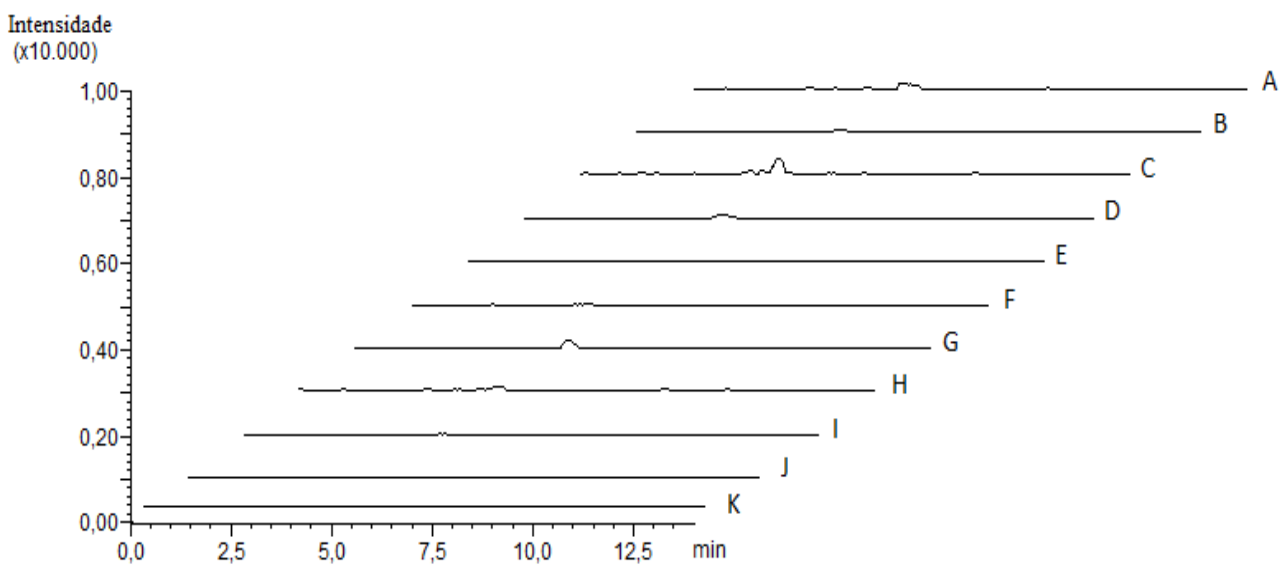

Figura 21 - Cromatograma obtido de amostras de soro branco diluídas em água ultra pura. Volume de injeção $=100 \mu \mathrm{L}$. A- Var $(\mathrm{m} / \mathrm{z} 212 \rightarrow \mathrm{m} / \mathrm{z} 169) ;$ B- Bup $(\mathrm{m} / \mathrm{z} 240 \rightarrow \mathrm{m} / \mathrm{z} 131)$; CHidroxibup $(\mathrm{m} / \mathrm{z} \quad 256 \rightarrow \mathrm{m} / \mathrm{z}, 238)$; D- Nic $(\mathrm{m} / \mathrm{z} 163 \rightarrow \mathrm{m} / \mathrm{z} 117)$; E- Cot $(\mathrm{m} / \mathrm{z} 177 \rightarrow \mathrm{m} / \mathrm{z}$ 80); FHidroxicot $(\mathrm{m} / \mathrm{z}$ 193 $\rightarrow \mathrm{m} / \mathrm{z}, 80)$; G- Var d-4 $(\mathrm{m} / \mathrm{z} 216 \rightarrow \mathrm{m} / \mathrm{z} 48) ;$ H- Hidroxibup d-6 $(\mathrm{m} / \mathrm{z}, 262 \rightarrow \mathrm{m} / \mathrm{z}$ 244); I- Nic d-4 $(\mathrm{m} / \mathrm{z}, 167 \rightarrow \mathrm{m} / \mathrm{z} 134) ; \mathbf{J}-$ Cot d-3 $(\mathrm{m} / \mathrm{z}, 180 \rightarrow \mathrm{m} / \mathrm{z}$ 80); K- Hidroxicot d-3 (m/z 196 $\rightarrow$ $\mathrm{m} / \mathrm{z}$ 80). Fonte: do autor e do colaborador Dr. Henrique Dipe de Faria, LATF, Unifal-MG.

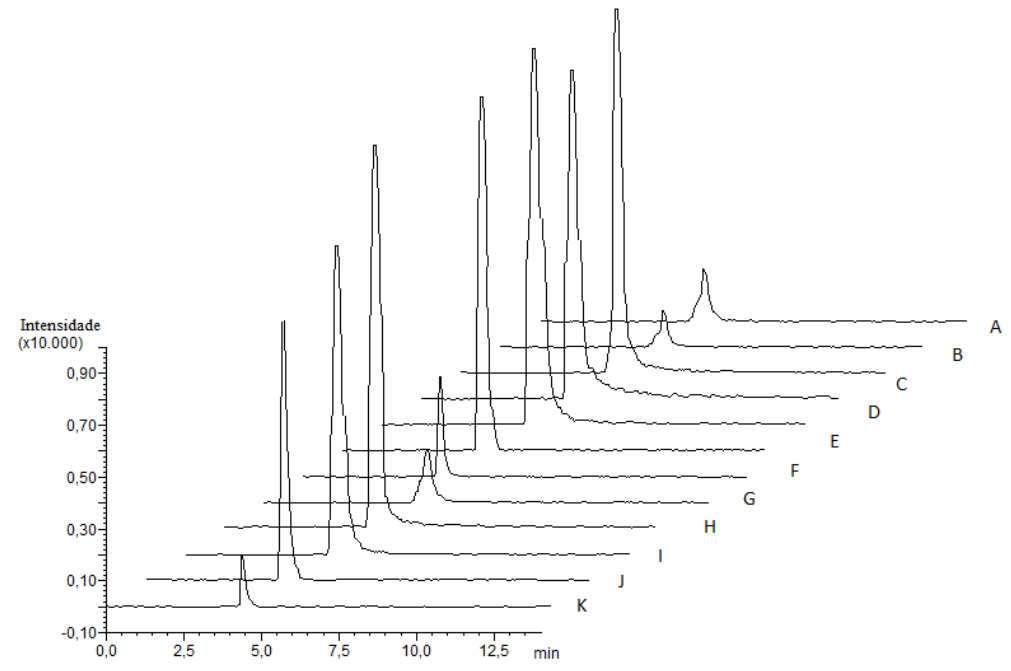

Figura 22 - Cromatograma obtido após análise de soro diluído e dopado com os analitos no nível médio de calibração e mais os padrões internos deuterados. A- Var $(\mathrm{m} / \mathrm{z} 212 \rightarrow \mathrm{m} / \mathrm{z}, 169)$; B- Bup $(\mathrm{m} / \mathrm{z}$ $240 \rightarrow m / z, 131)$; C- Hidroxibup $(m / z, 256 \rightarrow m / z, 238)$; D- Nic $(m / z, 163 \rightarrow m / z, 117) ; \mathbf{E}-\operatorname{Cot}(m / z, 177 \rightarrow m / z$ 80); F- Hidroxicot $(\mathrm{m} / \mathrm{z}$ 193 $\rightarrow \mathrm{m} / \mathrm{z}$ 80); G- Var d-4 $(\mathrm{m} / \mathrm{z}, 216 \rightarrow \mathrm{m} / \mathrm{z}$ 48); H- Hidroxibup d-6 $(\mathrm{m} / \mathrm{z} 262 \rightarrow$ $\mathrm{m} / \mathrm{z}$ 244); I- Nic d-4 $(\mathrm{m} / \mathrm{z} 167 \rightarrow \mathrm{m} / \mathrm{z}$ 134) ; J- Cot d-3 $(\mathrm{m} / \mathrm{z} 180 \rightarrow \mathrm{m} / \mathrm{z} 80)$; K- Hidroxicot d-3 $(\mathrm{m} / \mathrm{z} 196 \rightarrow$ $\mathrm{m} / \mathrm{z}$ 80). Fonte: do autor e do colaborador Dr. Henrique Dipe de Faria, LATF, Unifal-MG.

Foram realizados os testes de estabilidade de bancada, longo prazo e de congelamento e descongelamento. Para a análise de estabilidade de bancada soluções de soro dopada com os analitos foram analisadas imediatamente após a sua preparação e após 4 e 24 horas, verificando assim a estabilidade da amostra a curto prazo. Para uma 
análise a longo prazo, as amostras foram armazenadas a $-20^{\circ} \mathrm{C}$ por 30 dias e após foram avaliadas. Quanto análises de congelamento e descongelamento, foram realizados 3 ciclos de congelamento $-20^{\circ} \mathrm{C}$ e posterior descongelamento, e as amostras foram avaliadas.

O ensaio de recuperação da extração foi realizado em triplicata. A análise avaliou a recuperação relativa comparando-se a extração dos analitos a partir da matriz de soro com a de água, através da passagem da amostra pela coluna de extração (RAM). A recuperação relativa se dá pela relação das concentrações nas duas matrizes: (concentração no soro/ concentração na água) x 100.

O efeito residual (carry-over) foi avaliado injetando-se uma amostra de soro branco antes de uma amostra de soro dopado na maior concentração e, após, foi injetada novamente uma amostra de soro branco foram inferior a $20 \%$ daqueles obtidos no LQ.

Para avaliar o efeito matriz, foram comparados os resultados da análise das amostras de soro dopadas com os analitos em diferentes concentrações em matrizes diferentes (água e soro). O resultado para ser aceito precisava ser inferior a $15 \%$.

Posteriormente foi realizada a mensuração dos analitos em amostras reais de soro provenientes de pacientes submetidos ao tratamento antitabagismo com doses conforme bula. As Figuras 23 e 24 mostram os cromatogramas de amostras de pacientes submetidos ao tratamento com bupropiona e vareniclina, respectivamente. No momento da coleta das amostras os pacientes estavam fumando e além de apresentarem os analitos provenientes dos fármacos, também mostraram a presença de analitos provenientes da nicotina. 


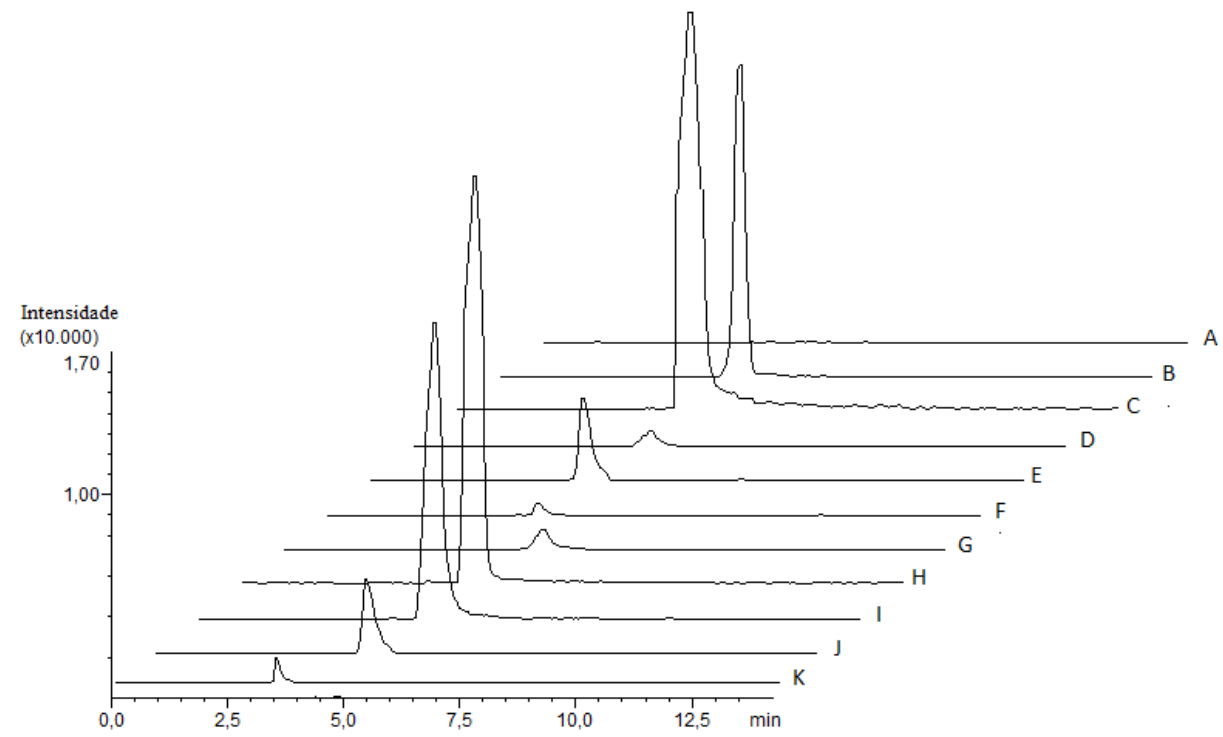

Figura 23 - Cromatograma obtido através da análise das amostras de soro dos pacientes tratados com bupropiona (150 mg 2x/dia). Os pacientes estavam fumando em torno de 10 cigarros/dia no dia da coleta. A- Var $(m / z$ 212 $\rightarrow \mathrm{m} / \mathrm{z} 169)$; B- Bup $(\mathrm{m} / \mathrm{z} 240 \rightarrow \mathrm{m} / \mathrm{z}$ 131); Chidroxibup $(\mathrm{m} / \mathrm{z} 256 \rightarrow \mathrm{m} / \mathrm{z} 238)$; D- Nic $(\mathrm{m} / \mathrm{z} 163 \rightarrow \mathrm{m} / \mathrm{z} 117)$; E- Cot $(\mathrm{m} / \mathrm{z} 177 \rightarrow \mathrm{m} / \mathrm{z}$ 80); FHidroxicot $(\mathrm{m} / \mathrm{z}, 193 \rightarrow \mathrm{m} / \mathrm{z}, 80)$; G- Var d-4 $(\mathrm{m} / \mathrm{z} 216 \rightarrow \mathrm{m} / \mathrm{z} 48)$; H- Hidroxibup d-6 $(\mathrm{m} / \mathrm{z} 262 \rightarrow \mathrm{m} / \mathrm{z}$ 244); I- Nic d-4 $(\mathrm{m} / \mathrm{z} \quad 167 \rightarrow \mathrm{m} / \mathrm{z} 134) ; \mathbf{J}-$ Cot d-3 $(\mathrm{m} / \mathrm{z} 180 \rightarrow \mathrm{m} / \mathrm{z}$ 80); K- Hidroxicot d-3 $(\mathrm{m} / \mathrm{z}$ $196 \rightarrow m / z$ 80). Fonte: do autor e do colaborador Dr. Henrique Dipe de Faria, LATF, Unifal-MG.

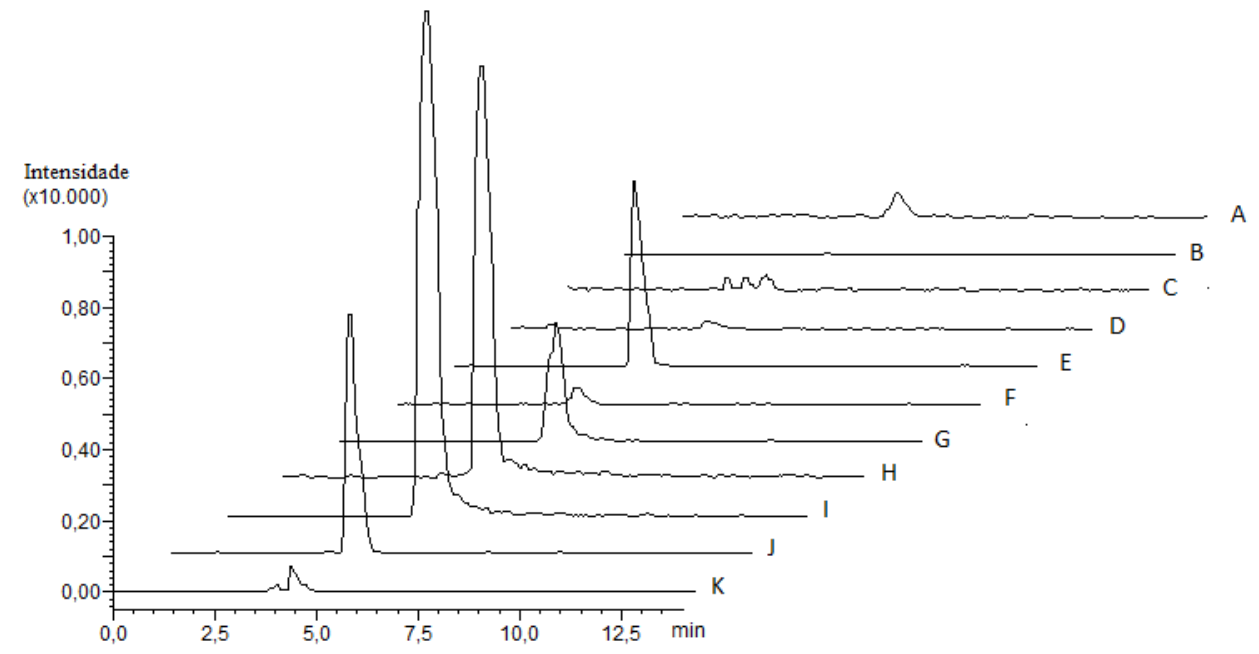

Figura 24 - Cromatograma obtido através da analise de amostras de soro de pacientes tratados com vareniclina $(1,0 \mathrm{mg} 2 \mathrm{x} / \mathrm{dia})$. Os pacientes fumavam em torno de 10 cigarros/dia no dia da coleta. A- Var $(\mathrm{m} / \mathrm{z} 212 \rightarrow \mathrm{m} / \mathrm{z}$ 169); B- Bup $(\mathrm{m} / \mathrm{z} 240 \rightarrow \mathrm{m} / \mathrm{z} 131)$; C- hidroxibup $(\mathrm{m} / \mathrm{z} 256 \rightarrow \mathrm{m} / \mathrm{z}$ 238); D- Nic $(\mathrm{m} / \mathrm{z} 163 \rightarrow \mathrm{m} / \mathrm{z}$ 117); E- Cot $(\mathrm{m} / \mathrm{z}$ 177 $\rightarrow \mathrm{m} / \mathrm{z}$ 80); F- Hidroxicot $(\mathrm{m} / \mathrm{z} 193 \rightarrow \mathrm{m} / \mathrm{z}$ 80); GVar d-4 $(\mathrm{m} / \mathrm{z}, 216 \rightarrow \mathrm{m} / \mathrm{z} 48)$; H- Hidroxibup d-6 $(\mathrm{m} / \mathrm{z} 262 \rightarrow \mathrm{m} / \mathrm{z} 244)$; I- Nic d-4 $(\mathrm{m} / \mathrm{z} \quad 167 \rightarrow \mathrm{m} / \mathrm{z}$ 134) ; J- Cot d-3 ( $\mathrm{m} / \mathrm{z}, 180 \rightarrow \mathrm{m} / \mathrm{z}$ 80); K- Hidroxicot d-3 $(\mathrm{m} / \mathrm{z}, 196 \rightarrow \mathrm{m} / \mathrm{z}, 80)$. Fonte: do autor e do colaborador Dr. Henrique Dipe de Faria, LATF, Unifal-MG. 
Tabela 6 - Parâmetros de validação obtidos na determinação de fármacos antitabagismo em soro humano

\begin{tabular}{|c|c|c|c|c|c|c|}
\hline Parâmetros de validação & Vareniclina & Bupropiona & Hidroxibupropiona & Nicotina & Cotinina & Hidroxicotinina \\
\hline Intervalo linear $\left(\mu \mathrm{g} \mathrm{L}^{-1}\right)$ & $5-100$ & $1-1000$ & $1-2000$ & $5-1000$ & $5-1000$ & $5-1000$ \\
\hline $\mathbf{r}^{2}(\bar{x}, \mathbf{n = 6})$ & 0,9952 & 0,9998 & 0,9998 & 0,9997 & 0,9998 & 0,9999 \\
\hline Declínio* $^{*}(\alpha)(\bar{x}, \mathrm{n}=6)$ & $0,0196 \pm 0,0095$ & $0,0045 \pm 0,0059$ & $0,0051 \pm 0,0057$ & $0,0087 \pm 0,0012$ & $0,0073 \pm 0,0048$ & $0,0075 \pm 0,0074$ \\
\hline Intercepto*( $\bar{x}, \mathbf{n}=\mathbf{6})$ & $-0,0316 \pm 0,0004$ & $-0,0022 \pm 0,0020$ & $0,0230 \pm 0,0025$ & $-0,0046 \pm 0,0065$ & $0,0767 \pm 0,0012$ & $0,1918 \pm 0,0013$ \\
\hline Tempo de retenção (min) & 5,21 & 5,01 & 4,85 & 4,97 & 4,46 & 4,41 \\
\hline $\mathbf{L D}\left(\mu g \mathbf{L}^{-1}\right)$ & 2,5 & 0,7 & 0,6 & 1,9 & 2,4 & 3,7 \\
\hline $\mathbf{L Q}\left(\mu \mathrm{g} \mathbf{L}^{-1}\right)$ & 5,0 & 1,0 & 1,0 & 5,0 & 5,0 & 5,0 \\
\hline Precisão intra-ensaio RSD \% $(\bar{x}, \mathrm{n}=6)$ & $9,3^{\mathrm{a}}$ & $15,3^{\mathrm{a}}$ & $14,0^{\mathrm{a}}$ & $9,0^{\mathrm{a}}$ & $11,7^{\mathrm{a}}$ & $12,8^{\mathrm{a}}$ \\
\hline Precisão inter-ensaio RSD\% ( $\bar{x}, \mathrm{n}=\mathbf{1 8}$, três dias) & $18,5^{\mathrm{a}}$ & $8,2^{\mathrm{a}}$ & $10,9^{\mathrm{a}}$ & $8,3^{\mathrm{a}}$ & $15,8^{\mathrm{a}}$ & $16,1^{\mathrm{a}}$ \\
\hline Acurácia intra-ensaio $E \%(\bar{x}, \mathrm{n}=6)$ & $19.6^{\mathrm{a}}$ & $-5,5^{\mathrm{a}}$ & $-6,5^{\mathrm{a}}$ & $15,8^{\mathrm{a}}$ & $-8,7^{\mathrm{a}}$ & $7,1^{\mathrm{a}}$ \\
\hline Acurácia inter-ensaio $E \%(\bar{x}, \mathrm{n}=18$, três dias) & $8,2^{\mathrm{a}}$ & $4,1^{\mathrm{a}}$ & $-8,7^{\mathrm{a}}$ & $14,6^{\mathrm{a}}$ & $-12,0^{\mathrm{a}}$ & $5,8^{\mathrm{a}}$ \\
\hline Recuperação da extração\% $(\bar{x}, \mathrm{n}=3)$ & $88,3^{\mathrm{a}}$ & $110,1^{\mathrm{a}}$ & $94,5^{\mathrm{a}}$ & $109,8^{\mathrm{a}}$ & $94,1^{\mathrm{a}}$ & $116,7^{\mathrm{a}}$ \\
\hline Estabilidade $^{1}$ E\% & $9,8^{\mathrm{a}}$ & $7,1^{\mathrm{a}}$ & $14,0^{\mathrm{a}}$ & $4,0^{\mathrm{a}}$ & $-13,2^{\mathrm{a}}$ & $8,6^{\mathrm{a}}$ \\
\hline Efeito matriz ${ }^{2} E \%$ & $-11,7^{\mathrm{a}}$ & $10,1^{\mathrm{a}}$ & $-5,5^{\mathrm{a}}$ & $9,8^{\mathrm{a}}$ & $-5,9^{\mathrm{a}}$ & $16,7^{\mathrm{a}}$ \\
\hline
\end{tabular}

*Média \pm Desvio padrão $(\mathrm{n}=6) .{ }^{\mathrm{a}}$ menor, ${ }^{\mathrm{b}}$ médio e ${ }^{\mathrm{c}}$ alto nível de calibração. ${ }^{1}$ Estabilidade de bancada $(4$ a 24 horas). Precisão: RSD\% $=[$ Desvio padrão/média] $\mathrm{x}$ 100. E\% $=[($ Média experimental da concentração/Concentração nominal) x 100] - 100. ${ }^{2}$ Efeito matriz: $E \%=$ [(Média da concentração experimental no solvente/Média experimental da concentração no soro) x 100] - 100. 


\subsubsection{Dados clínicos e demográficos dos pacientes submetidos a mensuração dos} analitos

As Tabelas 7 a 10 mostram as características clínicas e demográficas dos pacientes submetidos às análises de concentração dos analitos.

As Tabelas 7 e 8 referem-se aos pacientes tratados com vareniclina, sendo considerado o grupo total e os grupos de desfecho, respectivamente. Os pacientes do grupo resistente à vareniclina fumavam um maior número de cigarros/dia (antes do tratamento) em comparação com os pacientes que obtiveram sucesso (21 vs. 17 cigarros/dia, $\mathrm{P}=0,05)$.

As Tabelas 9 e 10 referem-se aos pacientes tratados com bupropiona no grupo total e de acordo com desfecho, respectivamente. O grupo resistente ao tratamento com bupropiona apresentou maior frequência de pacientes com alta DN (através dos escores FTND e Issa categorizados) e de pacientes que fumavam no dia da coleta, em comparação ao grupo sucesso $(\mathrm{FTND} \geq 6=83,3$ vs. $42,9 \%, \mathrm{P}=0,05$; Escore Issa $\geq 3=$ 100,0 vs. $42,9 \%, P=0,001$; fumo no dia da coleta $=100,0$ vs. $42,9 \%, P=0,001$, respectivamente).

Tabela 7 - Características clínicas e demográficas dos pacientes tratados com vareniclina submetidos às análises das concentrações dos analitos $(n=74)$

\begin{tabular}{lc}
\hline Idade (anos) & $51 \pm 12$ \\
Gênero, mulheres $(\boldsymbol{\%})$ & 50,0 \\
Etnia autodeclarada, brancos $(\boldsymbol{\%})$ & 73,0 \\
Índice de massa corporal $\left(\mathbf{K g} / \mathbf{m}^{\mathbf{2}}\right)$ & $26,3 \pm 4,9$ \\
Cigarros/dia inicial & $19 \pm 10$ \\
Fumo no dia da coleta $(\boldsymbol{\%})$ & 91,9 \\
FTND & $6,2 \pm 2,3$ \\
FTND, $\geq \mathbf{6}(\boldsymbol{\%})$ & 64,4
\end{tabular}


Escore Issa, $\geq 3(\%)$

Hipertensão (\%)

Dislipidemia (\%)

Diabetes melito tipo $2(\%)$

Depressão (\%)

Ansiedade (\%)
17,6

FTND = teste de Fagerström para dependência à nicotina Fagerström test for nicotine dependence (escala de 0 a 10 pontos). Escore Issa $=$ escore de consumo situacional Issa (escala de 0 a 4 pontos).

Tabela 8 - Características clínicas e demográficas dos pacientes tratados com vareniclina submetidos às análises das concentrações dos analitos de acordo com o desfecho de tratamento

\begin{tabular}{|c|c|c|c|}
\hline & Resistente $(n=41)$ & Sucesso $(n=33)$ & P valor \\
\hline Idade (anos) & $53 \pm 11$ & $49 \pm 13$ & 0,23 \\
\hline Gênero, mulheres (\%) & 56,1 & 42,4 & 0,24 \\
\hline Etnia autodeclarada, brancos (\%) & 68,3 & 78,8 & 0,31 \\
\hline Índice de massa corporal $\left(\mathrm{Kg} / \mathrm{m}^{2}\right)$ & $27,0 \pm 4,0$ & $25,5 \pm 5,8$ & 0,28 \\
\hline Cigarros/dia & $21 \pm 11$ & $17 \pm 7$ & $\mathbf{0 , 0 5}$ \\
\hline Fumo no dia da coleta $(\%)$ & 97,6 & 84,8 & 0,08 \\
\hline FTND & $6,5 \pm 2,2$ & $5,7 \pm 2,3$ & 0,19 \\
\hline FTND,$\geq 6(\%)$ & 65,9 & 62,5 & 0,77 \\
\hline Escore Issa, $\geq 3(\%)$ & 82,9 & 87,9 & 0,75 \\
\hline Hipertensão (\%) & 39,0 & 21,2 & 0,10 \\
\hline Dislipidemia (\%) & 34,1 & 45,5 & 0,32 \\
\hline Diabetes melito tipo $2(\%)$ & 7,3 & 12,1 & 0,69 \\
\hline Depressão (\%) & 12,2 & 15,2 & 0,71 \\
\hline Ansiedade (\%) & 14,6 & 21,2 & 0,46 \\
\hline
\end{tabular}

FTND = teste de Fagerström para dependência à nicotina - Fagerström test for nicotine dependence (escala de 0 a 10 pontos). Escore Issa = escore de consumo situacional Issa (escala de 0 a 4 pontos). 
Tabela 9 - Características clínicas e demográficas dos pacientes tratados com bupropiona submetidos às análises das concentrações dos analitos $(n=31)$

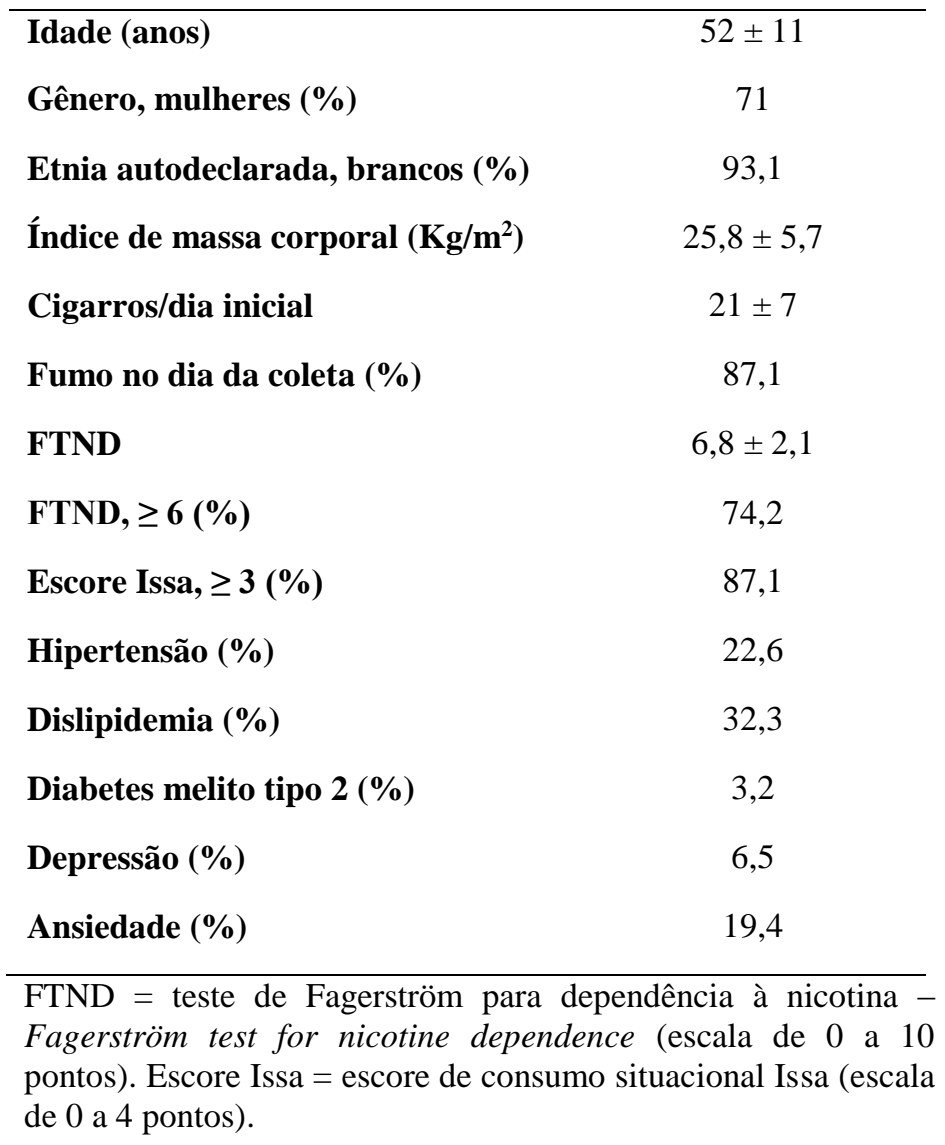

Tabela 10 - Características clínicas e demográficas dos pacientes tratados com bupropiona submetidos às análises das concentrações dos analitos de acordo com o desfecho de tratamento

\begin{tabular}{lccc}
\hline & Resistente $(\mathbf{n = 2 4})$ & Sucesso $(\mathbf{n}=\mathbf{7})$ & Valor de P \\
\hline Idade (anos) & $53 \pm 11$ & $50 \pm 11$ & 0,54 \\
Gênero, mulheres $(\%)$ & 70,8 & 71,4 & 1,00 \\
Etnia autodeclarada, brancos $(\boldsymbol{\%})$ & 95,7 & 83,3 & 0,38 \\
Índice de massa corporal $\left(\mathbf{K g} / \mathbf{m}^{\mathbf{2}}\right)$ & $25,2 \pm 6,1$ & $27,8 \pm 3,5$ & 0,15 \\
Cigarros/dia & $21 \pm 7$ & $23 \pm 7$ & 0,71 \\
Fumo no dia da coleta $(\%)$ & 100,0 & 42,9 & $\mathbf{0 , 0 0 1}$ \\
FTND & $7,3 \pm 1,5$ & $5,4 \pm 3,2$ & 0,11 \\
FTND, $\geq \mathbf{6}(\%)$ & 83,3 & 42,9 & $\mathbf{0 , 0 5}$ \\
Escore Issa, $\geq \mathbf{3}(\%)$ & 100,0 & 42,9 & $\mathbf{0 , 0 0 1}$ \\
Hipertensão $(\%)$ & 29,2 & 0,0 & 0,16
\end{tabular}




\begin{tabular}{lccc} 
Dislipidemia (\%) & 37,5 & 14,3 & 0,38 \\
Diabetes melito tipo 2 (\%) & 4,2 & 0,0 & 1,00 \\
$\begin{array}{l}\text { Depressão (\%) } \\
\text { Ansiedade (\%) }\end{array}$ & 8,3 & 0,0 & 1,00 \\
\hline $\begin{array}{l}\text { FTND = teste de Fagerström para dependência à nicotina - Fagerström test for nicotine } \\
\text { dependence (escala de 0 a 10 pontos). Escore Issa = escore de consumo situacional Issa (escala } \\
\text { de } 0 \text { a } 4 \text { pontos). }\end{array}$
\end{tabular}

\subsubsection{Análise de associação dos analitos com desfecho de tratamento}

A Tabela 11 mostra a frequência do desfecho de tratamento de acordo com os medicamentos antitabagismo, pacientes estes cujas amostras de soro foram submetidas à mensuração dos analitos.

Tabela 11 - Frequência do desfecho de tratamento nos pacientes submetidos às análises das concentrações dos analitos de acordo com os medicamentos antitabagismo

\begin{tabular}{lcc}
\hline Medicamento & Resistente (\%) & Sucesso (\%) \\
\hline Vareniclina (n=74) & 54,4 & 44,6 \\
Bupropiona (n=31) & 77,4 & 22,6 \\
\hline
\end{tabular}

As Tabelas de 12 a 15 mostram as concentrações dos analitos nas amostras de soro dos pacientes tratados com vareniclina e bupropiona no grupo total e de acordo com o desfecho de tratamento.

Os pacientes do grupo resistente, tanto os pacientes tratados com vareniclina (Tabela 13), quanto com bupropiona (Tabela 15), apresentaram concentração significativamente maior de cotinina e hidroxicotinina do que os grupos sucesso (tratamento com vareniclina: cotinina $=118,2$ vs. $70,6 \mu \mathrm{g} / \mathrm{L}, \mathrm{P}=0,009$; hidroxicotinina= 84,5 vs. 51,6 $\mu \mathrm{g} / \mathrm{L}, \mathrm{P}=0,02$. Tratamento com bupropiona: cotinina= 134,6 vs. $16,0 \mu \mathrm{g} / \mathrm{L}$, $\mathrm{P}=0,005$; hidroxicotinina $=97,2$ vs. $37,4 \mu \mathrm{g} / \mathrm{L}, \mathrm{P}=0,004)$. No entanto, quanto ao NMR, não houve diferença entre os desfechos de tratamento de ambos os fármacos. Além 
disso, somente o grupo de pacientes tratados com vareniclina continha pacientes com

NMR $<0,31$ (metabolizadores lentos para nicotina) e, ainda, sua frequência foi baixa (10,0 e 4,3\% para os grupos de desfecho resistente e sucesso, respectivamente).

Tabela 12 - Concentração dos analitos nas amostras de soro dos pacientes tratados com vareniclina

\begin{tabular}{|c|c|}
\hline Vareniclina $\mu \mathrm{g} / \mathrm{L}, \mathrm{n}=71$ & $8,3(8,1-9,5)$ \\
\hline Nicotina $\mu \mathrm{g} / \mathrm{L}, \mathbf{n}=\mathbf{3 1}$ & $7,5(7,6-11,2)$ \\
\hline Cotinina $\mu \mathrm{g} / \mathrm{L}, \mathbf{n}=65$ & $100,7(92,3-122,5)$ \\
\hline Hidroxicotinina $\mu \mathrm{g} / \mathrm{L}, \mathrm{n}=65$ & $68,1(63,8-87,4)$ \\
\hline NMR, $n=63$ & $0,69(0,67-1,02)$ \\
\hline NMR $<0,31(\%), n=63$ & 7,9 \\
\hline \multicolumn{2}{|c|}{$\begin{array}{l}\text { Valores de mediana das concentrações (Intervalo de confiança d } \\
95 \% \text { ). NMR=trans-3-hidroxicotinina/cotinina. NMR }<0,31 \\
\text { metabolizador lento. NMR } \geq 0,31=\text { metabolizador normal e rápido. } \\
\text { hidroxicotinina mensurada no soro foi considerada como send } \\
\text { trans-3- hidroxicotinina para o cálculo do NMR, já que a quantidad } \\
\text { de outros isômeros são irrelevantes. }\end{array}$} \\
\hline
\end{tabular}

Tabela 13 - Concentração dos analitos de acordo com o desfecho de tratamento com vareniclina

\begin{tabular}{|c|c|c|c|}
\hline & Resistente & Sucesso & $\mathbf{P}$ \\
\hline Vareniclina $\mu \mathrm{g} / \mathrm{L}, \mathbf{n}=71$ & $8,4(7,8-9,9)$ & $8,3(7,7-9,7)$ & 0,96 \\
\hline Nicotina $\mu \mathrm{g} / \mathrm{L}, \mathbf{n}=31$ & $8,3(7,4-12,7)$ & $7,0(5,9-10,5)$ & 0,32 \\
\hline Cotinina $\mu \mathrm{g} / \mathrm{L}, \mathrm{n}=65$ & $118,2(101,2-142,6)$ & $70,6(64,3-103,7)$ & 0,009 \\
\hline Hidroxicotinina $\mu \mathrm{g} / \mathrm{L}, \mathbf{n}=65$ & $84,5(70,2-103,2)$ & $51,6(43,4-72,1)$ & $\mathbf{0 , 0 2}$ \\
\hline NMR, $n=63$ & $0,74(0,62-1,07)$ & $0,61(0,55-1,13)$ & 0,64 \\
\hline NMR $<0,31(\%), n=63$ & 10,0 & 4,3 & 0,64 \\
\hline
\end{tabular}


Tabela 14 - Concentração dos analitos nas amostras de soro dos pacientes tratados com bupropiona

\begin{tabular}{lc}
\hline Bupropiona $\mu \mathbf{g} / \mathbf{L}, \mathbf{n}=\mathbf{3 0}$ & $36,9(33,2-49,3)$ \\
Hidroxibupropiona $\mu \mathbf{g} / \mathbf{L}, \mathbf{n = 2 3}$ & $736,8(586,0-782,4)$ \\
Nicotina $\mu \mathbf{g} / \mathbf{L}, \mathbf{n}=\mathbf{1 3}$ & $7,1(6,2-10,9)$ \\
Cotinina $\mu \mathbf{g} / \mathbf{L}, \mathbf{n}=\mathbf{2 7}$ & $115,9(97,1-164,8)$ \\
Hidroxicotinina $\mu \mathbf{g} / \mathbf{L}, \mathbf{n = 2 8}$ & $93,1(83,8-138,7)$ \\
$\mathbf{N M R , ~} \mathbf{n}=\mathbf{2 7}$ & $0,90(0,74-1,49)$ \\
$\mathbf{N M R}<\mathbf{0 , 3 1}(\boldsymbol{\%}), \mathbf{n}=\mathbf{2 7}$ & 0
\end{tabular}

Valores de mediana das concentrações (Intervalo de confiança de 95\%). NMR= trans-3-hidroxicotinina/cotinina. NMR $<0,31=$ metabolizador lento. NMR $\geq 0,31=$ metabolizador normal e rápido. Não houve pacientes com $\mathrm{NRM}<0,31$. A hidroxicotinina mensurada no soro foi considerada como sendo trans-3hidroxicotinina para o cálculo do NMR, já que a quantidade de outros isômeros são irrelevantes.

Tabela 15 - Concentração dos analitos de acordo com o desfecho de tratamento com bupropiona

\begin{tabular}{|c|c|c|c|}
\hline & Resistente & Sucesso & $\mathbf{P}$ \\
\hline Bupropiona $\mu \mathrm{g} / \mathrm{L}, \mathbf{n}=\mathbf{3 0}$ & $37,2(33,1-53,3)$ & $30,0(21,4-48,1)$ & 0,48 \\
\hline Hidroxibupropiona $\mu \mathrm{g} / \mathrm{L}, \mathbf{n}=\mathbf{2 3}$ & $779,5(607,8-830,8)$ & $512,8(295,7-819,5)$ & 0,12 \\
\hline Nicotina $\mu \mathrm{g} / \mathbf{L}, \mathbf{n}=\mathbf{1 3}$ & $7,1(6,2-10,9)$ & - & - \\
\hline Cotinina $\mu \mathrm{g} / \mathrm{L}, \mathbf{n}=27$ & $134,6(109,7-178,4)$ & $16,0(-19,5-71,2)$ & 0,005 \\
\hline Hidroxicotinina $\mu \mathrm{g} / \mathrm{L}, \mathbf{n}=28$ & $97,2(92,9-152,0)$ & $37,4(3,3-84,7)$ & 0,004 \\
\hline NMR, n=27 & $0,84(0,76-1,09)$ & $1,32(-3,71-8,84)$ & 0,14 \\
\hline NMR $<0,31(\%), n=27$ & 0 & 0 & - \\
\hline
\end{tabular}




\section{DISCUSSÃO}

\subsection{Para os dados da análise de expressão gênica}

O presente estudo clínico e exploratório identificou resultados significativos para expressão dos genes CHRNA7 e CHRNG de acordo com os tempos de coleta e o desfecho de tratamento com vareniclina. Amostras do grupo resistente nos tempos T2 e T4, isto é, já com o uso da vareniclina, apresentaram menores níveis de expressão gênica do CHRNA7 comparado às amostras do T0 (antes de iniciar o tratamento farmacológico). Estes resultados sugerem que o downregulation de $\alpha 7$ pode ter sido responsável pela não cessação do fumo nos indivíduos do grupo resistente, o que não foi observado nas amostras do grupo sucesso.

O gene CHRNA7 codifica a subunidade $\alpha 7$ dos nAChRs. Esta possui grande importância, está presente em diversos tecidos e possui associação consistente em vários estudos com o processo de dependência à nicotina, processos cognitivos e imunológicos ${ }^{119-124}$. Estudos também mostraram que há um locus contendo duplicação do gene CHRNA7 truncada, composta pelos exons 5-10 do gene CHRNA7, precidida de 4 exons únicos e uma deleção de dois pares de bases no éxon 6, o qual nomearam como CHRNFAN7. A maioria dos indivíduos possui uma ou duas cópias deste gene e são raros os casos em que esta cópia não está presente ${ }^{125,126}$.

No cérebro de ratos Sprague-Dawley, Ryan e Loiacono ${ }^{119}$ detectaram níveis de a7 transcritos em diversos locais como: na substância negra compacta ( $\mathrm{SNpc}$ ), na substância negra reticular (SNpr), na área tegmental ventral (VTA), no córtex e no hipocampo. Os ratos submetidos ao tratamento crônico com nicotina mostraram maiores níveis de mRNA da subunidade $\alpha 7$ em SNpc, SNpr e VTA em comparação ao grupo controle. A VTA faz parte do sistema de recompensa mesolímbico, o qual é muito estudado nos processos de ND ${ }^{12,15}$. No presente estudo (em amostras de PBMC), o 
grupo de pacientes resistentes também apresentou maior expressão de $\alpha 7$ no momento em que somente a nicotina estava presente no fumo crônico. Ao introduzir a vareniclina, as expressões foram diminuídas nos tempos T2 e T4, provavelmente devido ao antagonismo competitivo da vareniclina com a nicotina no receptor.

Benhammou et al ${ }^{127}$ realizaram um estudo com amostras de cérebro post mortem de fumantes e com amostras de sangue de voluntários fumantes e não fumantes. Através do uso de nicotina radiomarcada nas amostras de cérebro, mostraram que os sítios de ligação à nicotina, foram aumentados proporcionamente conforme o número de cigarros por dia. O mesmo estudo, ao analizar a expressão gênica e proteínas em linfócitos e células polimorfonucleares para um subconjunto de subunidades de receptores nicotínicos, essas células, assim como no tecido cerebral, exibiram maiores números de sítios de ligação de alta afinidade à nicotina em fumantes em comparação com não fumantes.

A vareniclina em estudos funcionais mostrou ter atividade agonista total nos receptores $\alpha 7^{40}$. Em um estudo realizou-se o tratamento crônico com vareniclina e/ou nicotina em camundongos (10 dias); os níveis das drogas no cérebro e no plasma e a tolerância e a expressão de 4 subtipos de nAChR, após dose aguda de nicotina, foram checados usando autoradiografia. O upregulation de receptores $\alpha 4 \beta 2$, devido ao tratamento crônico com vareniclina, foi similar ao promovido pela nicotina, e também ocorreu dowregulation de $\alpha 6 \beta 2$, assim como ocorreu com o uso de nicotina. A vareniclina aumentou significantemente os sítios de $\alpha 3 \beta 4$ e $\alpha 7$, enquanto a nicotina teve menor efeito nestes sítios. A combinação da nicotina com a vareniclina foi similar à vareniclina sozinha para os sítios de $\alpha 3 \beta 4$, enquanto para o sítio de $\alpha 7$ a combinação promoveu upregulation em menos regiões cerebrais em comparação com a vareniclina em monoterapia ${ }^{77}$. 
No presente estudo, os pacientes do grupo resistente apresentaram efeito semelhante associado ao uso combinado de vareniclina e nicotina (devido ao fumo), os níveis de expressão de CHRNA7 não foram mantidos como nos pacientes que obtiveram sucesso no tratamento. No entanto, o grupo sucesso só estava utilizando a vareniclina na ausência de nicotina entre os tempos T2 e T4, o que sugere que esse dowregulation pode ocorrer em subgrupo de resposta.

Diversos estudos mostraram diferenças na expressão gênica de $a 7$ em amostras de pacientes com diagnósticos psiquiátricos em comparação com indivíduos Sadios $102,128-134$.

Kunii et al ${ }^{128}$ mostraram diferença na expressão de $a 7$ em córtex pré-frontal dorsolateral post mortem de pacientes com depressão, ansiedade e transtorno bipolar e, inúmeros estudos mostraram menores níveis de expressão de $\alpha 7$ em pacientes com esquizofrenia ${ }^{102,129-134}$.

Estudos de indivíduos com esquizofrenia são ótimos modelos para o entendimento da importância do receptor $a 7$ em processos cognitivos, em ND e em como esses mecanismos estão intimamente relacionados. Diversos estudos mostraram que há uma maior prevalência de tabagismo em indivíduos com esquizofrenia comparados à população geral ${ }^{135,136}$.

Mexal el al ${ }^{102}$ realizaram um estudo com amostras de cérebro post mortem provenientes de indivíduos de 4 grupos distintos: controle não fumante, controle fumante, pacientes com esquizofrenia não fumantes e pacientes com esquizofrenia fumantes. O estudo realizou ensaio de expressão de mRNA e de proteína através de PCR quantitativo em tempo real e western blot. As sondas da PCR foram desenhadas para amplificar o gene completo CHRNA7 e sua cópia duplicada, o CHRFAM7A. Não fumantes com esquizofrênia apresentaram expressão reduzida de mRNA e de proteína 
em relação aos pacientes com esquizofrenia fumantes. Não fumantes com esquizofrenia apresentaram menor expressão em relação ao controle não fumante, mas essa diferença foi estatisticamente significativa apenas no nível do mRNA. Outros estudos post mortem cerebral mostraram menor expressão dos receptores nicotínicos no córtex e no hipocampo de indivíduos com esquizofrênia comparado aos controles saudáveis ${ }^{129-134}$.

O CHRFAM7A, assim como o CHRNA7, é polimórfico e variantes neste gene foram associadas à patologia auditória em casos de esquizofrenia. Processos diferenciados nos mecanismos de transcrição podem contribuir para um funcionamento anormal de $a 7$, como variações em promotor, splicing alternativo e/ou desequilíbrio de ligação com o SNP do gene de neuroregulina -1 (gene que codifica molécula de adesão celular envolvida em processos de neuroplasticidade sináptica). Estes processos podem estar envonvidos em endofenótipos da doença ${ }^{122,126,137-144}$.

A nicotina parece melhorar a audição em indivíduos com déficit auditório na esquizofrenia associado ao $\alpha 7$, permitindo uma melhor filtragem dos estímulos auditivos estranhos. A nicotina melhora a cognição na esquizofrenia e agentes alternativos que ativam o receptor nicotínico foram testados, e esses compostos melhoraram a atenção, a memória de trabalho e os sintomas negativos em um estudo complementar de pacientes não fumantes com esquizofrenia ${ }^{145}$.

Os estudos citados nos mostram grandes evidências da associação do $\alpha 7$ com ND, processos cognitivos e de resposta à vareniclina. Esses achados podem explicar nossos resultados em relação à diminuição da expressão de 7 no grupo de pacientes resistentes ao tratamento. Os pacientes do grupo sucesso mantiveram os níveis de expressão gênica em resposta à vareniclina, já no grupo resistente houve um dowregulation. Sugerimos que essa diminuição pode ter sido a responsável, ao menos em parte, pelos indivíduos não terem conseguido deixar de fumar. A nicotina pode estar 
compensando um déficit de $\alpha 7$ que os indivíduos resistentes podem apresentar. No entanto, não sabemos como seria a expressão de $\alpha 7$ nestes indivíduos na ausência do fumo.

Quanto ao gene $C H N R G$, não há muitos resultados na literatura. Este codifica a subunidade $\gamma$ dos receptores nicotínicos. A maioria dos estudos aponta associação da subunidade com distúrbios esquelético-musculares ${ }^{146-149}$.

No entanto, King et al ${ }^{65}$ encontraram a associação de polimorfismos neste gene com nausea no tratamento com vareniclina. E Keskitalo-Vuokko ${ }^{150}$ et al encontraram associação de SNPs em loci do cluster de genes CHRNG/CHRND (genes muitos próximos, o último codifica a subunidade delta dos nAChRs) com o nível de cotinina. Saccone et al ${ }^{151}$ encontraram a associação de 4 loci no cluster CHRND/CHRNG com ND. Em outro estudo, variantes nos genes CHRND/CHRNG mostraram associação modesta com o risco de ND em amostras de afro-americanos ${ }^{152}$.

Em um estudo o qual foi utilizado um modelo de esquizofrenia em ratos, no grupo de animais tratados com clozapina, foi encontrado downregulation do Chrng no núcleo accumbens. Neste mesmo estudo, Santoro et al não conseguiram formular uma hipótese para o achado devido ao lack de informações na literatura com o foco em ND ou performance cognitiva ${ }^{153}$.

Há algumas limitações no estudo. Primeira, o ensaio da análise de expressão gênica foi realizado com amostras de sangue periférico e não no SNC, o que poderia nos mostrar uma relação mais clara e direta do fármaco com a via de resposta. No entanto, a obtenção desta amostra é inviável. Em contrapartida, estudos já demonstraram que há similaridade entre a expressão gênica de células do SNC e de células de sangue periférico para alguns destes genes de receptores nicotínicos ${ }^{102}$. Segunda, não foi realizado ensaio de expressão gênica para amostras de indivíduos não fumantes, o que 
poderia fornecer mais parâmetros de comparação com os grupos resistente e sucesso. Terceira, não conseguimos qualidade necessária nas análises de genes potencialmente importantes.

\subsection{Para os dados da mensuração dos analitos}

Um dos maiores desafios em análises de amostras biológicas é eliminar os interferentes de sua matriz, sem alterar substancialmente as quantidades dos analitos presentes. A matriz de amostras de soro e plasma são complexas e envolve a presença de inúmeras macromoléculas como lipídios e proteínas que obstruem colunas análiticas, diminuem o tempo de duração de equipamentos e inviabilizam a interpretação dos dados devido a imensos picos e ruídos formados nos cromatogramas e espectros de massa. Inumeros trabalhos executam uma preparação prévia das amostras que envolve processos como a extração com uso de solventes, preciptação de proteínas, entre outros, os quais podem promover uma baixa recuperação dos analitos, tempo prolongado de bancada e gasto de materiais ${ }^{51,104-106}$.

Devido à esse fato, inúmeros estudos propuseram o uso de materiais de acesso restrito (RAMs) para a purificação da amostra sem tanto manuseio, dentre eles estão os nanotubos de carbono (CNTs) modificados 109, 110, 114-116.

O presente estudo desenvolveu uma coluna extratora composta por nanotubos híbridos de carbono e sílica modificados quimicamente com a adição de grupos hidrofíficos. Essa coluna permitiu uma ótima exclusão de macromoléculas (98\%). A água ultra pura foi o suficiente para ser utilizada como fase móvel de carregamento, o que é sustentável, além de não causar danos ao meio ambiente e o único preparo da amostra foi uma diluíção 1:1 também em água. O novo RAM desenvolvido foi 
encaminhado para pedido de patente (Anexo 5) e portanto os processos para o seu desenvolvimento foram mantidos em sigilo.

Os CNTs possuem uma grande área superfícial e ótima estabilidade em análise de compostos, no entanto, o material não promove a remoção de proteínas com eficiência 110115 . Os poros dos CNTs formam uma barreira física, excluindo ou permitindo a entrada de moléculas por tamanho, e os grupos hidrofílicos adicionados ao RAM desenvolvido não permitem a ligação de proteínas de forma irreversível, formando uma barreira físico-química. Os demais CNTs não modificados disponíveis não promovem a exclusão de macromoléculas com tanta efetividade quanto o material desenvolvido, além disso, o novo RAM, após limpeza, pode ser reutilizado cerca de 400 vezes (valor calculado durante os experimentos com amostras controle) .

Quanto a otimização do método de mensuração, a análise multidimensional, através de equipamentos conectados por válvulas comutadoras, promoveu a realização da extração, eluição, análise, limpeza e recondicionamento do sistema automáticamente. A análise completa de uma amostra foi realizada em apenas 15 minutos. O sistema permitiu a mensuração conjunta de diversos analitos com características físico-químicas diferentes de uma mesma amostra, mostrando bons sinais analíticos e perfis cromatográficos.

Quanto aos dados de validação, o método permitiu uma ótima recuperação dos analitos com valores próximos a 100\%, semelhante a outros estudos 104,, 117, 154, 155. A maior dificuldade encontrada neste estudo foi a configuração de parâmetros espectrométricos e cromatográficos que pudessem obter o máximo de recuperação e o menor LQ possível para a análise de vareniclina ainda em um contexto de análise multianalito. 
A dose posológica da vareniclina é muito baixa (1mg 2 vezes ao dia, a partir do $8^{\circ}$ dia de tratamento), em comparação com a da bupropiona (150 mg 2 vezes ao dia, a partir do $8^{\circ}$ dia de tratamento), dessa forma, as concentrações plasmáticas de vareniclina são muito baixas. Apesar do valor de LQ obtido $\left(5 \mu \mathrm{g} \mathrm{L}^{-1}\right)$ estar entre as médias plasmáticas de intervalo terapêutico $\left(4,0-7,0 \mu \mathrm{g} \mathrm{L} \mathrm{L}^{-1}\right.$ de vareniclina em plasma e soro) ${ }^{51,118}$, ao mensurar amostras de pacientes em um cenário real de tratamento, de 74 pacientes, apenas 3 amostras apresentaram concentração plasmática de vareniclina abaixo do limite de quantificação.

Quanto a recuperação do analito da matriz, a vareniclina também mostrou menor taxa $(88,3 \%)$ em relação aos outros analitos (valores próximos ao $100 \%)$, no entanto, essa taxa de recuperação é considerada alta e foi semelhante ao estudo de Dobrinas et al 156, o qual realizou a extração da amostra através de coluna extratora de fase sólida (SPE) disponível no mercado e a mensuração também foi realizada em um contexto multianalito. E ainda, a recuperação de vareniclina no presente estudo foi maior do que a obtida pelo trabalho de Al-Haj et al ${ }^{105}$, o qual realizou a preparação prévia da amostra por extração líquido-líquido (LLE) e a mensuração foi realizada para somente um analito $(47,59-48,72 \%)$. e obteve recuperação semelhante ao estudo de, os qual também realizou a análise de vareniclina em um cenário multianalito $(83,0$ - 92,0\%).

Para nicotina e cotinina, os valores de LQ obtidos no presente estudo $\left(5,0 \mu \mathrm{g} \mathrm{L}^{-1}\right)$ se assemelham aos obtidos nos estudos de Abdallah et al ${ }^{104}\left(7,0 \mu \mathrm{g} \mathrm{L}^{-1}\right.$ para cotinina), Onoue et al ${ }^{157}\left(5,0 \mu \mathrm{g} \mathrm{L}^{-1}\right.$ para nicotina e cotinina), Petersen et al ${ }^{117}\left(5,0 \mu \mathrm{g} \mathrm{L}^{-1}\right)$. Para bupropiona e hidroxibupropiona, o método proposto é capaz de mensurar pequenas quantidades do fármaco e de seu metabólito (LQ: 1,0 $\mu \mathrm{g} \mathrm{\textrm {L } ^ { - 1 }}$ para ambos), quantidades menores do que os LQs obtidos nos estudos de ${ }^{158}$ (5,5 para bupropiona e 6,0 $\mu \mathrm{g} / \mathrm{L}$ para 
hidroxibupropiona) e de ${ }^{155}\left(100 \mu \mathrm{g} \mathrm{L}^{-1}\right.$ para hidroxibupropiona), apesar das concentrações de metabólitos em estado de equilíbrio em pacientes tratados com doses terapêuticas do fármaco serem bem maiores $\left(45-75 \mu \mathrm{g} \mathrm{L}^{-1}\right.$ e de $\left.500-1500 \mu \mathrm{g} \mathrm{L}^{-1}\right)$, respectivamente para bupropiona e hidroxibupropiona ${ }^{118}$.

O Quadro 6 mostra os parâmetros analíticos do presente estudo comparados com outros estudos presentes na literatura.

Quanto às mensurações das amostras dos pacientes, não encontramos associação dos fármacos e seus metabólitos com desfecho de tratamento. Esse fato poderia ser explicado pelo pequeno número amostral do presente estudo.

Encontramos diferença significativa entre os grupos resistente e sucesso ao tratamento quanto aos parâmetros relacionados ao fumo e à DN. Os pacientes do grupo resistente tratados com vareniclina (ainda antes do início do tratamento) fumavam um maior número de cigarros/dia em comparação com os pacientes que obtiveram sucesso. O grupo resistente ao tratamento com bupropiona apresentou maior frequência de pacientes com alta DN (antes do tratamento) e de pacientes que fumavam no dia da coleta, em comparação ao grupo sucesso. Os dados também mostraram que os pacientes resistentes tratados com ambos os fármacos, no dia da coleta, apresentaram maiores concentrações dos metabólitos da nicotina. Esses dados podem indicar maior exposição ao fumo e maior DN podendo implicar na resposta ao tratamento antitabagismo.

Há algumas limitações nesse estudo. Primeira, os pacientes não fizeram exames de função hepática antes da inclusão no entudo, no entanto, a presença de comorbidades hepáticas foram questionadas. Segunda, não podemos obter total rigor nos horários de tomada dos medicamentos por parte dos pacientes, no entanto, os pacientes foram 
orientados à tomar o medicamento sempre no mesmo horário e foram questionados quanto ao cumprimento do protocolo. Terceira, o número amostral para a análise dos analitos e de NRM em estudos de associação com desfecho de tratamento é considerado modesto e consequentemente pode ter implicado nos resultados de não associação. 
Quadro 6 - Comparação dos dados de validação com outros estudos

\begin{tabular}{|c|c|c|c|c|c|c|c|c|}
\hline Analitos & $\begin{array}{c}\text { Purificação da } \\
\text { amostra/extração }\end{array}$ & Método & Amostra & Intervalo Linear $\left(\mu \mathbf{g ~ L}^{-1}\right)$ & Recuperação (\%) & $\mathbf{L D} \mu \mathbf{g} \mathbf{L}^{-1}$ & $\mathbf{L Q} \mu \mathbf{g} \mathbf{L}^{-1}$ & Referência \\
\hline Vareniclina, & & & & $5,0-100,0$ & 88,3 & 2,5 & 5,0 & \\
\hline Bupropiona & & & & $1,0-1000,0$ & 110,1 & 0,7 & 1,0 & \\
\hline Hidroxibupropiona & $\mathrm{CS}-\mathrm{SPE}$ (novo & & & $1,0-2000,0$ & 94,5 & 0,6 & 1,0 & Presente \\
\hline Nicotina & RAM) & & & $5,0-1000,0$ & 109,8 & 1,9 & 5,0 & estudo \\
\hline Cotinina & & & & $5,0-1000,0$ & 94,1 & 2,4 & 5,0 & \\
\hline Hidroxicotinina & & & & $5,0-1000,0$ & 116,7 & 3,7 & 5,0 & \\
\hline $\begin{array}{l}\text { Nicotitna } \\
\text { Cotinina }\end{array}$ & LLE & (LC-MS/MS) & Soro humano & $\begin{array}{c}0,3-52,5 \\
7,0-1500,0\end{array}$ & $\begin{array}{l}97,8-111,4 \\
97,3-115,6\end{array}$ & - & $\begin{array}{l}0,3 \\
7,0\end{array}$ & $\underset{104}{\text { Abdalla }}$ et al \\
\hline $\begin{array}{c}\text { Bupropiona } \\
\text { Hidroxibupropiona }\end{array}$ & $\mathrm{PP}+\mathrm{SPE}$ online & TFC-MS/MS) & Soro humano & $5,0-1000,0$ & $\begin{array}{l}158,0 \\
116,0\end{array}$ & $\begin{array}{l}1,3 \\
4,5\end{array}$ & $\begin{array}{l}5,5 \\
6,0\end{array}$ & $\begin{array}{c}\text { Petrides et } \\
a l^{158}\end{array}$ \\
\hline Vareniclina & LLE & $\begin{array}{l}\text { HPLC-MS/MS, } \\
\text { (API) }\end{array}$ & Plasma humano & $0,1-10,0$ & $47,59-48,72$ & 0,05 & 0,1 & $\underset{105}{\mathrm{Al}-\mathrm{Haj}}$ et al \\
\hline Vareniclina & LLE & $\begin{array}{c}\text { HPLC- } \\
\text { API/MS/MS }\end{array}$ & $\begin{array}{l}\text { Plasma } \\
\text { Urina }\end{array}$ & $\begin{array}{c}0,1-50,0 \\
1,0-500,0\end{array}$ & - & - & $\begin{array}{l}<0,1 \\
1,00\end{array}$ & $\underset{51}{\text { Faessel } \text { et al }}$ \\
\hline $\begin{array}{c}\text { Nicotina } \\
\text { cotinina } \\
\text { trans-3- } \\
\text { hidroxicotinina } \\
\text { vareniclina }\end{array}$ & $\begin{array}{l}\text { SPE (Oasis MCX } 10 \\
\text { mg 96-well extraction } \\
\text { plate) }\end{array}$ & UPLC-MS/MS & Soro humano & $\begin{array}{l}10,0-500,0 \\
10,0-500,0 \\
10,0-500,0 \\
10,0-250,0\end{array}$ & $\begin{array}{l}86,0-94,0 \\
70,0-87,0 \\
49,0-54,0 \\
83,0-92,0\end{array}$ & - & $\begin{array}{l}2,0 \\
1,0 \\
2,0 \\
1,0\end{array}$ & $\begin{array}{c}\text { Dobrinas } e t \\
\quad a l^{156}\end{array}$ \\
\hline
\end{tabular}




\begin{tabular}{|c|c|c|c|c|c|c|c|c|}
\hline $\begin{array}{l}\text { Nicotina } \\
\text { Cotinina }\end{array}$ & Centrifugação & $\begin{array}{c}\text { Diluição } \\
\text { isotópica estável } \\
\text { - UPLC- } \\
\text { MS/MS }\end{array}$ & Urina & $5,0-35000,0$ & $\begin{array}{l}96,8-105,1 \\
94,3-99,2\end{array}$ & $\begin{array}{l}0,7 \\
0,4\end{array}$ & $\begin{array}{l}1,7 \\
1,1\end{array}$ & $\underset{154}{\text { Kuhn et al }}$ \\
\hline Nicotina e Cotinina & LLE, PP, SPE & $\begin{array}{l}\text { (UPLC- } \\
\text { MS/MS) }\end{array}$ & $\begin{array}{l}\text { Sangue, urina e } \\
\text { outros tecidos de } \\
\text { rato }\end{array}$ & $10,0-600,0$ (plasma) & $\begin{array}{l}80 \% \text { (nicotina e } \\
\text { cotinina,com } \\
\text { precipitação) }\end{array}$ & 2,5 & 5,0 & $\underset{157}{\text { Onoue et al }}$ \\
\hline Cotinina & $\begin{array}{c}\text { LL, SPE (coluna } \\
\text { Zorbaxs XDB C8) }\end{array}$ & HPLC/UV & Soro e urina & $5,0-500,0$ & $97,8-102 \%$ & 0,18 & 5,0 & $\begin{array}{l}\text { Petersen } e t \\
a l^{117}\end{array}$ \\
\hline hidroxibupropiona & PP + SPE online & RP-HPLC/UV & Plasma humano & $100,0-2500,0$ & 61,18 & 100,0 & 100,0 & $\begin{array}{c}\text { Scherf- } \\
\text { Clavel et al } \\
155\end{array}$ \\
\hline
\end{tabular}

$\mathrm{CS}-\mathrm{SPE}=$ Extração em fase sólida no modo column switching, LLE= extração líquido-líquido, PP=precipitação de proteínas, SPE=extração em fase sólida, HPLC= cromatografia líquida de alta eficiência, UPLC=cromatografia líquida de ultra eficiência, RP-HPLC=Cromatografia líquida de alta eficiência em fase reversa, TFC=Cromatografia líquida turbulenta. API=ionização em pressão atmosférica,UV= detector ultravioleta, $\mathrm{MS} / \mathrm{MS}=$ espectometria de massas em tandem. 


\section{CONCLUSÕES}

Para a análise da expressão gênica, este estudo exploratório mostra a associação das subunidades $\alpha 7$ e $\gamma$ com a efetividade do tratamento com vareniclina. Estes resultados poderiam contribuir, ao menos em parte, para o desenvolvimento de uma terapêutica individualizada.

Para a mensuração de analitos, o novo RAM sintetizado é um produto de extremo valor científico, podendo apresentar diversas aplicações em análise de amostras de matrizes complexas, sem muita preparação prévia. Para a associação das concentrações dos fármacos e seus metabólitos com o desfecho de tratamento, são necessários estudos com um maior número amostral. 


\section{SUGESTÕES PARA ESTUDOS FUTUROS}

Sugerimos estudos que promovam maior entendimento das subunidades $\alpha 7$ e $\gamma$ dos nAChRs nos processos de dependência à nicotina e no tratamento com vareniclina. Sugerimos também estudos de investigação para novas aplicabilidades do novo RAM desenvolvido. 


\section{REFERÊNCIAS}

1. WHO. Tobacco. WHO Media Centre. 2015.

2. Oliveira AF, Valente JG, Leite IC. [Aspects of tobacco attributable mortality: systematic review]. Rev Saude Publica. 2008;42(2):335-345.

3. Koshiaris C, Aveyard P, Oke J, Ryan R, Szatkowski L, Stevens R, Farley A. Smoking cessation and survival in lung, upper aero-digestive tract and bladder cancer: cohort study. Br J Cancer. 2017;117(8):1224-1232.

4. Leppanen T, Toyras J, Mervaala E, Penzel T, Kulkas A. Severity of individual obstruction events increases with age in patients with obstructive sleep apnea. Sleep Med. 2017;37:32-37.

5. Cerda J, Bambs C, Vera C. Infant morbidity and mortality attributable to prenatal smoking in Chile. Rev Panam Salud Publica. 2017;41:e106.

6. Vigitel Brasil - Vigilância de fatores de risco e proteção para doenças crônicas por inquérito telefônico: Estimativas sobre frequência e distribuição sociodemográfica de fatores de risco e proteção para doenças crônicas nas capitais dos 26 estados brasileiros e no Distrito Federal em 2018. Brasília, 2019.

7. Rosemberg, J. Nicotina Droga Universal, Instituto Nacional de Câncer (www.inca.gov.br). 2004.

8. Kirchenchtein, C., Chatkin, J.M. Dependência da Nicotina. In: Diretrizes para Cessação do Tabagismo, Jornal Brasileiro de Pneumologia. Brasília, DF, 2004.

9. Fagerstöm, K. Uma breve apresentação da neurofarmacologia e fisiologia da dependência à nicotina. In: Gigliotti A.P.; Presman S. (Eds). Atualização no Tratamento do Tabagismo. ABP Saúde. 2006.

10. Gigliotti, A; Lemos, T. Quais são os mecanismos da dependência de nicotina? In: Manual de Condutas e Práticas em Tabagismo, Sociedade Brasileira de Pneumologia e Tisiologia. 2012.

11. Divisão de Controle do Tabagismo, Coordenação de Ações Estratégicas, Instituto Nacional de Câncer, Silva AG, Ministério da Saúde. Protocolo clínico e diretrizes terapêuticas dependência à nicotina, 2013.

12. Schultz W. Multiple reward signals in the brain. Nat Rev Neurosci. 2000;1(3):199-207.

13. Stolerman IP, Jarvis MJ. The scientific case that nicotine is addictive. Psychopharmacology (Berl). 1995;117(1):2-10; discussion 14-20. 
14. Koob GF, Volkow ND. Neurocircuitry of addiction. Neuropsychopharmacology. 2009;35(1):217-238.

15. Martin-Soelch C. Neuroadaptive changes associated with smoking: structural and functional neural changes in nicotine dependence. Brain Sci. 2013;3(1):159176.

16. Boening JA. Neurobiology of an addiction memory. J Neural Transm (Vienna). 2001;108(6):755-765.

17. Robbins TW, Everitt BJ. Limbic-striatal memory systems and drug addiction. Neurobiol Learn Mem. 2002;78(3):625-636.

18. Everitt BJ, Belin D, Economidou D, Pelloux Y, Dalley JW, Robbins TW. Review. Neural mechanisms underlying the vulnerability to develop compulsive drug-seeking habits and addiction. Philos Trans $R$ Soc Lond B Biol Sci. 2008;363(1507):3125-3135.

19. Fuentes RM, Notkola IL, Shemeikka S, Tuomilehto J, Nissinen A. Familial aggregation of blood pressure: a population-based family study in eastern Finland. J Hum Hypertens. 2000;14(7):441-445.

20. Gotti C, Zoli M, Clementi F. Brain nicotinic acetylcholine receptors: native subtypes and their relevance. Trends Pharmacol Sci. 2006;27(9):482-491.

21. Benowitz NL. Pharmacology of nicotine: addiction, smoking-induced disease, and therapeutics. Annu Rev Pharmacol Toxicol. 2009;49:57-71.

22. Benowitz NL. Clinical pharmacology of inhaled drugs of abuse: implications in understanding nicotine dependence. NIDA Res Monogr. 1990;99:12-29.

23. Picciotto MR, Zoli M, Rimondini R, Lena C, Marubio LM, Pich EM, Fuxe K, Changeux JP. Acetylcholine receptors containing the beta2 subunit are involved in the reinforcing properties of nicotine. Nature. 1998;391(6663):173-177.

24. Maskos U, Molles BE, Pons S, Besson M, Guiard BP, Guilloux JP, Evrard A, Cazala P, Cormier A, Mameli-Engvall M, Dufour N, Cloez-Tayarani I, Bemelmans AP, Mallet J, Gardier AM, David V, Faure P, Granon S, Changeux JP. Nicotine reinforcement and cognition restored by targeted expression of nicotinic receptors. Nature. 2005;436(7047):103-107.

25. Tapper AR, McKinney SL, Nashmi R, Schwarz J, Deshpande P, Labarca C, Whiteaker P, Marks MJ, Collins AC, Lester HA. Nicotine activation of alpha4* receptors: sufficient for reward, tolerance, and sensitization. Science. 2004;306(5698):1029-1032.

26. Aberger K, Chitravanshi VC, Sapru HN. Cardiovascular responses to microinjections of nicotine into the caudal ventrolateral medulla of the rat. Brain Res. 2001;892(1):138-146. 
27. Levin ED, Bettegowda C, Blosser J, Gordon J. AR-R17779, and alpha7 nicotinic agonist, improves learning and memory in rats. Behav Pharmacol. 1999;10(6-7):675-680.

28. Hajos M, Hurst RS, Hoffmann WE, Krause M, Wall TM, Higdon NR, Groppi VE. The selective alpha7 nicotinic acetylcholine receptor agonist PNU-282987 [N-[(3R)-1-Azabicyclo[2.2.2]oct-3-yl]-4-chlorobenzamide hydrochloride] enhances GABAergic synaptic activity in brain slices and restores auditory gating deficits in anesthetized rats. J Pharmacol Exp Ther. 2005;312(3):12131222.

29. Salas R, Orr-Urtreger A, Broide RS, Beaudet A, Paylor R, De Biasi M. The nicotinic acetylcholine receptor subunit alpha 5 mediates short-term effects of nicotine in vivo. Mol Pharmacol. 2003;63(5):1059-1066.

30. Henningfield JE, Stapleton JM, Benowitz NL, Grayson RF, London ED. Higher levels of nicotine in arterial than in venous blood after cigarette smoking. Drug Alcohol Depend. 1993;33(1):23-29.

31. Hukkanen J, Jacob P, 3rd, Benowitz NL. Metabolism and disposition kinetics of nicotine. Pharmacol Rev. 2005;57(1):79-115.

32. Dempsey D, Tutka P, Jacob P, 3rd, Allen F, Schoedel K, Tyndale RF, Benowitz NL. Nicotine metabolite ratio as an index of cytochrome P450 2A6 metabolic activity. Clin Pharmacol Ther. 2004;76(1):64-72.

33. Allenby CE, Boylan KA, Lerman C, Falcone M. Precision Medicine for Tobacco Dependence: Development and Validation of the Nicotine Metabolite Ratio. J Neuroimmune Pharmacol. 2016;11(3):471-483.

34. Llaquet H, Pichini S, Joya X, Papaseit E, Vall O, Klein J, Garcia-Algar O. Biological matrices for the evaluation of exposure to environmental tobacco smoke during prenatal life and childhood. Anal Bioanal Chem. 2010;396(1):379399.

35. Reichert J AA, Gonçalves CMC, Godoy I, Chatkin JM, Sales MPU et al. Diretrizes da Sociedade Brasileira de Pneumologia e Tisologia: Diretrizes para cessação do tabagismo - 2008*. J Bras Pneumol. 2008;34(10):845-880.

36. Fiore MC, Jae'n C. R., Baker T.B. Treating tobacco use and dependence: 2008 update. Clinical Practice Guideline. In: services USDohah, ed. Public Health Service. Rockville (md); 2008.

37. Kassem MG, Al Hossaini AM. Varenicline. Profiles Drug Subst Excip Relat Methodol. 2012;37:389-411.

38. Zoli M, Lena C, Picciotto MR, Changeux JP. Identification of four classes of brain nicotinic receptors using beta2 mutant mice. $J$ Neurosci. 1998;18(12):4461-4472. 
39. Hogg RC, Raggenbass M, Bertrand D. Nicotinic acetylcholine receptors: from structure to brain function. Rev Physiol Biochem Pharmacol. 2003;147:1-46.

40. Mihalak KB, Carroll FI, Luetje CW. Varenicline is a partial agonist at alpha4beta2 and a full agonist at alpha7 neuronal nicotinic receptors. Mol Pharmacol. 2006;70(3):801-805.

41. Swan GE, Javitz HS, Jack LM, Wessel J, Michel M, Hinds DA, Stokowksi RP, McClure JB, Catz SL, Richards J, Zbikowski SM, Deprey M, McAfee T, Conti DV, Bergen AW. Varenicline for smoking cessation: nausea severity and variation in nicotinic receptor genes. Pharmacogenomics J. 2012;12(4):349-358.

42. Kaur K, Kaushal S, Chopra SC. Varenicline for smoking cessation: A review of the literature. Curr Ther Res Clin Exp. 2009;70(1):35-54.

43. Catz SL, Jack LM, McClure JB, Javitz HS, Deprey M, Zbikowski SM, McAfee T, Richards J, Swan GE. Adherence to varenicline in the COMPASS smoking cessation intervention trial. Nicotine Tob Res. 2011;13(5):361-368.

44. Faessel HM, Burstein AH, Troutman MD, Willavize SA, Rohrbacher KD, Clark DJ. Lack of a pharmacokinetic interaction between a new smoking cessation therapy, varenicline, and digoxin in adult smokers. Eur J Clin Pharmacol. 2008;64(11):1101-1109.

45. Mohanasundaram UM, Chitkara R, Krishna G. Smoking cessation therapy with varenicline. Int J Chron Obstruct Pulmon Dis. 2008;3(2):239-251.

46. Faessel HM, Smith BJ, Gibbs MA, Gobey JS, Clark DJ, Burstein AH. Singledose pharmacokinetics of varenicline, a selective nicotinic receptor partial agonist, in healthy smokers and nonsmokers. J Clin Pharmacol. 2006;46(9):991998.

47. Faessel HM, Obach RS, Rollema H, Ravva P, Williams KE, Burstein AH. A review of the clinical pharmacokinetics and pharmacodynamics of varenicline for smoking cessation. Clin Pharmacokinet. 2010;49(12):799-816.

48. Ravva P, Gastonguay MR, Tensfeldt TG, Faessel HM. Population pharmacokinetic analysis of varenicline in adult smokers. Br J Clin Pharmacol. 2009;68(5):669-681.

49. Obach RS, Reed-Hagen AE, Krueger SS, Obach BJ, O'Connell TN, Zandi KS, Miller S, Coe JW. Metabolism and disposition of varenicline, a selective alpha4beta2 acetylcholine receptor partial agonist, in vivo and in vitro. Drug Metab Dispos. 2006;34(1):121-130.

50. Feng B, Obach RS, Burstein AH, Clark DJ, de Morais SM, Faessel HM. Effect of human renal cationic transporter inhibition on the pharmacokinetics of varenicline, a new therapy for smoking cessation: an in vitro-in vivo study. Clin Pharmacol Ther. 2008;83(4):567-576. 
51. Faessel HM, Gibbs MA, Clark DJ, Rohrbacher K, Stolar M, Burstein AH. Multiple-dose pharmacokinetics of the selective nicotinic receptor partial agonist, varenicline, in healthy smokers. J Clin Pharmacol. 2006;46(12):14391448.

52. Slemmer JE, Martin BR, Damaj MI. Bupropion is a nicotinic antagonist. $J$ Pharmacol Exp Ther. 2000;295(1):321-327.

53. Hughes JR, Stead LF, Lancaster T. Antidepressants for smoking cessation. Cochrane Database Syst Rev. 2007(1):CD000031.

54. Goodnick PJ. Pharmacokinetics of second generation antidepressants: bupropion. Psychopharmacol Bull. 1991;27(4):513-519.

55. Hesse LM, Venkatakrishnan K, Court MH, von Moltke LL, Duan SX, Shader RI, Greenblatt DJ. CYP2B6 mediates the in vitro hydroxylation of bupropion: potential drug interactions with other antidepressants. Drug Metab Dispos. 2000;28(10):1176-1183.

56. Faucette SR, Hawke RL, Lecluyse EL, Shord SS, Yan B, Laethem RM, Lindley CM. Validation of bupropion hydroxylation as a selective marker of human cytochrome P450 2B6 catalytic activity. Drug Metab Dispos. 2000;28(10):12221230.

57. Walsky RL, Astuccio AV, Obach RS. Evaluation of 227 drugs for in vitro inhibition of cytochrome P450 2B6. J Clin Pharmacol. 2006;46(12):1426-1438.

58. Walsky RL, Obach RS. A comparison of 2-phenyl-2-(1-piperidinyl)propane (ppp), 1,1',1"-phosphinothioylidynetrisaziridine (thioTEPA), clopidogrel, and ticlopidine as selective inactivators of human cytochrome P450 2B6. Drug Metab Dispos. 2007;35(11):2053-2059.

59. Quaak M, van Schooten FJ, van Schayck CP. Pharmacogenetics of smoking: how far to the clinic? Pharmacogenomics. 2014;15(6):723-726.

60. Swan GE, Lessov-Schlaggar CN. Tobacco addiction and pharmacogenetics of nicotine metabolism. J Neurogenet. 2009;23(3):262-271.

61. Tomaz PRX, Kajita MS, Santos JR, Scholz J, Abe TO, Gaya PV, Krieger JE, Pereira AC, Santos P. Cytochrome P450 2A6 and 2B6 polymorphisms and smoking cessation success in patients treated with varenicline. Eur J Clin Pharmacol.2019;75(11):1541-1545.

62. Tomaz PRX, Santos JR, Scholz J, Abe TO, Gaya PV, Negrao AB, Krieger JE, Pereira AC, Santos P. Cholinergic receptor nicotinic alpha 5 subunit polymorphisms are associated with smoking cessation success in women. BMC Med Genet.2018;19(1):55. 
63. Scholz J, Santos PC, Buzo CG, Lopes NH, Abe TO, Gaya PV, Pierri H, Amorim C, Pereira AC. Effects of aging on the effectiveness of smoking cessation medication. Oncotarget. 2016;7(21):30032-30036.

64. Issa JS, Santos PC, Vieira LP, Abe TO, Kuperszmidt CS, Nakasato M, Cardoso E, Amorim C, Pereira AC. Smoking cessation and weight gain in patients with cardiovascular disease or risk factor. Int J Cardiol. 2014;172(2):485-487.

65. King DP, Paciga S, Pickering E, Benowitz NL, Bierut LJ, Conti DV, Kaprio J, Lerman C, Park PW. Smoking cessation pharmacogenetics: analysis of varenicline and bupropion in placebo-controlled clinical trials. Neuropsychopharmacology. 2012;37(3):641-650.

66. Saccone NL, Baurley JW, Bergen AW, David SP, Elliott HR, Foreman MG, Kaprio J, Piasecki TM, Relton CL, Zawertailo L, Bierut LJ, Tyndale RF, Chen LS. The Value of Biosamples in Smoking Cessation Trials: A Review of Genetic, Metabolomic, and Epigenetic Findings. Nicotine Tob Res. 2018;20(4):403-413.

67. Rocha Santos J, Tomaz PR, Issa JS, Abe TO, Krieger JE, Pereira AC, Santos PC. CHRNA4 rs1044396 is associated with smoking cessation in varenicline therapy. Front Genet. 2015;6:46.

68. Tomaz PR, Santos JR, Issa JS, Abe TO, Gaya PV, Krieger JE, Pereira AC, Santos PC. CYP2B6 rs2279343 polymorphism is associated with smoking cessation success in bupropion therapy. Eur J Clin Pharmacol. 2015; 71(9):1067-73.

69. David SP, Brown RA, Papandonatos GD, Kahler CW, Lloyd-Richardson EE, Munafo MR, Shields PG, Lerman C, Strong D, McCaffery J, Niaura R. Pharmacogenetic clinical trial of sustained-release bupropion for smoking cessation. Nicotine Tob Res. 2007;9(8):821-833.

70. Lerman C, Shields PG, Wileyto EP, Audrain J, Pinto A, Hawk L, Krishnan S, Niaura R, Epstein L. Pharmacogenetic investigation of smoking cessation treatment. Pharmacogenetics. 2002;12(8):627-634.

71. Han DH, Joe KH, Na C, Lee YS. Effect of genetic polymorphisms on smoking cessation: a trial of bupropion in Korean male smokers. Psychiatr Genet. 2008;18(1):11-16.

72. Zanger UM, Klein K. Pharmacogenetics of cytochrome P450 2B6 (CYP2B6): advances on polymorphisms, mechanisms, and clinical relevance. Front Genet. $2013 ; 4: 24$.

73. Zhu AZ, Cox LS, Nollen N, Faseru B, Okuyemi KS, Ahluwalia JS, Benowitz NL, Tyndale RF. CYP2B6 and bupropion's smoking-cessation pharmacology: the role of hydroxybupropion. Clin Pharmacol Ther. 2012;92(6):771-777. 
74. Laib AK, Brunen S, Pfeifer P, Vincent P, Hiemke C. Serum concentrations of hydroxybupropion for dose optimization of depressed patients treated with bupropion. Ther Drug Monit. 2014;36(4):473-479.

75. Hutchison KE, Allen DL, Filbey FM, Jepson C, Lerman C, Benowitz NL, Stitzel J, Bryan A, McGeary J, Haughey HM. CHRNA4 and tobacco dependence: from gene regulation to treatment outcome. Arch Gen Psychiatry. 2007;64(9):10781086.

76. Smith RC, Zhubi A, Maloku E, Sershen H, Lajtha A, Davis JM, Costa E, Guidotti A. Varenicline treatment decreases DNMT1 mRNA expression in lymphocytes of schizophrenic patients who are cigarette smokers. Schizophr Res. 2010;119(1-3):269-270.

77. Marks MJ, O'Neill HC, Wynalda-Camozzi KM, Ortiz NC, Simmons EE, Short CA, Butt CM, McIntosh JM, Grady SR. Chronic treatment with varenicline changes expression of four $\mathrm{nAChR}$ binding sites in mice. Neuropharmacology. 2015;99:142-155.

78. Middleton FA, Pato CN, Gentile KL, McGann L, Brown AM, Trauzzi M, Diab H, Morley CP, Medeiros H, Macedo A, Azevedo MH, Pato MT. Gene expression analysis of peripheral blood leukocytes from discordant sib-pairs with schizophrenia and bipolar disorder reveals points of convergence between genetic and functional genomic approaches. Am J Med Genet B Neuropsychiatr Genet. 2005;136B(1):12-25.

79. Takahashi M, Hayashi H, Watanabe Y, Sawamura K, Fukui N, Watanabe J, Kitajima T, Yamanouchi Y, Iwata N, Mizukami K, Hori T, Shimoda K, Ujike H, Ozaki N, Iijima $\mathrm{K}$, Takemura $\mathrm{K}$, Aoshima $\mathrm{H}$, Someya $\mathrm{T}$. Diagnostic classification of schizophrenia by neural network analysis of blood-based gene expression signatures. Schizophr Res. 2010;119(1-3):210-218.

80. Lee J, Goh LK, Chen G, Verma S, Tan CH, Lee TS. Analysis of blood-based gene expression signature in first-episode psychosis. Psychiatry Res. 2012;200(1):52-54.

81. Sullivan PF, Fan C, Perou CM. Evaluating the comparability of gene expression in blood and brain. Am $J$ Med Genet $B$ Neuropsychiatr Genet. 2006;141B(3):261-268.

82. Hennings JM, Uhr M, Klengel T, Weber P, Putz B, Touma C, Czamara D, Ising M, Holsboer F, Lucae S. RNA expression profiling in depressed patients suggests retinoid-related orphan receptor alpha as a biomarker for antidepressant response. Transl Psychiatry. 2015;5:e538.

83. Ota VK, Noto C, Gadelha A, Santoro ML, Silva PN, Melaragno MI, Smith Mde A, Cordeiro Q, Bressan RA, Belangero SI. Neurotransmitter receptor and regulatory gene expression in peripheral blood of Brazilian drug-naive first- 
episode psychosis patients before and after antipsychotic treatment. Psychiatry Res.2013;210(3):1290-1292.

84. Kordi-Tamandani DM, Tajoddini S, Salimi F. Promoter Methylation and BDNF and DAT1 Gene Expression Profiles in Patients with Drug Addiction. Pathobiology. 2015;82(2):94-99.

85. Wongsriraksa A, Parsons ME, Whelan CJ. Characterisation of nicotine receptors on human peripheral blood mononuclear cells (PBMC). Inflamm Res. 2009;58(1):38-44.

86. Kawashima K, Fujii T. Expression of non-neuronal acetylcholine in lymphocytes and its contribution to the regulation of immune function. Front Biosci. 2004;9:2063-2085.

87. St-Pierre S, Jiang W, Roy P, Champigny C, LeBlanc E, Morley BJ, Hao J, Simard AR. Nicotinic Acetylcholine Receptors Modulate Bone Marrow-Derived Pro-Inflammatory Monocyte Production and Survival. PLoS One. 2016;11(2):e0150230.

88. Zdanowski R, Krzyzowska M, Ujazdowska D, Lewicka A, Lewicki S. Role of alpha7 nicotinic receptor in the immune system and intracellular signaling pathways. Cent Eur J Immunol. 2015;40(3):373-379.

89. Baez-Pagan CA, Delgado-Velez M, Lasalde-Dominicci JA. Activation of the Macrophage alpha7 Nicotinic Acetylcholine Receptor and Control of Inflammation. J Neuroimmune Pharmacol. 2015;10(3):468-476.

90. Kalkman HO, Feuerbach D. Modulatory effects of alpha7 nAChRs on the immune system and its relevance for CNS disorders. Cell Mol Life Sci. 2016;73(13):2511-2530.

91. Zakrzewicz A, Richter K, Agne A, Wilker S, Siebers K, Fink B, Krasteva-Christ G, Althaus M, Padberg W, Hone AJ, McIntosh JM, Grau V. Canonical and Novel Non-Canonical Cholinergic Agonists Inhibit ATP-Induced Release of Monocytic Interleukin-1beta via Different Combinations of Nicotinic Acetylcholine Receptor Subunits alpha7, alpha9 and alpha10. Front Cell Neurosci.2017;11:189.

92. Arreola R, Alvarez-Herrera S, Perez-Sanchez G, Becerril-Villanueva E, CruzFuentes C, Flores-Gutierrez EO, Garces-Alvarez ME, de la Cruz-Aguilera DL, Medina-Rivero E, Hurtado-Alvarado G, Quintero-Fabian S, Pavon L. Immunomodulatory Effects Mediated by Dopamine. $J$ Immunol Res.2016:3160486.

93. Nakajima M, Yamamoto T, Nunoya K, Yokoi T, Nagashima K, Inoue K, Funae Y, Shimada N, Kamataki T, Kuroiwa Y. Role of human cytochrome P4502A6 in C-oxidation of nicotine. Drug Metab Dispos. 1996;24(11):1212-1217. 
94. Messina ES, Tyndale RF, Sellers EM. A major role for CYP2A6 in nicotine Coxidation by human liver microsomes. $J$ Pharmacol Exp Ther. 1997;282(3):1608-1614.

95. Chen A, Krebs NM, Zhu J, Muscat JE. Nicotine metabolite ratio predicts smoking topography: The Pennsylvania Adult Smoking Study. Drug Alcohol Depend.2018;190:89-93.

96. Shahab L BL, McNeill, Tyndale RF. Does the nicotine metabolite ratio moderate smoking cessation treatment outcomes in real-world settings? A prospective study. Addiction. 2019;114(2):304-314. doi: 10.1111/add.14450.

97. Lea RA, Dickson S, Benowitz NL. Within-subject variation of the salivary 3HC/COT ratio in regular daily smokers: prospects for estimating CYP2A6 enzyme activity in large-scale surveys of nicotine metabolic rate. J Anal Toxicol. 2006;30(6):386-389.

98. Mooney ME, Li ZZ, Murphy SE, Pentel PR, Le C, Hatsukami DK. Stability of the nicotine metabolite ratio in ad libitum and reducing smokers. Cancer Epidemiol Biomarkers Prev. 2008;17(6):1396-1400.

99. Piestansky J, Marakova K, Veizerova L, Galba J, Mikus P. On-line column coupled isotachophoresis-capillary zone electrophoresis hyphenated with tandem mass spectrometry in drug analysis: varenicline and its metabolite in human urine. Anal Chim Acta 2014;826:84-93.

100. Fagerstrom KO, Heatherton TF, Kozlowski LT. Nicotine addiction and its assessment. Ear Nose Throat J. 1990;69(11):763-765.

101. Issa JS. A new nicotine dependence score and a new scale assessing patient comfort during smoking cessation treatment. J Bras Pneumol. 2012;38(6):761765.

102. Mexal S, Berger R, Logel J, Ross RG, Freedman R, Leonard S. Differential regulation of alpha7 nicotinic receptor gene (CHRNA7) expression in schizophrenic smokers. J Mol Neurosci. 2010;40(1-2):185-195.

103. Livak KJ, Schmittgen TD. Analysis of relative gene expression data using realtime quantitative PCR and the 2(-Delta Delta C(T)) Method. Methods. 2001;25(4):402-408.

104. Abdallah IA, Hammell DC, Stinchcomb AL, Hassan HE. A fully validated LCMS/MS method for simultaneous determination of nicotine and its metabolite cotinine in human serum and its application to a pharmacokinetic study after using nicotine transdermal delivery systems with standard heat application in adult smokers. J Chromatogr B Analyt Technol Biomed Life Sci. 2016;1020:6777. 
105. Al-Haj A, Alawi M, Arafat T, Hourani MK. Method development, validation and bioequivalence of varenicline in human plasma by liquid chromatography tandem mass spectrometry. J Chromatogr B Analyt Technol Biomed Life Sci. 2013;931:134-139.

106. Hegstad S, Stray-Pedersen A, Olsen L, Vege A, Rognum TO, Morland J, Christophersen AS. Determination of cotinine in pericardial fluid and whole blood by liquid chromatography-tandem mass spectrometry. J Anal Toxicol. 2009;33(4):218-222.

107. Santos MG, Moraes Gde O, Nakamura MG, dos Santos-Neto AJ, Figueiredo EC. Restricted access molecularly imprinted polymers obtained by bovine serum albumin and/or hydrophilic monomers' external layers: a comparison related to physical and chemical properties. Analyst. 2015;140(22):7768-7775.

108. de Lima MM, Vieira AC, Martins I, Boralli VB, Borges KB, Figueiredo EC. On-line restricted access molecularly imprinted solid phase extraction of ivermectin in meat samples followed by HPLC-UV analysis. Food Chem. 2015;197(Pt A):7-13.

109. Barbosa AF, Barbosa VM, Bettini J, Luccas PO, Figueiredo EC. Restricted access carbon nanotubes for direct extraction of cadmium from human serum samples followed by atomic absorption spectrometry analysis. Talanta. 2016;131:213-220.

110. de Faria HD, Abrao LC, Santos MG, Barbosa AF, Figueiredo EC. New advances in restricted access materials for sample preparation: A review. Anal Chim Acta. 2017;959:43-65.

111. FRANQUI, L. S. et al. Synthesis and characterization of a magnetic molecularly imprinted polymer for the selective extraction of nicotine and cotinine from urine samples followed by GC-MS analysis. Anal. Methods. 2015; 7(21): 92379244, 2015.

112. Santos MG, Tavares IM, Barbosa AF, Bettini J, Figueiredo EC. Analysis of tricyclic antidepressants in human plasma using online-restricted access molecularly imprinted solid phase extraction followed by direct mass spectrometry identification/quantification. Talanta. 2017;163:8-16.

113. U.S. Department of Health and Human Services; Food and Drug Administration (FDA), Center for Drug Evaluation and Research (CDER),Center for Veterinary Medicine (CVM). Guidance for Industry:Bioanalytical method validation. Biopharmaceutics. 2013.

114. GOMES, Raphael A. B. et al. Evaluation of the $\mathrm{pH}$ influence on protein exclusion by restricted access carbono nanotubes coated with bovine serum albumin. Journal Of Materials Science. 2016; 51(16):7407-7414. 
115. de Faria HD, Rosa MA, Silveira AT, Figueiredo EC. Direct extraction of tetracyclines from bovine milk using restricted access carbon nanotubes in a column switching liquid chromatography system. Food Chem. 2017;225:98-106.

116. de Faria HD, Bueno CT, Krieger JE, Krieger EM, Pereira AC, Santos P, Figueiredo EC. Online extraction of antihypertensive drugs and their metabolites from untreated human serum samples using restricted access carbon nanotubes in a column switching liquid chromatography system. J Chromatogr A. 2017;1528:41-52.

117. Petersen GO, Leite CE, Chatkin JM, Thiesen FV. Cotinine as a biomarker of tobacco exposure: development of a HPLC method and comparison of matrices. J Sep Sci. 2010;33(4-5):516-521.

118. Brunen S, Vincent PD, Baumann P, Hiemke C, Havemann-Reinecke U. Therapeutic drug monitoring for drugs used in the treatment of substance-related disorders: literature review using a therapeutic drug monitoring appropriateness rating scale. Ther Drug Monit. 2011;33(5):561-572.

119. Ryan RE, Loiacono RE. Nicotine regulates alpha7 nicotinic receptor subunit mRNA: implications for nicotine dependence. Neuroreport. 2001;12(3):569572.

120. Cameli C, Bacchelli E, De Paola M, Giucastro G, Cifiello S, Collo G, Cainazzo MM, Pini LA, Maestrini E, Zoli M. Genetic variation in CHRNA7 and CHRFAM7A is associated with nicotine dependence and response to varenicline treatment. Eur J Hum Genet. 2018;26(12):1824-1831.

121. Wallace TL, Bertrand D. Importance of the nicotinic acetylcholine receptor system in the prefrontal cortex. Biochem Pharmacol. 2013;85(12):1713-1720.

122. Dempster EL, Toulopoulou T, McDonald C, Bramon E, Walshe M, Wickham H, Sham PC, Murray RM, Collier DA. Episodic memory performance predicted by the $2 \mathrm{bp}$ deletion in exon 6 of the "alpha 7-like" nicotinic receptor subunit gene. Am J Psychiatry. 2006;163(10):1832-1834.

123. Enioutina EY, Myers EJ, Tvrdik P, Hoidal JR, Rogers SW, Gahring LC. The nicotinic receptor Alpha7 impacts the mouse lung response to LPS through multiple mechanisms. PLoS One. 2015;10(3):e0121128.

124. Sinkus ML, Graw S, Freedman R, Ross RG, Lester HA, Leonard S. The human CHRNA7 and CHRFAM7A genes: A review of the genetics, regulation, and function. Neuropharmacology. 2015;96(Pt B):274-288.

125. Gault J, Robinson M, Berger R, Drebing C, Logel J, Hopkins J, Moore T, Jacobs S, Meriwether J, Choi MJ, Kim EJ, Walton K, Buiting K, Davis A, Breese C, Freedman R, Leonard S. Genomic organization and partial duplication of the human alpha7 neuronal nicotinic acetylcholine receptor gene (CHRNA7). Genomics. 1998;52(2):173-185. 
126. Riley B, Williamson M, Collier D, Wilkie H, Makoff A. A 3-Mb map of a large Segmental duplication overlapping the alpha7-nicotinic acetylcholine receptor gene (CHRNA7) at human 15q13-q14. Genomics. 2002;79(2):197-209.

127. Benhammou K, Lee M, Strook M, Sullivan B, Logel J, Raschen K, Gotti C, Leonard S. [(3)H]Nicotine binding in peripheral blood cells of smokers is correlated with the number of cigarettes smoked per day. Neuropharmacology. 2000;39(13):2818-2829.

128. Kunii Y, Zhang W, Xu Q, Hyde TM, McFadden W, Shin JH, Deep-Soboslay A, Ye T, Li C, Kleinman JE, Wang KH, Lipska BK. CHRNA7 and CHRFAM7A mRNAs: co-localized and their expression levels altered in the postmortem dorsolateral prefrontal cortex in major psychiatric disorders. Am J Psychiatry. 2015;172(11):1122-1130.

129. Breese CR, Lee MJ, Adams CE, Sullivan B, Logel J, Gillen KM, Marks MJ, Collins AC, Leonard S. Abnormal regulation of high affinity nicotinic receptors in subjects with schizophrenia. Neuropsychopharmacology. 2000;23(4):351364.

130. Freedman R, Hall M, Adler LE, Leonard S. Evidence in postmortem brain tissue for decreased numbers of hippocampal nicotinic receptors in schizophrenia. Biol Psychiatry. 1995;38(1):22-33.

131. Guan ZZ, Zhang X, Blennow K, Nordberg A. Decreased protein level of nicotinic receptor alpha7 subunit in the frontal cortex from schizophrenic brain. Neuroreport. 1999;10(8):1779-1782.

132. Martin-Ruiz CM, Haroutunian VH, Long P, Young AH, Davis KL, Perry EK, Court JA. Dementia rating and nicotinic receptor expression in the prefrontal cortex in schizophrenia. Biol Psychiatry. 2003;54(11):1222-1233.

133. Marutle A, Zhang X, Court J, Piggott M, Johnson M, Perry R, Perry E, Nordberg A. Laminar distribution of nicotinic receptor subtypes in cortical regions in schizophrenia. J Chem Neuroanat. 2001;22(1-2):115-126.

134. Leonard S, Breese C, Adams C, Benhammou K, Gault J, Stevens K, Lee M, Adler L, Olincy A, Ross R, Freedman R. Smoking and schizophrenia: abnormal nicotinic receptor expression. Eur J Pharmacol. 2000;393(1-3):237-242.

135. Kumari V, Postma P. Nicotine use in schizophrenia: the self medication hypotheses. Neurosci Biobehav Rev. 2005;29(6):1021-1034.

136. de Leon J, Diaz FJ. A meta-analysis of worldwide studies demonstrates an association between schizophrenia and tobacco smoking behaviors. Schizophr Res. 2005;76(2-3):135-157. 
137. Flomen RH, Collier DA, Osborne S, Munro J, Breen G, St Clair D, Makoff AJ. Association study of CHRFAM7A copy number and 2 bp deletion polymorphisms with schizophrenia and bipolar affective disorder. Am J Med Genet B Neuropsychiatr Genet. 2006;141B(6):571-575.

138. Gault J, Hopkins J, Berger R, Drebing C, Logel J, Walton C, Short M, Vianzon R, Olincy A, Ross RG, Adler LE, Freedman R, Leonard S. Comparison of polymorphisms in the alpha7 nicotinic receptor gene and its partial duplication in schizophrenic and control subjects. Am J Med Genet B Neuropsychiatr Genet. 2003;123B(1):39-49.

139. Perl O, Strous RD, Dranikov A, Chen R, Fuchs S. Low levels of alpha7nicotinic acetylcholine receptor mRNA on peripheral blood lymphocytes in schizophrenia and its association with illness severity. Neuropsychobiology. 2006;53(2):88-93.

140. Raux G, Bonnet-Brilhault F, Louchart S, Houy E, Gantier R, Levillain D, Allio G, Haouzir S, Petit M, Martinez M, Frebourg T, Thibaut F, Campion D. The -2 bp deletion in exon 6 of the 'alpha 7-like' nicotinic receptor subunit gene is a risk factor for the P50 sensory gating deficit. Mol Psychiatry. 2002;7(9):1006-1011.

141. Leonard S, Gault J, Hopkins J, Logel J, Vianzon R, Short M, Drebing C, Berger R, Venn D, Sirota P, Zerbe G, Olincy A, Ross RG, Adler LE, Freedman R. Association of promoter variants in the alpha7 nicotinic acetylcholine receptor subunit gene with an inhibitory deficit found in schizophrenia. Arch Gen Psychiatry. 2002;59(12):1085-1096.

142. Mathew SV, Law AJ, Lipska BK, Davila-Garcia MI, Zamora ED, Mitkus SN, Vakkalanka R, Straub RE, Weinberger DR, Kleinman JE, Hyde TM. Alpha7 nicotinic acetylcholine receptor mRNA expression and binding in postmortem human brain are associated with genetic variation in neuregulin 1. Hum Mol Genet. 2007;16(23):2921-2932.

143. Severance EG, Yolken RH. Novel alpha7 nicotinic receptor isoforms and deficient cholinergic transcription in schizophrenia. Genes Brain Behav. 2008;7(1):37-45.

144. Severance EG, Dickerson FB, Stallings CR, Origoni AE, Sullens A, Monson ET, Yolken RH. Differentiating nicotine- versus schizophrenia-associated decreases of the alpha7 nicotinic acetylcholine receptor transcript, CHRFAM7A, in peripheral blood lymphocytes. J Neural Transm (Vienna). 2009;116(2):213220.

145. Olincy A, Freedman R. Nicotinic mechanisms in the treatment of psychotic disorders: a focus on the alpha7 nicotinic receptor. Handb Exp Pharmacol. 2012; (213):211-232.

146. Kariminejad A, Almadani N, Khoshaeen A, Olsson B, Moslemi AR, Tajsharghi H. Truncating CHRNG mutations associated with interfamilial variability of the 
severity of the Escobar variant of multiple pterygium syndrome. $B M C$ Genet.2016;17(1):71.

147. Liu Y, Wang L, Yang YK, Liang Y, Zhang TJ, Liang N, Yang LM, Li SJ, Shan D, Wu QQ. Prenatal diagnosis of fetal skeletal dysplasia using targeted nextgeneration sequencing: an analysis of 30 cases. Diagn Pathol. 2019;14(1):76.

148. Natera-de Benito D, Topf A, Vilchez JJ, Gonzalez-Quereda L, DominguezCarral J, Diaz-Manera J, Ortez C, Bestue M, Gallano P, Dusl M, Abicht A, Muller JS, Senderek J, Garcia-Ribes A, Muelas N, Evangelista T, Azuma Y, McMacken G, Paipa Merchan A, Rodriguez Cruz PM, Camacho A, Jimenez E, Miranda-Herrero MC, Santana-Artiles A, Garcia-Campos O, Dominguez-Rubio R, Olive M, Colomer J, Beeson D, Lochmuller H, Nascimento A. Molecular characterization of congenital myasthenic syndromes in Spain. Neuromuscul Disord. 2017;27(12):1087-1098.

149. Seo J, Choi IH, Lee JS, Yoo Y, Kim NK, Choi M, Ko JM, Shin YB. Rare cases of congenital arthrogryposis multiplex caused by novel recurrent CHRNG mutations. J Hum Genet. 2015;60(4):213-215.

150. Keskitalo-Vuokko K, Pitkaniemi J, Broms U, Heliovaara M, Aromaa A, Perola M, Ripatti S, Salminen O, Salomaa V, Loukola A, Kaprio J. Associations of nicotine intake measures with CHRN genes in Finnish smokers. Nicotine Tob Res.2011;13(8):686-690.

151. Saccone NL, Saccone SF, Hinrichs AL, Stitzel JA, Duan W, Pergadia ML, Agrawal A, Breslau N, Grucza RA, Hatsukami D, Johnson EO, Madden PA, Swan GE, Wang JC, Goate AM, Rice JP, Bierut LJ. Multiple distinct risk loci for nicotine dependence identified by dense coverage of the complete family of nicotinic receptor subunit (CHRN) genes. Am J Med Genet B Neuropsychiatr Genet. 2009;150B(4):453-466.

152. Saccone NL, Schwantes-An TH, Wang JC, Grucza RA, Breslau N, Hatsukami D, Johnson EO, Rice JP, Goate AM, Bierut LJ. Multiple cholinergic nicotinic receptor genes affect nicotine dependence risk in African and European Americans. Genes Brain Behav. 2010;9(7):741-750.

153. Santoro ML, Ota VK, Stilhano RS, Silva PN, Santos CM, Diana MC, Gadelha A, Bressan RA, Melaragno MI, Han SW, Abilio VC, Belangero SI. Effect of antipsychotic drugs on gene expression in the prefrontal cortex and nucleus accumbens in the spontaneously hypertensive rat (SHR). Schizophr Res. 2014;157(1-3):163-168.

154. Kuhn J, Vollmer T, Martin C, Hendig D, Knabbe C. Fast and sample cleanupfree measurement of nicotine and cotinine by stable isotope dilution ultraperformance liquid chromatography-tandem mass spectrometry. $J$ Pharm Biomed Anal. 2012;67-68:137-143. 
155. Scherf-Clavel M, Wahl O, Menke A, Unterecker S. Determination of hydroxybupropion in human serum for routine therapeutic drug monitoring in psychiatry: A tool for dose-individualization in treatment with bupropion. Biomed Chromatogr. 2019;33(10):e4609.

156. Dobrinas $M$, Choong E, Noetzli M, Cornuz J, Ansermot N, Eap CB. Quantification of nicotine, cotinine, trans-3'-hydroxycotinine and varenicline in human plasma by a sensitive and specific UPLC-tandem mass-spectrometry procedure for a clinical study on smoking cessation. J Chromatogr B Analyt Technol Biomed Life Sci. 2011;879(30):3574-3582.

157. Onoue S, Yamamoto N, Seto Y, Yamada S. Pharmacokinetic study of nicotine and its metabolite cotinine to clarify possible association between smoking and voiding dysfunction in rats using UPLC/ESI-MS. Drug Metab Pharmacokinet. 2011;26(4):416-422.

158. Petrides AK, Moskowitz J, Johnson-Davis KL, Jannetto PJ, Langman LJ, Clarke $\mathrm{W}$, Marzinke MA. The development and validation of a turbulent flow-liquid chromatography-tandem mass spectrometric method for the simultaneous quantification of citalopram, sertraline, bupropion and hydroxybupropion in serum. Clin Biochem. 2014;47(15):73-79. 
APÊNDICE - TCLE

\section{TERMO DE CONSENTIMENTO LIVRE E ESCLARECIDO}

\section{HOSPITAL dAS CLÍNICAS dA FACULDADE DE MEDICINA dA UNIVERSIDADE DE SÃo PAULO-HCFMUSP}

\section{Registro das explicações do pesquisador ao paciente ou seu representante legal sobre a pesquisa, consignando:}

Você está sendo convidado (a) a participar de um projeto de pesquisa. Este projeto tem como objetivos principais, para os indivíduos fumantes submetidos aos tratamentos farmacológicos antitabagismo, associar o efeito das características genéticas (DNA ou RNA) e do metabolismo (concentração dos produtos de metabolismo dos medicamentos no sangue) com a eficiência do tratamento antitabagismo. O objetivo do estudo é saber por que algumas pessoas respondem bem aos medicamentos antitabagismo, enquanto outras pessoas não respondem e consequentemente não conseguem parar de fumar. Para isto, precisaremos de amostras de sangue, cuja quantidade é comumente solicitada em exames laboratoriais de rotina (2 tubos a cada visita $=20 \mathrm{~mL}$ ). Precisaremos também, do seu consentimento para que dados de seu prontuário médico sejam consultados. Para os pacientes que utilizarão o medicamento bupropiona, precisaremos de amostras de sangue na primeira consulta (visita T-1) e duas semanas após o início do tratamento medicamentoso (visita T2). Para os pacientes que utilizarão o medicamento vareniclina, precisaremos de uma amostra de sangue na primeira consulta (visita $\mathrm{T}-1$ ), na segunda consulta - ainda antes de iniciar o tratamento com medicamento (visita T0), duas semanas após o início do tratamento medicamentoso (visita T2) e quatro semanas após o início do tratamento medicamentoso (visita T4). Os desconfortos mais comuns que podem ocorrer com sua participação neste estudo são os mesmos de uma coleta de sangue no braço, por exemplo, leve dor no local da punção e, eventualmente, hematoma local. Este sangue será encaminhado ao Laboratório de Genética e Cardiologia Molecular do Instituto do Coração onde será armazenado somente para a pesquisa. Sua participação é totalmente voluntária. Após ler entender e esclarecer suas dúvidas você assinará 2 vias de igual teor desse documento (termo de consentimento Livre e Esclarecido). Ainda, você poderá solicitar o seu desligamento deste projeto a qualquer momento bastando para tal entrar em contato os pesquisadores no tel (11) 2661-5592 ou 2661-5995. Em qualquer etapa do estudo, você terá acesso aos profissionais responsáveis pela pesquisa para esclarecimento de eventuais dúvidas. O pesquisador responsável é a Dra Jaqueline Scholz, que pode ser encontrada no endereço Av. Dr. Enéas de Carvalho Aguiar, 44, Instituto do Coração, Bloco 2, andar 1, Programa Ambulatorial de Tratamento Tabagismo INCOR-HCFMUSP, telefone (11) 2661-5592. Se você tiver alguma consideração ou dúvida sobre a ética da pesquisa, entre em contato com o Comitê de Ética em Pesquisa (CEP) - Rua Ovídio Pires de Campos, 225 - 5o andar - tel: (11) 2661-7585, FAX: (011) 2661-7585 - e-mail: 
cappesq.adm@hc.fm.usp.br. Poderá também solicitar a destruição das amostras que estarão armazenadas no mesmo laboratório.

As informações obtidas serão analisadas em conjunto com outros pacientes, não sendo divulgada a identificação de nenhum paciente. Não haverá nenhuma despesa por parte do participante. Também não há compensação financeira relacionada à sua participação. Benefício direto para o participante é a possibilidade de parar de fumar e ser bem monitorado durante todo o processo de 12 semanas.

Estas informações poderão auxiliar na elaboração de programas eficazes para o uso da informação das características individuais em usuários de medicamentos antitabagismo.

Acredito ter sido suficientemente informado a respeito das informações que li ou que foram lidas para mim, descrevendo o estudo "Análise da associação dos perfis de expressão gênica, dos genótipos preditores de metabolização e das concentrações de metabólitos com a resposta ao tratamento antitabagismo" Eu discuti com o Dra. Jaqueline Scholz, com a Juliana da Rocha dos Santos e/ou Paulo Roberto Xavier Tomaz sobre a minha decisão em participar nesse estudo. Ficaram claros para mim quais são os propósitos do estudo, os procedimentos a serem realizados, seus desconfortos e riscos, as garantias de confidencialidade e de esclarecimentos permanentes. Concordo voluntariamente em participar deste estudo e poderei retirar o meu consentimento a qualquer momento, antes ou durante 0 mesmo, sem penalidades ou prejuízo ou perda de qualquer benefício que eu possa ter adquirido, ou no meu atendimento neste Serviço.

Assinatura do paciente/representante legal

Data

11

Assinatura da testemunha

Data

para casos de pacientes menores de 18 anos, analfabetos, semi-analfabetos ou portadores de deficiência auditiva ou visual.

(Somente para o responsável do projeto)

Declaro que obtive de forma apropriada e voluntária o Consentimento Livre e Esclarecido deste paciente ou representante legal para a participação neste estudo.

Data

11


DADOS DE IDENTIFICAÇÃO DO SUJEITO DA PESQUISA OU RESPONSÁVEL LEGAL

1.NOME:

DOCUMENTO DE IDENTIDADE № : SEXO : $M \square \quad F \square$

DATA NASCIMENTO

ENDEREÇO

BAIRRO:

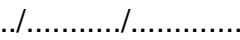

2.RESPONSÁVEL LEGAL

NATUREZA (grau de parentesco, tutor, curador etc.).

DOCUMENTO DE IDENTIDADE :

SEXO: $M \square \quad F \square$

DATA DE NASCIMENTO:

$. / \ldots \ldots . . . \ldots \ldots \ldots . . .$. ENDEREÇO:

№

APTO:

BAIRRO:

CEP:

CIDADE:

ESTADO

DADOS SOBRE A PESQUISA

1. TÍTULO DO SUBPROJETO DE PESQUISA: “Análise da associação dos perfis de expressão gênica, dos genótipos preditores de metabolização e das concentrações de metabólitos com a resposta ao tratamento antitabagismo"

PESQUISADOR RESPONSÁVEL: Dr. Jaqueline Scholz

CARGO/FUNÇÃO: Médico Assistente, Médico Pesquisador - InCor - HCFMUSP CRM SP № 60.179

UNIDADE DO HCFMUSP: Programa Ambulatorial de Tratamento Tabagismo InCor-HCFMUSP.

PESQUISADOR EXECUTANTE: Juliana da Rocha dos Santos CRF SP ㄲo 62776

CARGO/FUNÇÃO: PÓS-GRADUANDA- InCor - HCFMUSP

UNIDADE DO HC-FMUSP: Laboratório de Genética e Cardiologia Molecular InCor-HCFMUSP.

3. AVALIAÇÃO DO RISCO DA PESQUISA:

$\begin{array}{llll}\text { RISCO MÍNIMO } & \square & \text { RISCO MÉDIO } \\ \text { RISCO BAIXO } & x & \text { RISCO MAIOR }\end{array}$

4. DURAÇÃO DA PESQUISA: 4 anos 
ANEXO 1 - Aprovação no Comitê de Ética em Pesquisa

\section{$4341 / 16 / 007$}

USP - HOSPITAL DAS
CLÍNICAS DA FACULDADE DE Slotoforma
MEDICINA DA UNIVERSIDADE
DE SÃO PAULO - HCFMUSP

\section{PARECER CONSUBSTANCIADO DO CEP}

\section{DADOS DA EMENDA}

Título da Pesquisa: "Eficácia do uso de Marcadores Genéticos na Escolha do Tratamento Farmacológico do Tabagismo"

Pesquisador: Jaqueline Ribeiro Scholz

Área Temática: Genética Humana:

(Trata-se de pesquisa envolvendo Genética Humana que não necessita de análise ética por parte da CONEP;);

Versão: 6

CAAE: 60133816.0 .0000 .0068

Instituição Proponente: Hospital das Clínicas da Faculdade de Medicina da USP

Patrocinador Principal: FUNDACAO DE AMPARO A PESQUISA DO ESTADO DE SAO PAULO

\section{DADOS DO PARECER}

Número do Parecer: 3.689 .924

Apresentação do Projeto:

Serão incluídos no estudo 300 indivíduos fumantes provenientes do Programa Ambulatorial de Tratamento do Tabagismo (software PAF) do InCor do Hospital das Clínicas da Faculdade de Medicina da Universidade de São Paulo (HC/FMUSP), com idade 18. Os pacientes selecionados serão randomizados em duas abordagens: abordagem farmacogenética e abordagem tradicional. A abordagem farmacogenética $(n=150)$ consistirá na escolha do tratamento farmacológico conforme os genótipos apresentados para os polimorfismos CYP2B6 rs2279343 e CHRNA4 rs1044396 (maiores detalhes do tratamento no tópico "Protocolo de tratamento farmacológico"). A abordagem tradicional $(n=150)$ consistirá no tratamento farmacológico com vareniclina, conforme já estabelecido no programa (Figura 1). O tratamento farmacológico de ambas abordagens será conduzido por 12 semanas e serão considerados desfechos de sucesso no tratamento: a abstinência contínua ao tabaco (ACT) nas $4^{\underline{a}}$ e $12^{\mathrm{a}}$ semanas. Os pacientes tratados com vareniclina, provenientes de ambas abordagens de tratamento farmacológico, poderão receber a coadministração de bupropiona se não pararem de fumar após 4 semanas de tratamento ou se apresentarem escala de conforto no tratamento $\mathrm{PAF}<2021$

\section{Objetivo da Pesquisa:}

Objetivo Primário: Avaliar comparativamente a taxa de cessação do tabagismo no grupo controle e

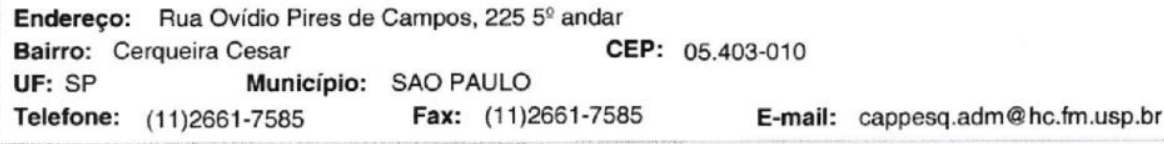




\section{réc \\ USP - HOSPITAL DAS \\ CLÍNICAS DA FACULDADE DE QRlotoforma MEDICINA DA UNIVERSIDADE DE SÃO PAULO - HCFMUSP}

Continuação do Parecer: 3.689 .924

no grupo intervenção farmacogenética com 4 semanas e entre a 9 e 12 semana.

Objetivo Secundário:Avaliação do comportamento alimentar de acordo com o tipo de tratamento farmacológico.

\section{Avaliação dos Riscos e Benefícios:}

Riscos:Baixo risco referente a coleta de punção venosa do material, efeitos colaterais das medicações já conhecidas em uso ha mais de 10 anos.Benefícios:Cessação do tabagismo .

\section{Comentários e Considerações sobre a Pesquisa:}

Estudo em andamento, trata-se de envio de relatórios parciais, atualização de TCLE, apresentação de sub projeto da pesquisadora Juliana da Rocha Santos e alteração do título.

\section{Considerações sobre os Termos de apresentação obrigatória:}

Os termos de apresentação obrigatória estão claros e bem descritos.

\section{Recomendações:}

Não há.

\section{Conclusões ou Pendências e Lista de Inadequações:}

De acordo com a alteração do título do subprojeto de "Análise da associação dos perfis de Expressão Gênica, dos genótipos preditores de metabolização e das concentrações de Metabólitos com a resposta ao Tratamento Antitabagismo", para "Análise da associação dos perfis de expressão gênica e das concentrações de metabólitos com a resposta ao tratamento antitabagismo", de execução da pesquisadora Juliana da Rocha Santos. Aprovado os relatórios parciais datados de setembro de 2019 e aprovada a nova versão do TCLE.

\section{Considerações Finais a critério do CEP:}

Este parecer foi elaborado baseado nos documentos abaixo relacionados:

\begin{tabular}{|l|l|c|l|c|}
\hline \multicolumn{1}{|c|}{ Tipo Documento } & \multicolumn{1}{|c|}{ Arquivo } & Postagem & Autor & Situação \\
\hline Informações Básicas & PB_INFORMAÇŌES_BÁSICAS_145186 & $10 / 10 / 2019$ & & Aceito \\
do Projeto & 4_E5.pdf & $18: 00: 46$ & & Aceito \\
\hline TCLE / Termos de & TCLE_SUBPROJETO_JULIANA_RISCA & $10 / 10 / 2019$ & Elaine Lagonegro \\
Assentimento / & DO.docx & $17: 57: 09$ & Santana Martinho & \\
Justificativa de & & & & \\
Ausência & & & Aceito \\
\hline TCLE / Termos de & TCLE_SUBPROJETO_JULIANA_EMEN & $10 / 10 / 2019$ & Elaine Lagonegro & \\
Assentimento / & DADO.docx & $17: 56: 50$ & Santana Martinho & \\
Justificativa de & & & & \\
\hline
\end{tabular}

Endereço: Rua Ovídio Pires de Campos, $2255^{\circ}$ andar

Bairro: Cerqueira Cesar CEP: $05.403-010$

UF: SP

Município: SAO PAULO

Telefone: (11)2661-7585

Fax: (11)2661-7585

E-mail: cappesq.adm@hc.fm.usp.br 
Continuação do Parecer: 3.689 .924

\begin{tabular}{|c|c|c|c|c|}
\hline Ausência & $\begin{array}{l}\text { TCLE_SUBPROJETO_JULIANA_EMEN } \\
\text { DADO.docx }\end{array}$ & $\begin{array}{c}10 / 10 / 2019 \\
17: 56: 50\end{array}$ & $\begin{array}{l}\text { Elaine Lagonegro } \\
\text { Santana Martinho }\end{array}$ & Aceito \\
\hline Outros & $\begin{array}{l}\text { SUBPROJETO_JULIANA_RISCADO.do } \\
\mathrm{c}\end{array}$ & $\begin{array}{c}10 / 10 / 2019 \\
17: 56: 26 \\
\end{array}$ & $\begin{array}{l}\text { Elaine Lagonegro } \\
\text { Santana Martinho }\end{array}$ & Aceito \\
\hline $\begin{array}{l}\text { Projeto Detalhado / } \\
\text { Brochura } \\
\text { Investigador }\end{array}$ & $\begin{array}{l}\text { SUBPROJETO_JULIANA_EMENDADO. } \\
\text { doc }\end{array}$ & $\begin{array}{c}10 / 10 / 2019 \\
17: 55: 48\end{array}$ & $\begin{array}{l}\text { Elaine Lagonegro } \\
\text { Santana Martinho }\end{array}$ & Aceito \\
\hline Outros & $\begin{array}{l}\text { RELATORIO_PARCIAL_SUBPROJETO } \\
\text { docx }\end{array}$ & $\begin{array}{c}10 / 10 / 2019 \\
17: 55: 08 \\
\end{array}$ & $\begin{array}{l}\text { Elaine Lagonegro } \\
\text { Santana Martinho } \\
\end{array}$ & Aceito \\
\hline Outros & $\begin{array}{l}\text { RELATORIO_PARCIAL_PROJETO_PRI } \\
\text { NCIPAL.docx }\end{array}$ & $\begin{array}{c}10 / 10 / 2019 \\
17: 54: 47\end{array}$ & \begin{tabular}{|l|} 
Elaine Lagonegro \\
Santana Martinho \\
\end{tabular} & Aceito \\
\hline Outros & FORM_EMENDA_Juliana.pdf & $\begin{array}{c}10 / 10 / 2019 \\
17: 54: 18\end{array}$ & $\begin{array}{l}\text { Elaine Lagonegro } \\
\text { Santana Martinho } \\
\end{array}$ & Aceito \\
\hline Outros & Carta_Emenda_Juliana.pdf & $\begin{array}{c}10 / 10 / 2019 \\
17: 53: 53\end{array}$ & $\begin{array}{l}\text { Elaine Lagonegro } \\
\text { Santana Martinho } \\
\end{array}$ & Aceito \\
\hline $\begin{array}{l}\text { TCLE / Termos de } \\
\text { Assentimento / } \\
\text { Justificativa de } \\
\text { Ausência }\end{array}$ & $\begin{array}{l}\text { TCLE_VERSAO_04_2019_PATRICIA.d } \\
\text { ocx }\end{array}$ & $\begin{array}{l}28 / 06 / 2019 \\
16: 15: 38\end{array}$ & $\begin{array}{l}\text { Elaine Lagonegro } \\
\text { Santana Martinho }\end{array}$ & Aceito \\
\hline $\begin{array}{l}\text { Projeto Detalhado / } \\
\text { Brochura } \\
\text { Investigador }\end{array}$ & $\begin{array}{l}\text { PROTOCOLO_CORRIGIDO_PATRICIA. } \\
\text { docx }\end{array}$ & $\begin{array}{c}28 / 06 / 2019 \\
16: 15: 19\end{array}$ & $\begin{array}{l}\text { Elaine Lagonegro } \\
\text { Santana Martinho }\end{array}$ & Aceito \\
\hline Outros & FORM_EMENDA.pdf & $\begin{array}{c}28 / 06 / 2019 \\
16: 15: 06 \\
\end{array}$ & $\begin{array}{l}\text { Elaine Lagonegro } \\
\text { Santana Martinho } \\
\end{array}$ & Aceito \\
\hline Outros & CARTA_EMENDA.pdf & $\begin{array}{c}28 / 06 / 2019 \\
16: 14: 46\end{array}$ & \begin{tabular}{|l|} 
Elaine Lagonegro \\
Santana Martinho \\
\end{tabular} & Aceito \\
\hline Outros & TCLE_versao2_2017_12_12.pdf & $\begin{array}{c}02 / 02 / 2018 \\
11: 43: 56\end{array}$ & $\begin{array}{l}\text { GRAZIELE PEREIRA } \\
\text { LUNAS }\end{array}$ & Aceito \\
\hline Outros & Relatorio_Parcial_2017_13_12.pdf & $\begin{array}{c}02 / 02 / 2018 \\
11: 43: 09\end{array}$ & $\begin{array}{l}\text { GRAZIELE PEREIRA } \\
\text { LUNAS }\end{array}$ & Aceito \\
\hline Outros & $\begin{array}{l}\text { Projeto_Paulo_Inclusao_NMR_2017_12 } \\
\text { 12.pdf }\end{array}$ & $\begin{array}{l}02 / 02 / 2018 \\
11: 42: 32 \\
\end{array}$ & $\begin{array}{l}\text { GRAZIELE PEREIRA } \\
\text { LUNAS }\end{array}$ & Aceito \\
\hline Outros & $\begin{array}{l}\text { Fomulario_de_emenda_e_brochuras_20 } \\
17 \_12 \_12 \text {.pdf }\end{array}$ & $\begin{array}{c}02 / 02 / 2018 \\
11: 42: 06 \\
\end{array}$ & $\begin{array}{l}\text { GRAZIELE PEREIRA } \\
\text { LUNAS }\end{array}$ & Aceito \\
\hline Outros & Carta_emenda_2017_12_12.pdf & $\begin{array}{c}02 / 02 / 2018 \\
11: 41: 39 \\
\end{array}$ & $\begin{array}{l}\text { GRAZIELE PEREIRA } \\
\text { LUNAS }\end{array}$ & Aceito \\
\hline Outros & TERMO_OUTORGA.pdf & $\begin{array}{c}26 / 06 / 2017 \\
10: 55: 58 \\
\end{array}$ & $\begin{array}{l}\text { GRAZIELE PEREIRA } \\
\text { LUNAS }\end{array}$ & Aceito \\
\hline Outros & RELATORIO_2017.pdf & $\begin{array}{c}26 / 06 / 2017 \\
10: 55: 43 \\
\end{array}$ & $\begin{array}{l}\text { GRAZIELE PEREIRA } \\
\text { LUNAS }\end{array}$ & Aceito \\
\hline Outros & PLANILHA_CUSTOS.pdf & $\begin{array}{c}26 / 06 / 2017 \\
10: 55: 07\end{array}$ & $\begin{array}{l}\text { GRAZIELE PEREIRA } \\
\text { LUNAS }\end{array}$ & Aceito \\
\hline Outros & DECLARACAO_MATRICULA.pdf & $\begin{array}{c}26 / 06 / 2017 \\
10: 54: 48\end{array}$ & $\begin{array}{l}\text { GRAZIELE PEREIRA } \\
\text { LUNAS }\end{array}$ & Aceito \\
\hline Outros & Carta_INCLUSAO_SUB.pdf & $\begin{array}{c}26 / 06 / 2017 \\
10: 54: 26 \\
\end{array}$ & $\begin{array}{l}\text { GRAZIELE PEREIRA } \\
\text { LUNAS }\end{array}$ & Aceito \\
\hline
\end{tabular}

Endereço: Rua Ovídio Pires de Campos, $2255^{\circ}$ andar

Bairro: Cerqueira Cesar

CEP: $05.403-010$

UF: SP Municipio: SAO PAULO

Telefone: (11)2661-7585 Fax: (11)2661-7585 E-mail: cappesq.adm@hc.fm.usp.br 


USP - HOSPITAL DAS
CLÍNICAS DA FACULDADE DE QRICINA DA UNIVERSIDADE
DE SÃO PAULO - HCFMUSP

Continuação do Parecer: 3.689 .924

\begin{tabular}{|c|c|c|c|c|}
\hline Outros & $\begin{array}{l}\text { Analise_Orcamentaria_subprojeto_Paul } \\
\text { o Tomaz.pdf }\end{array}$ & $\begin{array}{c}26 / 06 / 2017 \\
10: 54: 00\end{array}$ & $\begin{array}{l}\text { GRAZIELE PEREIRA } \\
\text { LUNAS }\end{array}$ & Aceito \\
\hline Outros & SUB_PAULO_XAVIER.pdf & $\begin{array}{c}26 / 06 / 2017 \\
10: 53: 29 \\
\end{array}$ & $\begin{array}{l}\text { GRAZIELE PEREIRA } \\
\text { LUNAS }\end{array}$ & Aceito \\
\hline Outros & DeclaraCAO_de_matrlcula.pdf & $\begin{array}{l}29 / 05 / 2017 \\
15: 14: 02\end{array}$ & $\begin{array}{l}\text { GRAZIELE PEREIRA } \\
\text { LUNAS }\end{array}$ & Aceito \\
\hline Outros & $\begin{array}{l}\text { SDC_4341_16_007_PARECER_SCOC_ } \\
\text { JULIANA.pdf }\end{array}$ & $\begin{array}{l}29 / 05 / 2017 \\
15: 12: 15\end{array}$ & $\begin{array}{l}\text { GRAZIELE PEREIRA } \\
\text { LUNAS }\end{array}$ & Aceito \\
\hline Outros & Carta_inclusao_subprojeto.pdf & $\begin{array}{c}29 / 05 / 2017 \\
15: 07: 53 \\
\end{array}$ & $\begin{array}{l}\text { GRAZIELE PEREIRA } \\
\text { LUNAS }\end{array}$ & Aceito \\
\hline Outros & Aditivo_termo_de_Outorga.pdf & $\begin{array}{c}29 / 05 / 2017 \\
15: 07: 03 \\
\end{array}$ & $\begin{array}{l}\text { GRAZIELE PEREIRA } \\
\text { LUNAS }\end{array}$ & Aceito \\
\hline $\begin{array}{l}\text { TCLE / Termos de } \\
\text { Assentimento / } \\
\text { Justificativa de } \\
\text { Ausência }\end{array}$ & TCLE_SubProjeto_Juliana.pdf & $\begin{array}{c}29 / 05 / 2017 \\
15: 05: 59\end{array}$ & $\begin{array}{l}\text { GRAZIELE PEREIRA } \\
\text { LUNAS }\end{array}$ & Aceito \\
\hline Outros & Orcamento.pdf & $\begin{array}{c}29 / 05 / 2017 \\
15: 05: 48\end{array}$ & $\begin{array}{l}\text { GRAZIELE PEREIRA } \\
\text { LUNAS }\end{array}$ & Aceito \\
\hline Outros & SubProjeto_Juliana.pdf & $\begin{array}{c}29 / 05 / 2017 \\
15: 05: 20 \\
\end{array}$ & $\begin{array}{l}\text { GRAZIELE PEREIRA } \\
\text { LUNAS }\end{array}$ & Aceito \\
\hline Outros & ON_LINE_ASSINADA.pdf & $\begin{array}{c}20 / 09 / 2016 \\
13: 51: 34 \\
\end{array}$ & \begin{tabular}{l|} 
Elaine Lagonegro \\
Santana Martinho
\end{tabular} & Aceito \\
\hline Folha de Rosto & FR_ASSINADA.pdf & $\begin{array}{c}20 / 09 / 2016 \\
13: 50: 57 \\
\end{array}$ & $\begin{array}{l}\text { Elaine Lagonegro } \\
\text { Santana Martinho }\end{array}$ & Aceito \\
\hline $\begin{array}{l}\text { TCLE / Termos de } \\
\text { Assentimento / } \\
\text { Justificativa de } \\
\text { Ausência } \\
\end{array}$ & $\begin{array}{l}\text { TCLEpesquisageneticaversaoatualizada } \\
\text { cappesq.docx }\end{array}$ & $\begin{array}{l}19 / 08 / 2016 \\
17: 32: 13\end{array}$ & Jaqueline Scholz & Aceito \\
\hline $\begin{array}{l}\text { Projeto Detalhado / } \\
\text { Brochura } \\
\text { Investigador }\end{array}$ & Brochurainvestigador.docx & $\begin{array}{c}10 / 08 / 2016 \\
10: 12: 51\end{array}$ & Jaqueline Scholz & Aceito \\
\hline Outros & SilmaraPosGraduacao.pdf & $\begin{array}{c}10 / 08 / 2016 \\
10: 11: 42 \\
\end{array}$ & Jaqueline Scholz & Aceito \\
\hline Outros & $\begin{array}{l}\text { RegistroProjetoComissaoCientificaAnex } \\
\text { oA.pdf }\end{array}$ & $\begin{array}{l}10 / 08 / 2016 \\
10: 10: 45 \\
\end{array}$ & Jaqueline Scholz & Aceito \\
\hline Outros & PARECERPCARANONIMIZADOS.pdf & $\begin{array}{c}10 / 08 / 2016 \\
10: 08: 36 \\
\end{array}$ & Jaqueline Scholz & Aceito \\
\hline Outros & $\begin{array}{l}\text { Analise_Orcamentaria_SDC_4341_16_0 } \\
\text { 07.pdf }\end{array}$ & $\begin{array}{c}10 / 08 / 2016 \\
09: 57: 54\end{array}$ & Jaqueline Scholz & Aceito \\
\hline Orçamento & Orcamento.docx & $\begin{array}{c}10 / 08 / 2016 \\
09: 56: 28\end{array}$ & Jaqueline Scholz & Aceito \\
\hline Brochura Pesquisa & Brochuraprojetotabacogenetica.docx & $\begin{array}{l}10 / 08 / 2016 \\
09: 56: 02\end{array}$ & Jaqueline Scholz & Aceito \\
\hline
\end{tabular}

Situação do Parecer:

Endereço: Rua Ovídio Pires de Campos, $2255^{\circ}$ andar

Bairro: Cerqueira Cesar

CEP: $05.403-010$

UF: SP

Município: SAO PAULO

Telefone: (11)2661-7585

Fax: (11)2661-7585

E-mail: cappesq.adm@hc.fm.usp.br 


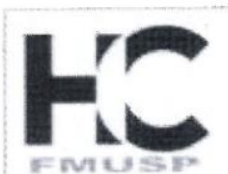

Continuação do Parecer: 3.689 .924

\section{USP - HOSPITAL DAS \\ CLÍNICAS DA FACULDADE DE \\ MEDICINA DA UNIVERSIDADE \\ DE SÃO PAULO - HCFMUSP}

\section{Q platoformo}

Aprovado

Necessita Apreciação da CONEP:

Não

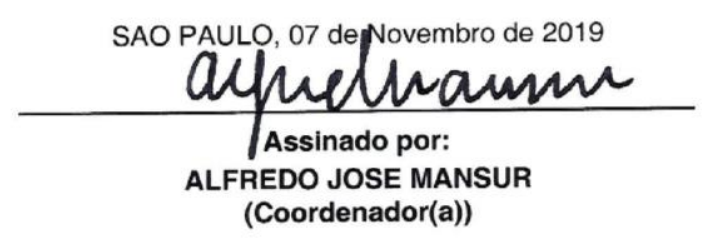

$\frac{14}{\text { Arma Rucia }}$

Endereço: Rua Ovídio Pires de Campos, $2255^{\circ}$ andar

Bairro: Cerqueira Cesa

CEP: $05.403-010$

UF: SP

Município: SAO PAULO

Telefone: (11)2661-7585

Fax: (11)2661-7585

E-mail: cappesq.adm@hc.fm.usp.br 
ANEXO 2 - Teste de Fagerström para a dependência à nicotina (versão em Português)

1. Quanto tempo após acordar você fuma seu primeiro cigarro?
(1) Dentro de 5 minutos
3
(2) Entre 6-30 minutos
2
(3) Entre 31-60 minutos

1
(4) Após 60 minutos
0

(5) Não fuma

2. Você acha dificil não fumar em lugares proibidos, como igrejas, ônibus, etc.?
(1) Sim
(0) Não
1
0

3. Qual cigarro do dia traz mais satisfação?
(1) O primeiro da manhã
(2) Outros
1
(3) Nenhum

4. Quantos cigarros você fuma por dia?

$\begin{array}{ll}\text { (1) Menos de } 10 & 0 \\ \text { (2) De } 11 \text { a } 20 & 1 \\ \text { (3) De 21 a } 30 & 2 \\ \text { (4) Mais de } 31 & 3\end{array}$

3

(5) Não fuma

5. Você fuma mais freqūentemente pela manhã?

(1) $\mathrm{Sim} \quad 1$

(0) Não 0

6. Você fuma mesmo doente?

(1) $\mathrm{Sim} \quad 1$

(0) Não 0

\section{Conclusão sobre o grau de dependência:}

$0-2$ pontos $=$ muito baixo

$3-4$ pontos $=$ baixo

5 pontos $=$ médio

$6-7$ pontos $=$ elevado

$8-10$ pontos $=$ muito elevado

Fonte: Pietrobon RC, Barbisan JN, Manfroi WC, Utilização do teste de dependência à nicotina de Fagerström como um instrumento de medida do grau de dependência. Versão em Português. Rev HCPA 2007;27(3):31-6. 


\section{ANEXO 3 - Escore de consumo situacional Issa}

\begin{tabular}{lll}
\hline 1. Necessita fumar para melhorar atenção, concentração e produção? & $\mathrm{Sim}$ & Não \\
2. Necessita fumar quando esta ansioso(a),tenso(a) ou preocupado(a)? & $\mathrm{Sim}$ & Não \\
3. Necessita fumar quando esta triste ou aborrecido(a)? & $\mathrm{Sim}$ & Não \\
$\begin{array}{l}\text { 4. Necessita fumar quando esta tomando bebida alcoólica, } \\
\text { após refeição ou quando está em ambientes festivos? }\end{array}$ & $\mathrm{Sim}$ & Não \\
\hline
\end{tabular}

Resultados: cada resposta "sim" equivale a 1 ponto. Até 1 ponto: baixa dependência; 2-3 pontos: moderada dependência; e 4 pontos: alta dependência.

Fonte: Issa, J S. Um novo escore para dependência a nicotina e uma nova escala de conforto do paciente durante o tratamento do tabagismo. J Bras Pneumol 38(6): 761-5. 
ANEXO 4 - Desenho de estudo do projeto "Eficácia do uso de marcadores genéticos na escolha do tratamento farmacológico do tabagismo"

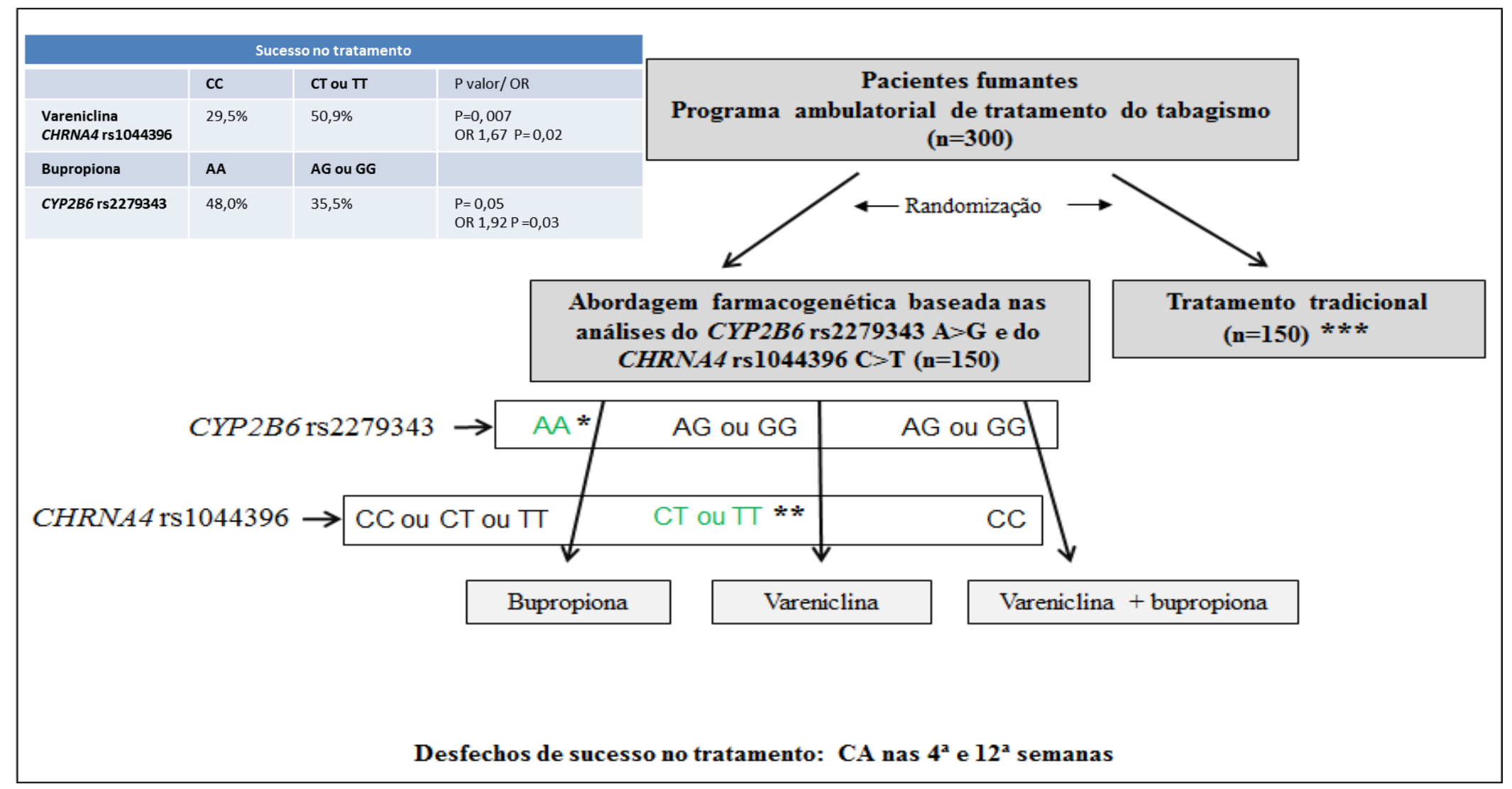

Desenho do estudo. Será randomizado em dois braços um número amostral total de 300 pacientes. No braço da esquerda, 150 pacientes serão tratados com base em teste genético para os polimorfismos CYP2B6 (rs2279343) e CHRNA4 (rs1044396). No braço da direita, 150 pacientes farão o tratamento tradicional com vareniclina (o fármaco de maior efetividade no tratamento antitabagismo). Em um estudo anterior, nosso grupo de pesquisadores ${ }^{51,52}$ mostrou maior sucesso terapêutico nos pacientes portadores dos genótipos AA para o gene CYP2B6 nos pacientes tratados com bupropiona e nos portadores dos genótipos CT e TT para o gene CHRNA4 nos pacientes tratados com vareniclina. A escolha do tratamento no braço farmacogenético prioriza o tratamento mais barato (bupropiona), dessa forma, primeiramente é analisado o genótipo para o rs2279343, se o paciente apresentar o genótipo AA, o mesmo é tratado com bupropiona; se ele tiver o genótipo AG ou GG, é analisado o genótipo para o polimorfismo rs1044396. Se o paciente apresentar o genótipo CT ou TT para o rs1044396 ele é tratado com vareniclina, se ele apresentar o genótipo CC (não favorável a nenhum dos fármacos), ele é tratado com vareniclina e bupropiona em uso concomitante. Será comparado o custo-efetividade do tratamento baseado em farmacogenética em relação ao tratamento com vareniclina. Os pacientes são acompanhados por 12 semanas durante o tratamento farmacológico: visita inicial (T-1), antes do início da terapêutica (T0), 2, 4, 6, 8 e 12 semanas após o tratamento (T2, T4, T6, T8, T12). Obs: Os pacientes que não conseguirem parar de fumar até a $4^{\text {a }}$ semana de tratamento em monoterapia, é adicionada a segunda medicação. Fonte: Eficácia do uso de marcadores genéticos na escolha do tratamento farmacológico do tabagismo, InCor-HCFMUSP. Projeto de doutorado da Dra Patrícia Viviane Gaya, sob a orientação da Dr Jaqueline R. Scholz., desenvolvido a partir dos resultados dos estudos da nossa equipe de pesquisadores: Rocha Santos et al, $2015^{67}$ e Tomaz et al, $2015^{68}$ 
ANEXO 5 - Pedido de depósito de patente na Agência de Inovação e Empreendedorismo da Universidade Federal de Alfenas-MG

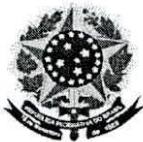

MINISTÉRIO DA EDUCAÇÃO

Universidade Federal de Alfenas. UNIFAL-MG

Agência de Inovação e Empreendedorismo da UNIFAL-MG

Rua Gabriel Monteiro da Silva, 700, Prédio O Sala 308A. Alfenas/MG. CEP 37130-001

Fone: (35) 3701-952

\section{Declaração}

Declaro para os devidos fins, que o Professor e Pesquisador Dr. Henrique Dipe de Faria, deu entrada no Pedido de Depósito de Patente intitulada "Híbrido de nanotubos de carbono e tetraetilortosilicato de acesso restrito a macromoléculas por meio de inserção de monômeros hidrofilicos na superfície externa" através do Processo: 23087.000128/2019-84, o qual se encontra em andamento, sendo que os resultados precisam ser mantidos em sigilo para a devida proteção.

Por ser verdade, firmo a presente.

Alfenas, 07 de janeiro de 2019

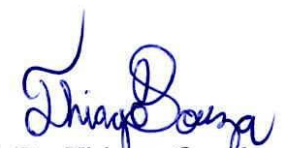

Prof. Dr. Thiago Corrêa de Souza

Diretor da Agência de Inovação e Empreendedorismo

I9/UNIFAL-MG em exercício 